\section{Mykenische Keramik in der Rhodopenregion. Herkunft, regionaler Kontext und sozialökonomische Grundlagen}

\author{
Reinhard Jung \\ Stefan Alexandrov \\ Elena Bozhinova \\ Hans Mommsen
}

mit einem Appendix von Anno Hein

und Vassilis Kilikoglou

\begin{abstract}
Zusammenfassung
Dieser Beitrag behandelt mykenische Keramik aus den Siedlungen von Dragojna in den Rhodopen und Koprivlen im Mestatal. Die Produktionsregionen der Gefäße konnten mittels Neutronenaktivierungsanalyse (NAA) bestimmt werden, wobei die früheren Resultate zu Dragojna hier den neuen Ergebnissen zu Koprivlen gegenüber gestellt werden. Sie bieten Gelegenheit, die Entwicklung der Kontakte zwischen dem Ostbalkanraum und der Nordägäis wie auch dem mykenischen Griechenland einer Neubewertung zu unterziehen. Es zeichnen sich zwei ökonomisch-historische Perioden ab. Die frühere umfasst die Phasen SH IIB und SH IIIA1 und zeichnet sich durch den Import mykenischer Keramik wie auch mykenischer Waffen aus den Gebieten des sich etablierenden und expandierenden mykenischen Palaststaats im Rahmen gerichteter, direkter Austauschkontakte aus. Diese könnten mit dem Goldabbau in den Rhodopen zusammenhängen. Die jüngere Periode dauerte etwa von SH IIIB bis SH IIIC Früh. $\mathrm{Zu}$ dieser Zeit gelangte mykenische Keramik aus unterschiedlichen Produktionsregionen in den Ostbalkanraum, teils aus nordägäischen Werkstätten, teils aus dem mykenischen Süden. Importe oder Imitationen spätpalast- oder nachpalastzeitlicher Waffen sind hingegen nicht belegt.
\end{abstract}

\section{Schlüsselbegriffe}

Bronzezeit, Dragonja, Koprivlen, Rhodopen, Mestatal, Bulgarien, Ostbalkanraum, Nordägäis, mykenisches Griechenland, mykenische Keramik, Neutronenaktivierungsanalyse.

Abstract - Mycenaean Pottery in the Rhodope Region. Origin, Regional Context and Socio-Economic Foundations

This contribution is dealing with Mycenaean pottery from the settlement sites of Dragoyna in the Rhodopes and Koprivlen in the Mesta
Valley. The production regions of that pottery could be established by means of Neutron Activation Analysis (NAA), and we compare the earlier results of Dragoyna with the new ones from Koprivlen. These results give us the opportunity to re-evaluate the development of contacts between the eastern Balkans, the northern Aegean and Mycenaean Greece. Two economic-historical periods can be discerned. The earlier one comprises the phases LH IIB and IIIA1 and is characterised by the importation of Mycenaean pottery and Mycenaean weapons from the regions of the rising and expanding Mycenaean palace state in the framework of directional exchange of products. This could have been linked to gold mining in the Rhodopes. The later period lasted from approximately LH IIIB to LH IIIC Early. During that time Mycenaean pottery from different production regions reached the eastern Balkans, some from northern Aegean workshops, some from the Mycenaean south. In contrast, imports or imitations of late palatial or post-palatial weapons are not attested.

\section{Keywords}

Bronze Age, Dragoyna, Koprivlen, Rhodopes, Mesta Valley, Bulgaria, eastern Balkans, northern Aegean, Mycenaean Greece, Mycenaean pottery, Neutron Activation Analysis.

\section{Einleitung}

Das Problem der spätbronzezeitlichen Südkontakte der Bevölkerungsgruppen des ostbalkanischen Raums ist aufgrund der Grabungsergebnisse von Ada Tepe vor einem völlig neuen Hintergrund zu sehen, wie auch die Beiträge von Hristo Popov und Kolleg/inn/en und von Barbara Horejs in dem vorliegenden Band zeigen. Neben den schon länger bekannten Bronzewaffen mykenischen Typs ergänzt in den 
letzten Jahren auch zunehmend mykenische Keramik das Fundspektrum des Ostbalkanraums. Noch ist das Vorkommen von Gefäßen gesichert mykenischen Typs im thrakischen Raum jedoch sehr begrenzt. Vor diesem Hintergrund bietet das Vorliegen neuer Analyseergebnisse zur Herkunft der in Koprivlen gefundenen mykenischen Keramik eine willkommene Gelegenheit, den wichtigsten mykenischen Keramikfunden Bulgariens einen eigenen kurzen Beitrag zu widmen und sie in ihren regionalen wie überregionalen sozialen und ökonomischen Kontext zu stellen.

Behandelt werden hier in erster Linie die Fundorte Dragojna in den nördlichen Zentralrhodopen und Koprivlen im Mestatal zwischen Pirin- und Rhodopengebirge. Die mykenische Keramik dieser zwei Siedlungen wurde mit Neutronenaktivierungsanalyse (NAA) zwecks Herkunftsbestimmung im Bonner Labor analysiert. Aus der Debatte um die spätbronzezeitlichen Südkontakte ausschließen kann man heute die Funde von Drehscheibenkeramik aus dem bulgarischen Drama (Fundort Kajrjaka, eine Siedlung mit Speichergruben ${ }^{1}$ ), für die ebenfalls NAA-Daten vorliegen. ${ }^{2}$ Die nachfolgende Forschung konnte nämlich inzwischen die archaische Zeitstellung der betreffenden Scherben nachweisen. ${ }^{3}$

\section{Dragojna}

\subsection{Die Befunde und Fundensembles}

Vor wenigen Jahren wurde ein für die Bewertung der mykenisch-thrakischen Kontakte bedeutsamer Fundkomplex mykenischer Gefäße und des sie begleitenden lokalen Repertoires handgemachter Keramikkategorien aus der Höhensiedlung von Dragojna in den Zentralrhodopen

1 Lichardus et al. 1996, 112-113 und Abb. 42/2, 3, 7. - Lichardus et al. 2002, 154-156 und Abb. 13-14. - In den Publikationen von 1996 wurden nur drei Scherben als mykenisch angesprochen: LicHARDUs et al. 1996, 112-113 und Abb. 42/2, 3, 7. - Mommsen et al. 1996, 131-133, aber unter Verweis auf LichaRdus et al. 1996, 112-113 und Abb. 42/2, 3, 8. - Für andere Scherben wurde eine geometrische Zeitstellung angenommen (Lichardus et al. 1996, 113 und Abb. 42/1) bzw. eine mykenische oder früheisenzeitliche Datierung (MOMmsEN et al. 1996, 131-133 - unter Verweis auf LichARDus et al. 1996, 113 und Abb. 42/4-7).

2 Mommsen et al. 1996.

3 Gimatzidis in Vorbereitung. - Die Scherben wurden sämtlich in nachbronzezeitlichen Kontexten gefunden: Lichardus et al. 1996, 112. Manche unspezifischen Wandscherben, die nur einen linearen Dekor zeigen, sind sicher aus sich heraus nicht datierbar, doch würden auch die NAA-Ergebnisse, die bei mindestens drei Proben auf Werkstätten in der Ostägäis verweisen, besser zu einer archaischen als einer mykenischen Datierung passen. Proben Nr. 2 und 4 gehören zu Gruppe KlzE (Klazomenai), Nr. 9 gehört zu Gruppe TeosB.
(Abb. 8/7) vorgelegt. ${ }^{4}$ Der Fundort liegt auf zwei Gipfeln des Berges, Goljama (Groß-) und Malka (Klein-)Dragojna genannt, während das Areal zwischen den Gipfeln in der Spätbronzezeit unbesiedelt blieb (Abb. 1). Der Ort umfasste also zwei getrennte Siedlungsbereiche. Es ist derzeit unklar, ob die beiden Sektoren zu unterschiedlichen Zeiten bewohnt waren. An beiden Stellen wurden große Mengen Keramik gefunden, doch nur wenige Baustrukturen waren nach der intensiven Nutzung des Orts in der folgenden Eisenzeit sowie im Hellenismus erhalten geblieben. Zwei Stützmauern auf der mittleren Terrasse von Malka Dragojna und ein Fußbodenniveau zwischen den Felsen von Goljama Dragojna (Abb. 2/L) wurden während zehn Grabungskampagnen untersucht. ${ }^{5}$ Der Fußboden wurde sorgfältig aus zwei aufeinanderfolgenden Scherben- und Steinlagen verlegt, um das Terrain zu ebnen, was höchstwahrscheinlich der Anlage eines Hauses diente. Zwischen diesen Scherben und in den an den Fußboden angrenzenden Bereichen wurden einige Fragmente importierter, größtenteils mykenischer Drehscheibengefäße gefunden, die bereits einschließlich chemischer Analysen publiziert wurden (siehe unten und Abb. 3). ${ }^{6}$ Wenige weitere Scherben importierter Drehscheibengefäße, die sich unter den Funden handgemachter lokaler Keramik sowohl von der Goljama Dragojna als auch von der Malka Dragojna identifizieren ließen, sind nicht sicher zu klassifizieren, da es sich nur um sehr kleine Fragmente handelt und sich auf ihrer Oberfläche nur Reste linearen Dekors erhalten haben. ${ }^{7}$ Dieses im Vergleich zu anderen gleichzeitigen Fundorten nördlich der ägäischen Küstenregion umfängliche Importspektrum zeichnet Dragojna als ein wichtiges und reiches Zentrum im thrakischen Raum aus. Voraussetzungen dafür waren die wahrscheinliche Lage des Ortes an einer Hauptverbindungsroute zwischen dem Inneren des Kontinents und der ägäischen Küste wie auch die Erzlagerstätten in der umgebenden Region, die auch heute noch abgebaut werden.

Die handgemachte Keramik aus Dragojna stellt ein klassisches Beispiel eines Fundensembles spätbronzezeitlicher südbulgarischer Keramik der Rhodopenvariante dar. Sie ist von hoher Qualität und reich mit verschiedenen geometrischen Motiven verziert. Das Spektrum an Gefäßtypen und Mustern spricht für eine Datierung in die entwickelten Phasen der Periode, zwischen dem 15. und 13. Jh. v. u. Z. Da noch keine chronologische Sequenz für die Formen- und

\footnotetext{
4 Bozhinova, Jung, Mommsen 2013.

5 Bozhinova, Jung, Mommsen 2013, 50-52 und Abb. 3. - BozhiNOVA 2014, 52, 78 und Abb. 16/1.

6 Bozhinova, Jung, Mommsen 2013, 67-72 und Taf. 14/1-6.

7 Bozhinova 2014, 87 und Abb. 25/6-7.
} 


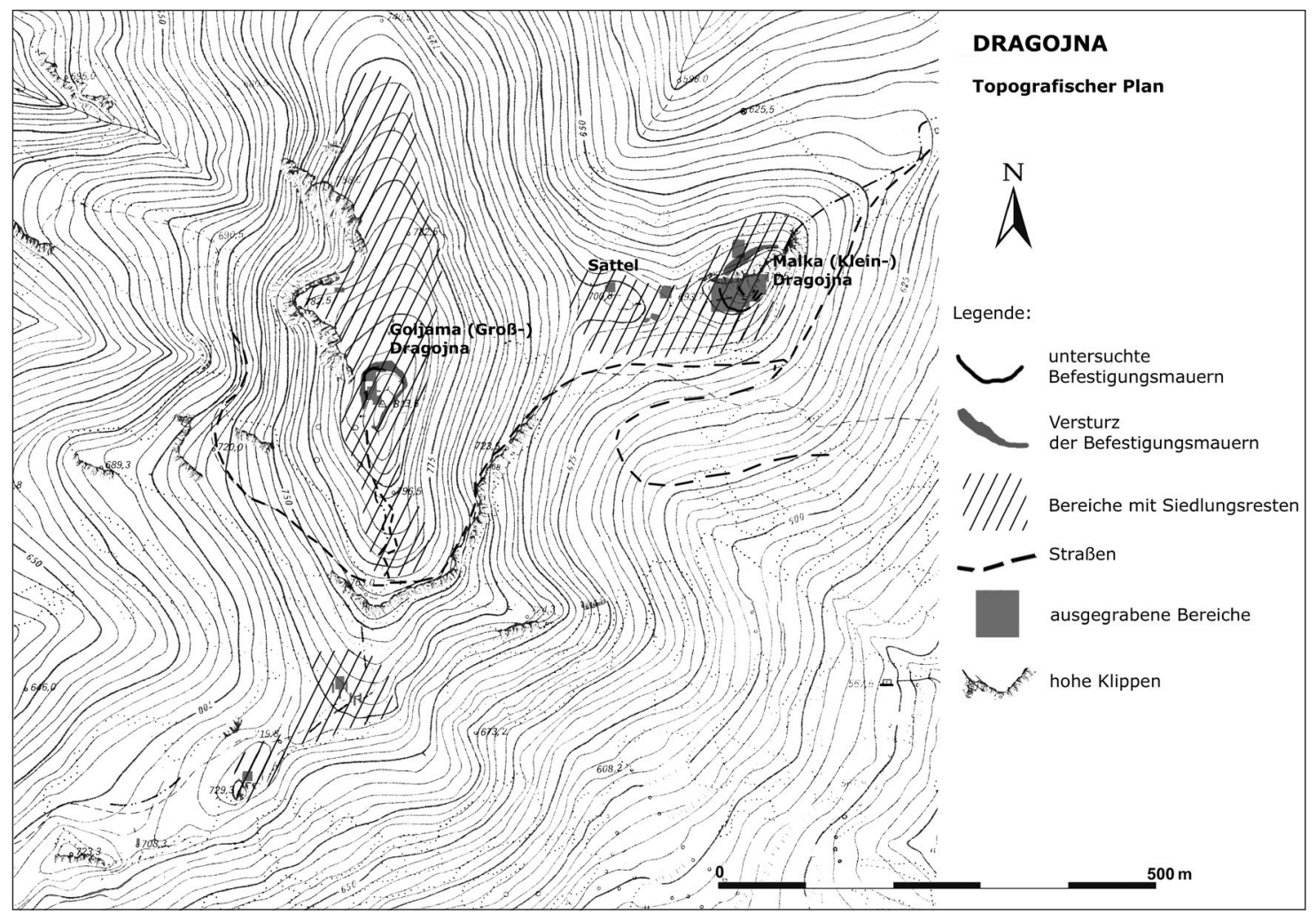

Abb. 1. Topografischer Plan der Grabungsareale von Dragojna (Grafik: E. Bozhinova).

Musterentwicklung der spätbronzezeitlichen Keramik Bulgariens vorliegt, ist derzeit keine phasenspezifische Datierung des Fundorts möglich. Sowohl von der Goljama als auch von der Malka Dragojna liegen einige wenige Gefäße vor, deren Formen und Verzierungstechniken zu jenen gehören, die in früheren Perioden der Bronzezeit üblich waren. ${ }^{8}$ Sie bieten Indizien für den zeitlichen Ansatz des Siedlungsbeginns am Ende der Mittel- oder zu Beginn der Spätbronzezeit, was einer konventionellen Datierung ins 16. Jh. v. u. Z. entsprechen würde.

Es ist nicht klar, ob Dragojna auch noch in der letzten Phase der Spätbronzezeit und am Übergang zur Eisenzeit besiedelt war. ${ }^{9}$ Die Charakteristika der Keramik dieser Periode machen es unmöglich, sie außerhalb von stratifizierten Kontexten zu identifizieren. Das liegt daran, dass eine Kombination von Typen, die typische Vertreter der früheren Phasen der Spätbronzezeit sind, und solchen, die in der Früheisenzeit häufig werden, das Keramikspektrum dieser

8 Bozhinova, Jung, Mommsen 2013, 65 und Taf. 13/3-8. - BozhiNova 2014, 79 und Abb. 17/1-2. - Der Übergang von der Mittel- zur Spätbronzezeit in der Rhodopenregion ist derzeit noch kaum bekannt.

9 Bozhinova, Jung, Mommsen 2013, 65. - Bozhinova 2014, 56-58.
Periode charakterisiert. Die Gefäße sind undekoriert - abgesehen von Kanneluren auf den neuen Keramiktypen, die dann die gesamte Früheisenzeit über gebräuchlich waren.

\subsection{Die mykenische Keramik}

Fünf eindeutig mykenische Fragmente, die von mindestens vier verschiedenen Gefäßen stammen, liegen vor: Es handelt sich um drei oder vier Pokale FT 255 und ein kleines geschlossenes Gefäß (Abb. 3). Relativchronologisch datierbar sind die Pokalfragmente. Sie lassen sich anhand stratifizierter Parallelen aus Südgriechenland der Phase SH IIIA1 zuweisen. ${ }^{10}$ Das Schulterfragment eines kleinen geschlossenen

10 Eine ausführliche Diskussion findet sich bei Bozhinova, Jung, Mommsen 2013, 67-72, Kat. Nr. 1-4 und Taf. 14/1-4: Parallelen für die technologischen Merkmale bieten mykenische Gefäße der Phasen SH IIB und IIIA1 aus Thessalien. Gefäßformen, lineare Dekore und Muster sprechen für den gleichen Zeitansatz, während die besten und chronologisch aussagekräftigsten Parallelen aus Kontexten der Phase SH IIIA1 in Mykene („Atreusbothros“), Argos (Deiras-Nekropole) und Sparta (Menelaion, Schichten der Erbauungsphase des „Herrenhauses 2“, auf den Fußböden des „Herrenhauses 1“) vorliegen. Dies überrascht nicht, da aus Thessalien noch keine umfangreichen Fundkomplexe dieser Zeitstellung publiziert sind. 


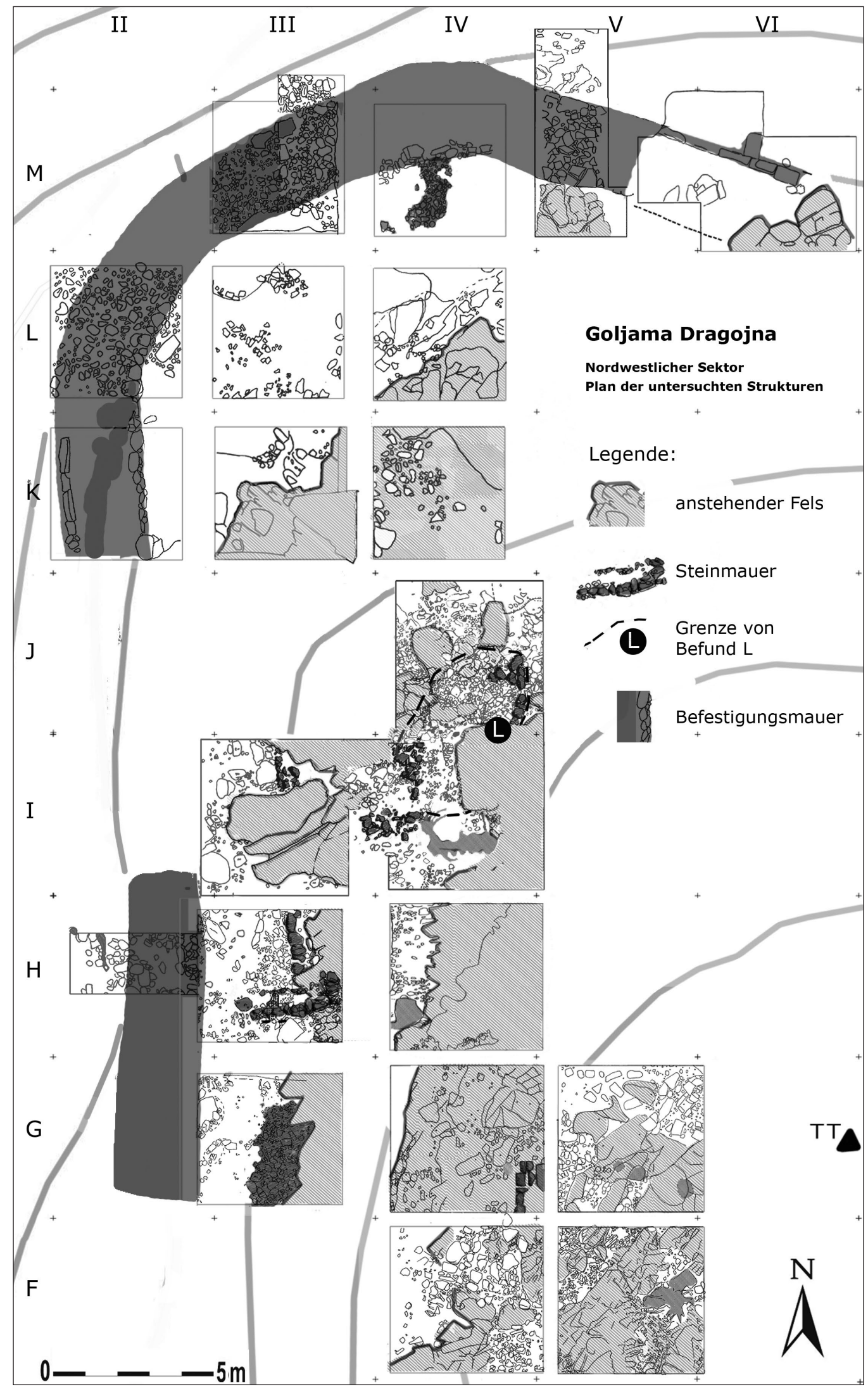

Abb. 2. Siedlungsareal Goljama Dragojna mit dem Befund L (Grafik: E. Bozhinova). 

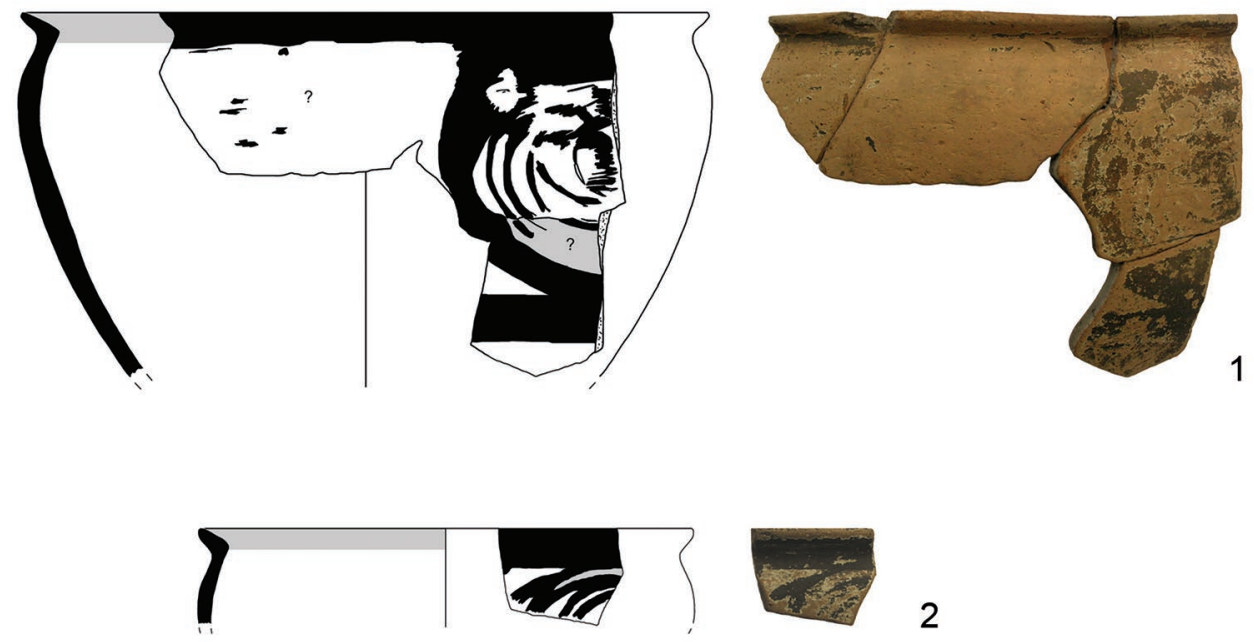

2
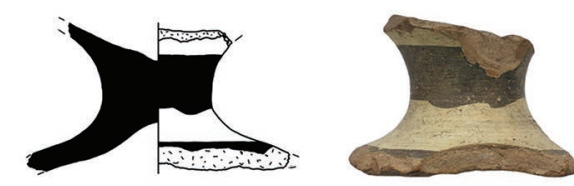

3

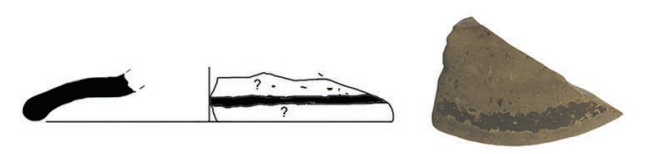

4

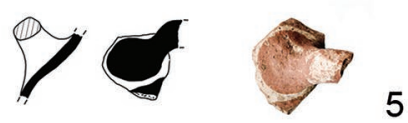

Abb. 3. Mykenische Keramik aus Goljama Dragojna (1:3) (Zeichnungen und Fotos: E. Bozhinova, R. Jung).

Gefäßes kann durchaus ebenfalls in dieser Zeitphase gefertigt worden sein. ${ }^{11}$

Die NAA in Bonn ergab eine Zuordnung der vier beprobten mykenischen Scherben, d. h. dreier Pokalfragmente und des Fragments des kleinen geschlossenen Gefäßes, zu einer einzigen chemischen Gruppe. Diese konnte aufgrund von Übereinstimmungen mit modern anstehenden Tonen im thessalischen Dhimíni bei Vólos einer mykenischen Töpferei in Dhimíni zugewiesen werden. Produkte dieser Werkstatt ließen sich mittels NAA vor allem in Thessalien selbst, doch in Einzelfällen auch in Troia und Dragojna nachweisen. ${ }^{12}$

11 Bozhinova, Jung, Mommsen 2013, 68-72, Kat. Nr. 5 und Taf. 14/5

12 Bozhinova, Jung, Mommsen 2013, 73-77.

\subsection{Die Verkehrswege Richtung Süden}

Einer der wichtigen Verkehrswege, die das Tal der Maritsa (des Hebros/Evros) mit der ägäischen Küste verbanden, dürfte durch die Region von Dragojna verlaufen sein. Eine Straße war hier in der hellenistischen und römischen Zeit in Benutzung, und es ist sehr wahrscheinlich, dass sie bereits auf die Spätbronzezeit zurückgeht. Der Verkehrsweg der so genannten östlichen Transrhodopenstraße wurde auf der Grundlage von Siedlungsmustern und Münzfunden rekonstruiert. Zwei Straßen, eine von Philippopolis im Westen und eine aus Augusta Traiana im Osten treffen sich etwas südlich von Dragojna, in dem heutigen Dorf Topolovo. Die aus dem Osten kommende verläuft über den Berg von Dragojna. Nach der Vereinigung der beiden Wege setzt sich die Route in gerader Linie nach Süden, durch die höheren 
Bereiche der Rhodopen fort, um Xanthi und Abdera an der Ägäisküste zu erreichen. ${ }^{13}$

\section{Koprivlen}

\subsection{Die Befunde und Fundensembles}

Der Fundort Koprivlen liegt am Fuß der Südosthänge des Piringebirges, auf einer überschwemmungssicheren Südterrasse eines kleinen westlichen Nebenflusses des Nestos (Abb. 8/12). Er ist nach Ost-Südost ausgerichtet mit einem exzellenten Blick auf das gesamte mittlere Nestostal und die Rhodopen. Die Siedlung liegt an der antiken Straße, die Nordwestthrakien mit der Ägäis durch den Nestos und die Ebene von Drama verband. Sie wurde 1998 und 1999 im Rahmen von Rettungsgrabungen im Zuge der Instandsetzung der internationalen Straße II-19 (Gotse Delčev - Drama) teilweise ausgegraben. ${ }^{14}$

Die Grabungen brachten zwei spätbronzezeitliche Bauhorizonte, den älteren zweiten Bauhorizont (Zeitphase Koprivlen I) und den jüngeren ersten Bauhorizont (Zeitphase Koprivlen II), sowie eine Reihe von früheisenzeitlichen Strukturen zutage. Die spätbronzezeitlichen Häuser waren über eine Länge von mindestens $60 \mathrm{~m}$ hinweg locker angeordnet. ${ }^{15}$ Die Baustrukturen des älteren spätbronzezeitlichen Bauniveaus wurden in der regionalüblichen Flechtwerktechnik errichtet. Kein vollständig erhaltenes Gebäude wurde in diesem Niveau angetroffen, doch wiesen einige der untersuchten Herdstellen mehrfach aufgetragene Tonschichten auf, so dass eine längere Zeitspanne für die ältere Siedlung der Spätbronzezeit zu erschließen ist. Aufgrund der Keramikauswertung konnte dieses Siedlungsniveau in die SBZ 1 datiert werden. ${ }^{16}$

Im weiteren Verlauf der Spätbronzezeit wurde auf den Resten der älteren eine neue Siedlung erbaut, die aber unter Verwendung anderer Bautechniken auch einem gänzlich anderen Plan folgt (Abb. 4). In dem ergrabenen Abschnitt konnten zwei lange Mauern aufgedeckt werden, die wohl als Stützmauern gedient hatten und von Nordwesten Richtung Südosten in einem Abstand von etwa $10 \mathrm{~m}$ parallel zueinander verlaufen. Diese Mauern wurden aus mittleren bis großen Steinen errichtet, wobei ihre Fundamente bis zu vier Steinreihen hoch sein können. Zu beiden Seiten der Mauern hatte man Häuser und andere Konstruktionen errichtet. Sie haben Steinfundamente derselben Bauweise wie die langen Mauern, während das aufgehende Mauerwerk aus Lehmziegeln (Abb. 5) bestand, was nur auf südlichen Einfluss

13 Madzharov 2009, 287. - Madzharov 2010, Abb. 1/a.

14 Bozkova, Delev, Vulcheva 2002.

15 Alexandrov 2002, 63-69, 323-327 und Abb. 4-10.

16 Alexandrov 2002, 67-69, 78-79, 325-326 und Abb. 7-8. zurückgehen kann. ${ }^{17}$ Ein Lehmziegel ist so gut erhalten, dass sich seine ursprünglichen Maße rekonstruieren lassen: $38 \times 8 \times 8 \mathrm{~cm}^{18}$

Obgleich nur ein kleiner Teil der Siedlung untersucht wurde, lässt sich recht deutlich ein bestimmter Siedlungsplan erkennen, der aus langen, parallelen Stützmauern und dazwischen angeordneten Häusern und Gassen/Straßen besteht. Die Häuser hatten ovale oder apsidale Form und bezogen in einigen Fällen auch die langen Stützmauern mit ein. Herdstellen, die jenen aus dem älteren Siedlungsniveau ähneln, sowie große Öfen wurden im Inneren der Häuser freigelegt. Innerhalb und außerhalb der Häuser hatte man Pithoi in Gruben eingelassen. Dieses Siedlungsniveau wurde in die SBZ 2 datiert. ${ }^{19}$

In der Früheisenzeit wurde der nördliche Bereich der Siedlung für kultische Aktivitäten genutzt. Drei Brandgräber und einige Gruben wurden hier untersucht. Im Zuge dieser Tätigkeiten hatte man Steine der spätbronzezeitlichen Mauern wiederverwendet, so dass einige der älteren Bauten zerstört worden waren.

Das keramische Fundmaterial mykenischen Typs aus Koprivlen umfasst Fragmente von fünf bis sechs Gefäßen (Kat. 1-5; Abb. 7) ${ }^{20}$ und dazu sieben vollkommen abgeriebene Wandscherben, über deren mögliche Zugehörigkeit zu den vorher genannten Gefäßen keine Aussagen mehr getroffen werden können. ${ }^{21}$ Diese Gefäße stammen aus vier verschiedenen Häusern der jüngeren Siedlungsphase Koprivlen II oder wurden in deren unmittelbarer Nähe gefunden (Abb. 4).22

\subsubsection{Struktur 19-50, 22-10, 23-10}

Es handelt sich um ein längsovales Haus, das westlich der besser erhaltenen nördlichen Stützmauer liegt und seinen

17 Alexandrov 2002, 65-67, 69. - Vgl. Horejs 2007a, 298-299 und Taf. 76/b.

18 Lehmziegel aus den zentralmakedonischen Tellsiedlungen der Spätbronzezeit sind hinsichtlich ihrer Länge und Höhe vergleichbar, haben allerdings stets eine größere Breite als das Exemplar aus Koprivlen. In Kastanás liegen komplette Ziegelmaße aus den Schichten $17(52 \times 30 \times 7-8 \mathrm{~cm} ; 48 \times 30 \times 8 \mathrm{~cm}), 16(42 \times 40 \times 7-8 \mathrm{~cm} ; 40 \times 30$ $\times 7 \mathrm{~cm}), 15(48 \times 31 \times 8 \mathrm{~cm}), 14 \mathrm{~b}(48 \times 36 \times 6-8 \mathrm{~cm} ; 48 \times 36 \times 7 \mathrm{~cm})$, $14 \mathrm{a}(48 \times 36 \times 7 \mathrm{~cm} ; 48 \times 35 \times 7 \mathrm{~cm}), 13(40 \times 32 \times 8 \mathrm{~cm})$ und $12(42 \times$ $29 \times 8 \mathrm{~cm}$ ) vor: HäNSEL 1989, 78, 80, 90, 100, 110, 121, 130, 138, 143 , 159, 173. - Von der Toumba des Prähistorischen Olynth konnten in den Schichten $5(35 \times 28 \times 8 \mathrm{~cm})$ und $3(40 \times 40 \times 8 \mathrm{~cm})$ komplette Ziegelmaße abgenommen werden: HänsEl, Aslanis 2010, 229, 245. 19 Alexandrov 2002, 79-80, 324-325 und Abb. 5-6.

20 Alexandrov 2002, 74-75, Kat. Nr. 1-6; 337 und Abb. 30. - Das Skyphosfragment (AleXandrov 2002, 75, Kat. Nr. 1; 337 und Abb. 30/3) konnte leider weder neu aufgenommen noch beprobt werden. 21 Die genauen Fundkontexte dieser kleinen, schlecht erhaltenen Fragmente sind nicht mehr zu eruieren.

22 Alexandrov 2002, 65-67, 74-75. 


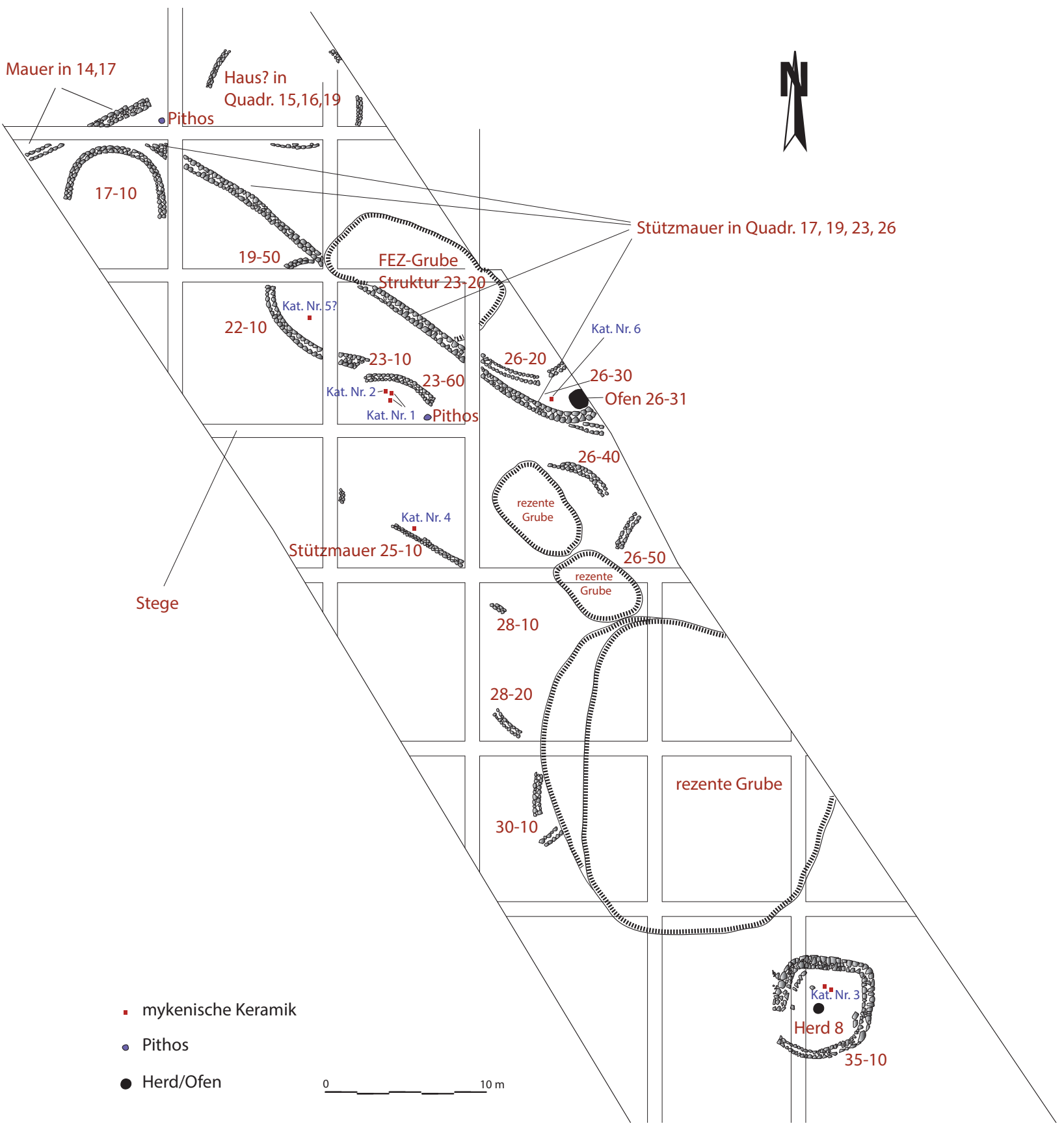

Abb. 4. Siedlungsplan von Koprivlen (Zeitphase Koprivlen II). Mykenische Keramik = rote Quadrate, Pithoi = lila Kreise, Herde und Öfen = schwarze Strukturen (Grafik: St. Alexandrov).

Eingang vermutlich im Südosten hatte. Seine Maße betragen etwa 4,20 × 8,0 m. Die Fundamente bestehen aus zwei Steinreihen mittlerer Größe. Im Zuge späterer Aktivitäten wurden große Teile des Fußbodens zerstört. Der erhaltene Teil besteht aus eingeebnetem und gestampftem Lehm. Scherben mehrerer handgemachter sowie eines scheibengedrehten mykenischen Gefäßes (wahrscheinlich Abb. 7/5) wurden in Höhe des Fußbodenniveaus gefunden (Abb. 4). ${ }^{23}$

\subsubsection{Struktur 23-60}

Möglicherweise handelt es sich um den Teil eines Hauses. Erhalten ist das Fundament eines Ovals, das aus zwei Reihen mittel- bis großformatiger Steine besteht. 1,10 m südlich der Mauer wurde ein in den Boden eingelassener Pithos gefunden. Fragmente von Lehmverputz, Gefäßscherben und drei Drehscheibenfragmente, die zu zwei verschiedenen mykenischen Gefäßen gehören (Kat. Nr. 1-2, Abb. 7/1-2), 


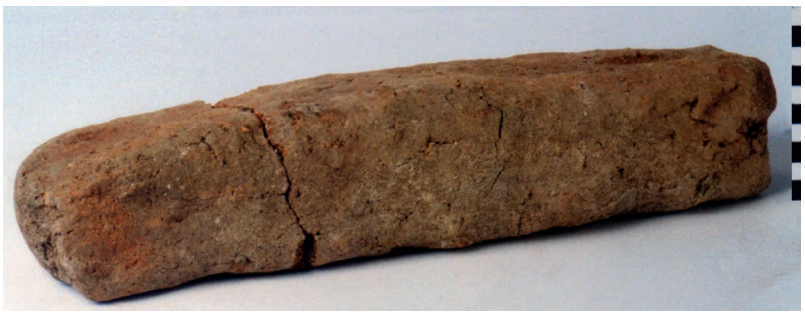

Abb. 5. Lehmziegel aus dem jüngeren Siedlungshorizont von Koprivlen (Phase Koprivlen II). Maße: $38 \times 8 \times 8 \mathrm{~cm}$ (Foto: St. Alexandrov).

wurden südlich des erhaltenen Mauerabschnitts gefunden (Abb. 4$){ }^{24}$

\subsubsection{Struktur 25-10}

Es handelt sich um die schlechter erhaltene südliche Stützmauer. Diese ist 0,50 m dick, aufgebaut aus zwei Reihen von mittelgroßen Steinen (Abb. 4). Eine beträchtliche Menge Tierknochen und Scherben wurde beiderseits der Mauer gefunden. Das Fragment eines mykenischen Drehscheibengefäßes (Kat. Nr. 4, Abb. 7/4) kam nordöstlich der Mauer zutage (Abb. 4). ${ }^{25}$

\subsubsection{Struktur 26-30}

Möglicherweise handelt es sich um einen Raum. Er liegt südlich von Haus 26-20 und ist mit diesem durch einen $0,70 \mathrm{~m}$ breiten Eingang verbunden. Die Fundamentmauern bestehen aus zwei Reihen mittelgroßer Steine. Die Südmauer hat die Form einer Apsis und folgt darin dem gebogenen Verlauf der Südmauer von Haus 26-20. Der Ostteil des Raums liegt außerhalb der Grabungsfläche. Der Boden besteht aus eingeebnetem Stampflehm. Ein 1,20 × 1,0 m großer hufeisenförmiger Ofen war nahe der Südmauer platziert (Abb. 4/26-31). Keramikscherben sowie kleine Steine und Kiesel bildeten seinen Unterbau, während der Ofenboden aus einer 0,02 $\mathrm{m}$ dicken Schicht fein geschlämmten Tons bestand. Vier Pfeilspitzen aus Bronze lagen zwischen dem Ofen und der Südwand von Haus 26-20, eine weitere auf den Steinen der Südmauer. Eine beträchtliche Menge Tierknochen und Keramikscherben einschließlich eines mykenischen scheibengedrehten Fragments (Kat. Nr. 6, Abb. 7/6) lagen auf dem Fußboden (Abb. 4). ${ }^{26}$

\subsubsection{Struktur 35-10}

Es handelt sich um einen Nord-Süd orientierten Apsidenbau, dessen 1,30 m breiter Eingang im Westen lag (Abb. 6).

24 Alexandrov 2002, 66, 75, Kat. Nr. 2-4; 336 und Abb. 27-28; 337 und Abb. 30/4, 5, 7 .

25 Alexandrov 2002, 66, 337 und Abb. 30/1.

26 Alexandrov 2002, 66, 337 und Abb. 30/3; 338 und Abb. 32.
In Nord-Süd-Richtung misst das Haus 6,60 m, in OstWest-Richtung 6,20 m. Die Fundamente waren aus zwei Steinreihen errichtet. Aufgrund des Gefälles des Baugrunds sind die in der Nordwand verbauten Steine bis zu $1 \mathrm{~m}$ lang und 0,60 m breit, während die Steine in den übrigen Mauerabschnitten nur mittlere Größe erreichen. Im Nordteil des Hauses wurde eine Steinpackung aus mittelgroßen Steinen zur Nivellierung des Untergrunds verlegt. Der eigentliche Hausfußboden bestand aus eingeebnetem und gestampftem Lehm. Eine kleine runde Herdstelle von 0,54 m Durchmesser liegt in der Mitte des Hauses. Sie hat ein Kieselpflaster als Unterlage, während ihre Oberseite aus einer 0,02 m dicken Lage fein geschlämmten Tons besteht. Drei große Steine hatte man horizontal im Inneren des Hauses verlegt; einen nahe beim Eingang, die anderen beiden gegenüber vom Eingang. Einige Keramikscherben, darunter auch zwei eines scheibengedrehten mykenischen Gefäßes (Kat. Nr. 3, Abb. 7/3), wurden auf dem Fußboden gefunden. ${ }^{27}$

\subsection{Die mykenische Keramik}

Vom Fußboden der Struktur 26-30, die sich leider nicht zu einem kompletten Hausgrundriss ergänzen lässt, stammt das Randfragment eines Skyphos' FT 284/285A, der außen mit einem schmalen Randband dekoriert ist (Kat. Nr. 6, Abb. 7/6). ${ }^{28}$ Die senkrechte Purpurschnecke mit gefüllter Öffnung (FM 23, 3) ist ein Muster, das in Süd- und Zentralgriechenland nur in den frühen Phasen der Periode SH IIIB häufig auf Skyphoi auftrat und danach nur noch sehr selten zur Bemalung dieses offenen Gefäßtyps verwendet wurde. ${ }^{29}$ In Thessalien findet sich ein einzelnes Exemplar des Skyphos' A mit senkrechten Purpurschnecken in der wohl bereits in SH IIIC Früh $1 \mathrm{zu}$ datierenden Zerstörungsschicht von Dhimíni. Die nach oben weisende Öffnung des Schneckengehäuses ist in diesem Fall nicht gefüllt, während der spitz zulaufende untere Teil nicht mit einer Punktreihe verziert, sondern monochrom ausgeführt ist (FM 23,18), ${ }^{30}$ was eine späte Variante des Motivs darstellt. ${ }^{31}$ Das an dem

27 Alexandrov 2002, 67, 325 und Abb. 6.

28 Alexandrov 2002, 68, 74-75, Kat. Nr. 1; 337 und Abb. 30/3. 29 Andrikou 2006, 34-35, 75-76, Kat. Nr. 205; 112 und Taf. 12/205. - Podzuweit 2007, 27, Beilage 3 und Taf. 4/10; 5/1.

30 Adrymi-Sismani 2012, 164, 173 und Abb. 6/BE 36002. - Es ist sehr schwer, das Material aus der Zerstörungsschicht von dem der Nachbesiedlung chronologisch abzusetzen.

31 Wichtig sind hier die Skyphoi A aus dem vor der Westseite der Oberburg abgelagerten Schutt der so genannten Epichosis, der vorwiegend in SH IIIB Ende und zu einem geringeren Teil in SH IIIC Früh 1 datiert: KARDAMAKi 2015, 93-94. In diesem Material haben 6 von 13 mit senkrechten Purpurschnecken verzierten Skyphoi A einen ausgefüllten Muschelkörper, während dieser nur bei zweien gemäß der älteren Mustervariante mit einer Punktreihe gefüllt ist und bei einem dritten schließlich in parallele Linien aufgelöst erscheint: Voigtländer 2003, 37-38, Kat Nr. S 2 - S 14 und Taf. 13/S 2-S 14; Taf. 97/S 2-S 12; Taf. 98/S 13, S 14. 


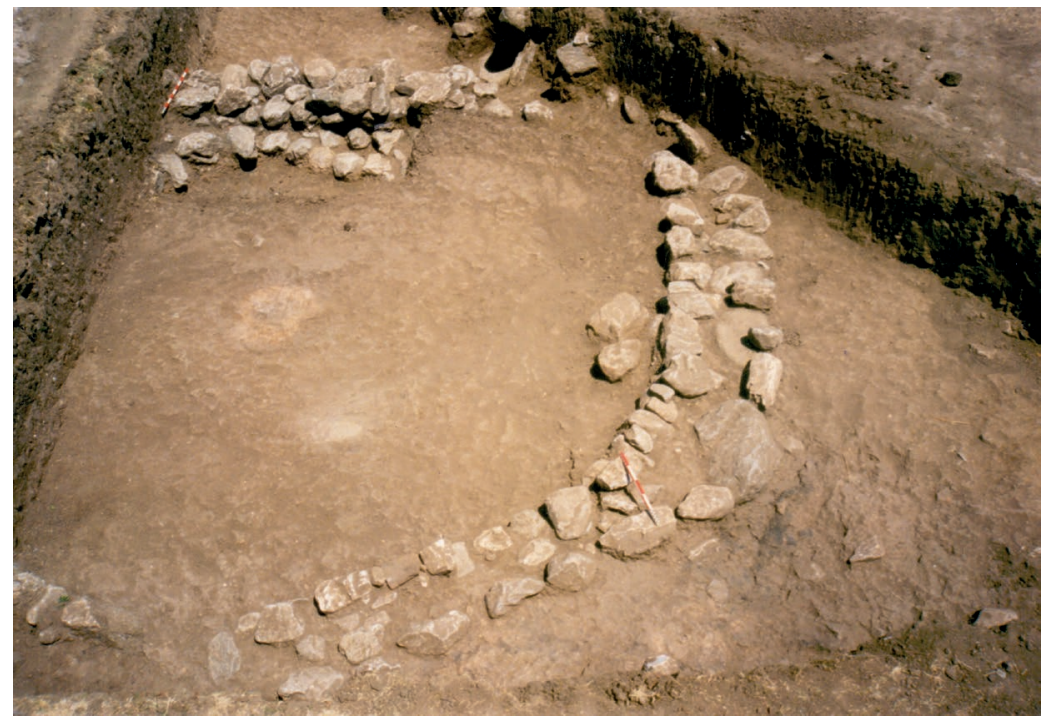

Abb. 6. Östliche Hälfte des Hausbefunds von Struktur 35-10, Blickrichtung Norden (Foto: St. Alexandrov).
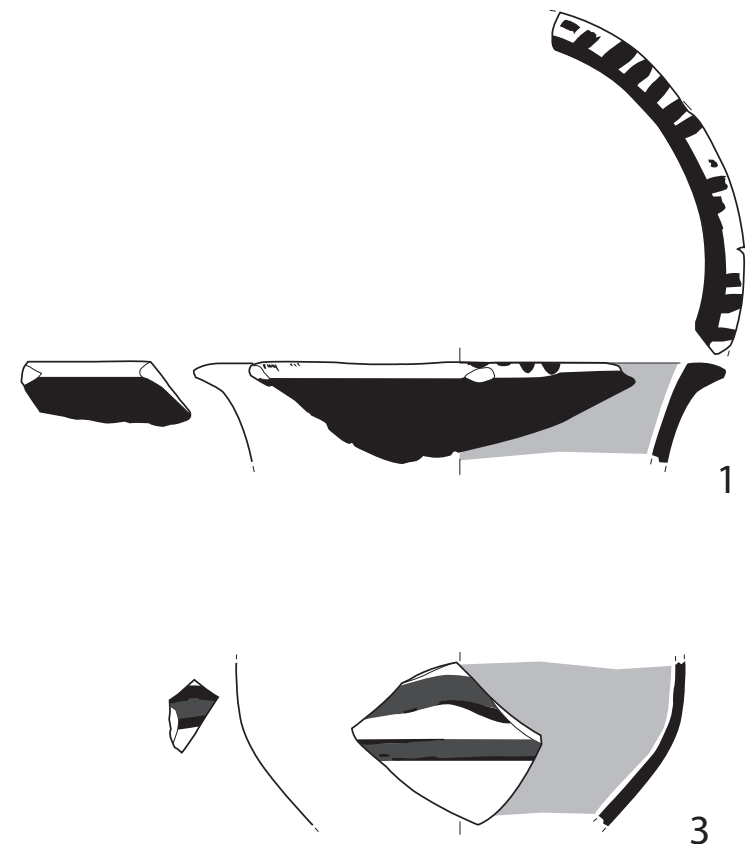

3
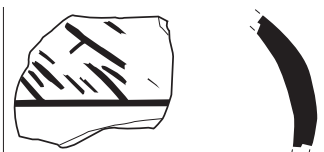

5

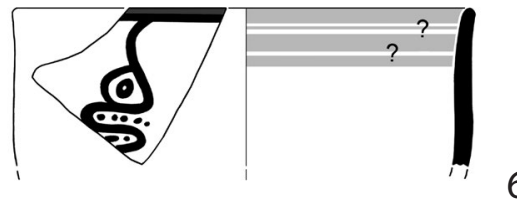

0

$10 \mathrm{~cm}$

Abb. 7. Mykenische Keramik aus dem jüngeren Siedlungshorizont von Koprivlen (Phase Koprivlen II). - Kat. Nr. 1-2 aus Struktur 23-60. - Kat. Nr. 3 aus Struktur 35-10. - Kat. Nr. 4 nordöstlich der Stützmauer 25-10. - Kat. Nr. 5 vermutlich aus Struktur 19-50, 22-10, 23-10. - Kat. Nr. 6 aus Struktur 26-30 (1:3) (Kat. Nr. 1-5: Zeichnungen: R. Jung, Digitalisierung R. Yassine; Kat. Nr. 6: Zeichnung Stoiko Shatov, Digitalisierung R. Jung). 
Fragment aus Koprivlen zu beobachtende Verzierungsdetail der mit einem Kreis bzw. Punkt ausgefüllten Öffnung ist also ein zuverlässiges chronologisches Indiz. ${ }^{32}$ Obgleich das untere Ende des Purpurschneckenmotivs auf dem Skyphos A von Koprivlen nicht erhalten ist, kann man demnach annehmen, dass dieses Gefäß eher in der ersten als in der zweiten Hälfte von SH IIIB getöpfert wurde. Diese Datierung nach den süd- und zentralgriechischen stratigrafischen Abfolgen erscheint vertretbar, da mit Purpurschnecken verzierte Skyphoi A nicht zum Repertoire der zentralmakedonischen Töpferwerkstätten gehörten.

Zwei nicht anpassende Randfragmente aus Struktur 23-60 (Kat. Nr. 1, Abb. 7/1) können einer großen Schulterhenkelamphore (FT 34/35) zugewiesen werden. ${ }^{33}$ Die kleinere Scherbe weist eindeutige Brandspuren und zudem auflagernde schwarze organische Substanzen auf. Der Erhaltungszustand reicht aber aus, um Reste desselben Streifenmusters auf der Lippe zu identifizieren, die das größere Fragment zieren. Es handelt sich um ein qualitativ hoch stehendes Töpferprodukt, dessen Bemalung ursprünglich glänzend gewesen sein muss. Derartige Schulterhenkelamphoren finden sich in Süd- und Zentralgriechenland in der Regel seltener in Siedlungen und häufiger als Beigaben in den mehrfach belegten spätmykenischen Kammergräbern - mit der Auswirkung, dass sich viele nicht kontextuell datieren lassen. Datierbare Parallelen belegen einen Produktionszeitraum des Typs mit entsprechender monochromer und Musterbemalung von SH IIIA2 (Spät) ${ }^{34}$ bis mindestens SH IIIB Ende. ${ }^{35}$ In Nordgriechenland gibt es einzelne Belege für den Typ aus Zentral- ${ }^{36}$ und Ostmakedonien. ${ }^{37}$

32 Keiner der zuvor zitieren Skyphoi A der Tirynther Epichosis mit ausgefülltem Körper hat eine Öffnung mit Kreis- oder Punktfüllung (vgl. Anm. 31). Der Skyphos A aus der thebanischen Zerstörungsschicht des SH IIIB Ende stellt eine Ausnahme dar, denn er zeigt eine Purpurschnecke mit monochromer Spitze, doch mit einem Punkt in der Öffnung: ANDrikou 2006, 75-76, Kat. Nr. 205; 112 und Taf. 12/205. - Zur chronologischen Aussagekraft der Öffnungen der Purpurschneckenschalen siehe SCHÖNFELd 1988, 167, 170, 184.

33 Alexandrov 2002, 75, Kat. Nr. 3 und 4; 337 und Abb. 30/5, 7. 34 Mykene, Pétsas-Haus, Magazin A (SH IIIA Spät): Papadimitriou, Petsas 1951, 208 und Abb. 5 (ganze Gefäße); 224. - Shelton 2007, 173 und Taf. 46/a.

35 Tiryns, „Epichosis“ (SH IIIB Ende [-IIIC Früh 1]): VoigTLäNDER 2003, 113, Kat. Nr. G 24 und Taf. 83/G 24 (Fragment vom Rand bis zur Schulter mit einem erhaltenen Vertikalhenkel).

36 Toumba von Thessaloníki, Phasen 4D-4C (SH IIIC Früh): ANDREOU 2009, 33 und Abb. 8/4 (Randfragment, Lippe nach außen abgeschrägt). - Kastanás, Schicht 15 (SH IIIB Ende): Jung 2002, 317 und Taf. 4/43 (Randfragment, rein monochrom dekoriert, ohne Randmuster).

37 Stathmós Anjístas (Abb. 8/26), Schicht 1 (Aufschüttung des makedonischen Tumulus'): Koukouli-Chrysanthaki 1980, 65; 75 und Abb. 16/25. - Jung 2002, 565 Nr. 6 (Schulterfragment mit übereinander angeordneten Reihen konzentrischer Bögen ähnlich FM 70,8, doch mit Punktwolken unter den Bögen; größter Durchmesser ca. $22 \mathrm{~cm})$.
Ebenfalls von einer Schulterhenkelamphore könnte ein Schulterfragment stammen, dessen schlecht erhaltenes Muster wohl als Netz FM 57,2 zu ergänzen ist (Kat. Nr. 5, Abb. 7/5). ${ }^{38}$ Das Fragment, das vermutlich aus Struktur 1950, 22-10, 23-10 stammt, gehört aufgrund des zu geringen Bauchdurchmessers allerdings nicht $\mathrm{zu}$ demselben Gefäß wie Kat. Nr. 1. Es wäre vielmehr den mittelgroßen Schulterhenkelamphorentypen FT 39-42 zuzuschreiben, die über einen langen Zeitraum von der entwickelten Palastzeit (SH IIIA Spät bis SH IIIB Mitte) bis in die frühe Nachpalastzeit hinein produziert wurden. ${ }^{39}$ Eine nähere typologische Bestimmung sowie eine genauere Datierung sind aufgrund des schlechten Erhaltungszustands nicht möglich.

Ein außen monochromes und innen mit einem Randband dekoriertes Randfragment eines kleinen geschlossenen Gefäßes mit fast unverdickter und nur leicht gekanteter Lippe (Kat. Nr. 2, Abb. 7/2) stammt wiederum aus Struktur 23-60. ${ }^{40}$ Aufgrund von besser erhaltenen Parallelen kann es zu einem gerundeten Alabastron FT 85, ${ }^{41}$ FT 86, ${ }^{42}$ einem eckigen Alabastron FT 94/96/97, ${ }^{43}$ einem späten Schulterhenkelamphoriskos FT $48^{44}$ oder einem Bauchhenkelamphoriskos mit zweiFT $59^{45}$ bzw. drei Henkeln FT $61^{46}$ gehört haben. Die zitierten Parallelen aus verschiedenen Regionen Griechenlands erlauben eine Datierung von SH IIIB Mitte

38 Dieses Fragment war bislang unpubliziert.

39 Furumark 1941, 590-591. - Furumark 1992, Taf. 28-30. - Netzmuster sind auch in Südgriechenland für mittelgroße Schulterhenkelamphoren FT 39-42 belegt: Persson 1931, 106 und Abb. 81/unten Mitte und Abb. 82; 107 Nr. 57. - Wace 1932, 97 Nr. 12 und Taf. 48/12. 40 Alexandrov 2002, 75, Kat. Nr. 2; 337 und Abb. 30/4. 41 Midea, Westtor, Zerstörungsschicht (SH IIIB Ende): DemaKOPOUlOu 2003, 82-83 und Abb. 6/1 (Rand geringfügig verdickt). 42 Mykene, Kultzentrum, Areal 36, Zerstörungsschicht auf dem Fußboden der Phase VII (SH IIIB Mitte) oder Verfüllung der Phase VIII (SH IIIB Ende): French, Taylour 2007, CD-ROM, 327-329, Kat. Nr. 66-523 (ganzes Gefäß, Dekor 11.0).

43 Kastanás (Abb. 8/10), Schichten (14a)-14b: Jung 2002, 336 und Taf. 10/113 (Dekor 11.0).

44 Tiryns, Schutt der Palastzerstörung im Bereich der Westtreppe (SH IIIB Ende): KARDAmaKi 2015, 86 und Abb. 4/5 (Fragment von Rand und Hals). - Mykene, Kultzentrum, Korridor 34, Zerstörung der Phase VIII (SH IIIB Ende): French, TAYlour 2007, 31, 34 und Taf. 10/c; CD-ROM, 431, Kat. Nr. 69-403 (ganzes Gefäß, wohl Dekor $10.9=$ Rand und Hals außen monochrom, innen unbemalt). Mykene, Kultzentrum, Korridor 34N, Zerstörung der Phase VIII (SH IIIB Ende): French, Taylour 2007, CD-ROM, 452, Kat. Nr. 69-419 (ganzes Gefäß, Dekor 11.0). - Midea, Westtor, Zerstörungsschicht (SH IIIB Ende): Demakopoulou 2003, 82-83 und Abb. 6/4. - Ássiros A (Abb. 8/2), Phase 8: Wardle 1993, 126 und Abb. 3/2; 129. 45 Midea, Westtor, Zerstörungsschicht (SH IIIB Ende): Demakopoulou, Divari-Valakou, Schallin 2004, 10 und Abb. 6.

46 Peratí, Kammergrab 141, Kinderbestattung, von Iakovidis in Phase II datiert, doch möglicherweise noch SH IIIC Früh: Iakovidis 1969-1970, Bd. I, 226, 228-229, Nr. 1022; Bd. II, 400 und Tab.; Bd. III, Taf. 66/ $\beta / 1022$. -Mountjoy 1999, 565-566 und Abb. 208/316 (Dekor 11.0). 
bis SH IIIC Früh, obgleich sich auch ein noch etwas späterer Zeitansatz nicht ausschließen lässt, zumal nichts von der Schulter des Gefäßes aus Koprivlen erhalten ist.

Das Wandfragment eines kleinen offenen Gefäßes (Kat. Nr. 4, Abb. 7/4) aus Struktur 25-10 kann mit aller Vorsicht einer Kylix FT 257 zugewiesen werden. ${ }^{47}$ Darauf deutet der Wandungsverlauf in Kombination mit dem Muster, einer schrägen Purpurschnecke FM 23,5, hin, wie sie in allen mykenischen Regionen häufig zur Verzierung dieses Gefäßtyps verwendet wurde. Der monochrome Innendekor von Kylikes FT 256-258B war nicht auf der Peloponnes, ${ }^{48}$ doch dafür in Mittelgriechenland ${ }^{49}$ und Thessalien ${ }^{50}$ sowie in Zentral- und Ostmakedonien üblich. Die Datierung des Beginns dieser mittel- und nordgriechischen Dekorvariante der Kylikes mit s-förmigem Wandungsprofil bereitet gewisse Schwierigkeiten. Sicher ist zunächst, dass derartige Gefäße ganz am Ende der Palastzeit bzw. zu Beginn der Nachpalastzeit in diesen Regionen allgemein in Verwendung waren. Dies belegen die Exemplare aus der Zerstörung der „Megara" von Dhimíni, ${ }^{51}$ aus einem Gebäude in Frandsí südlich von Lamía ${ }^{52}$ sowie ein Fund aus Eleón..$^{53}$ Was Makedonien angeht, so wurden in Kastanás (Abb. 8/10) zwei Randfragmente in Kontexten der Schichten (14b)-15 bzw. (13)-14a gefunden. Diese datieren demnach ebenfalls in den Zeitraum vom späten SH IIIB bis zum frühen SH IIIC. ${ }^{54}$ Das aus Schicht 15 oder 14b stammende Stück ist mit seinem schrägen Purpurschneckenmotiv eine exakte Parallele für

47 Alexandrov 2002, 75, Kat. Nr. 5; 337 und Abb. 30/1.

48 Kartierung der Gesamtverbreitung bei Jung 2002, 143-144 und Abb. 53.

49 Neufunde aus dem böotischen Eleon (Burke, Burns, Charami 2012, 9 und Abb. 54 - eine Kylix des „Zygouries-Typs“ FT 258A mit dem Dekor 9.2) sowie aus Frandsí im Sperchióstal (Karantzali 2012, 1218, 1231 und Abb. 10/1, 4, 3, 5).

50 Neufunde aus Néa Ioniá in Vólos: Batziou-Efstathiou 1999, 117, Kat. Nr. 1.

51 Zerstörungsschicht der Phase SH IIIC Früh 1: AdRYmi-Sismani 2012, 164-165, 174 und Abb. 7/BE 46745, BE 46746.

52 Die Mehrzahl der Kylikes FT 257 und 258B aus dem betreffenden Gebäude zeigt einen monochromen Innendekor (KARANTZALI 2012, 1218, Anm. 44), während wenige besser erhaltene Gefäße auf den Hausfußböden (v. a. KARANTZALi 2012, 1217, 1228 und Abb. 7/7; 12/6) sowie der überwiegend monochrome Innendekor der Skyphoi und das Vorkommen von Tassen FT 215 mit mittelbreitem Randband (KARANTZALi 2012, 1217-1218, 1228 und Abb. 7) auf einen zeitlichen Ansatz in SH IIIC Früh 1 hindeuten. - Vgl. KARDAMAKI 2015. 53 Eleon, Kontext mit Material aus SH IIIB Ende und SH IIIC Früh 1: Burke, Burns, Charami 2012, 9 und Abb. 54.

54 Jung 2002, 319-320, 347 und Taf. 5/52; 14/154. - Diese Scherben stehen für die FT 257 und 258B, während zwei Wandfragmente mit einem Purpurschneckenpaar aus Schicht 14b (Jung 2002, 328-329 und Taf. 7/83) dem innen monochromen „Zygouries-Typ“ FT 258A angehören könnten. die Scherbe aus Koprivlen. Dennoch könnten die frühesten Kylikes FT 257-258B mit Varianten des Dekors 9 (meist 9.2 mit schmalem Randband) im Norden bereits gleichzeitig mit der Blütezeit der entsprechenden innen nicht monochromen Kylikes in Südgriechenland, d. h. von SH IIIA Spät bis SH IIIB Mitte, gefertigt worden sein. Einen Hinweis in diese Richtung stellt das Randfragment einer Kylix FT 257 ohne Randband und mit monochromer Innenseite (Dekor 9.2.1) dar, das im ostmakedonischen Stathmós Anjístas (Abb. 8/26) gefunden wurde und mit gestielten Spiralen verziert ist. Es stammt nämlich aus der tiefsten Schicht dieser Siedlung, die deutlich unter jenen Straten liegt, welche Keramik des späten SH IIIB und der Periode SH IIIC erbrachten. ${ }^{55}$

Als letzte sind zwei Wandscherben aus Struktur 35-10 von Koprivlen zu nennen, die zu einem Skyphos FT 284/285 mit monochromem Innendekor (Skyphos B bzw. $\mathrm{C}^{56}$ ) gehört haben dürften (Kat. Nr. 3, Abb. 7/3). ${ }^{57}$ Seine Ware unterscheidet dieses Gefäß deutlich von jenen aus Struktur 23-60. Einzelne weit geschwungene waagerechte Wellenbänder sind die häufigsten bzw. zweithäufigsten Muster der Skyphoi A sowie der innen monochromen Skyphoi in Zentralmakedonien..$^{58}$ Exakte Form-, Dekor- und Musterparallelen für das Gefäß aus Koprivlen wurden in Kastanás, Schicht 14b (SH IIIC Früh), ${ }^{59}$ Ássiros A (Abb. 8/2), Phasen 9 und 7 (SH IIIA Spät bis SH IIIB Früh bzw. SH IIIC), ${ }^{60}$ auf der Toumba von Thessaloníki (Abb. 8/27) in Phase 4 (SH IIIC Früh bis maximal IIIC Entwickelt) ${ }^{61}$ sowie in Periwoláki (Abb. 8/19) ${ }^{62}$ gefunden. In Südgriechenland haben die Wellenbandskyphoi in der Regel eine linear bemalte Innenwandung. ${ }^{63}$ Innen monochrome Exemplare sind weitaus seltener ${ }^{64}$ wobei die Produkte attischer Töpfereien hier

55 Koukouli-Chrysanthaki 1980, 65; 74-75 und Abb. 16/A 648. - Jung 2002, 145-146, 239-240, 565, Nr. 4 und Taf. 73/7.

56 Zur Definition dieser Termini siehe Kardamaki 2009, 204-206, 225-231.

57 Alexandrov 2002, 75, Kat. Nr. 6; 337 und Abb. 30/2, 6.

58 Jung 2002, 81-83, 91-92.

59 Jung 2002, 92, 325-326 und Taf. 7/72

60 WardLE 1993, 127, 132-133 und Abb. 7/1. - Jung 2002, 92, 325326.

61 Andreou 2003, 195, 206 und Abb. 6/KA 1998.

62 Jung 2002, 560 und Taf. 70/7 (abweichend nur im Dekor: mit zwei breiten Unterbändern, Ubd. 2.2).

63 Voigtländer 2003, 73-75 und Taf. 109-110. - Kardamaki 2009, 221-222.

64 Tiryns, Unterburg, Töpferofen (SH IIIC Früh): PodzuweIT 1981, 207-208 und Abb. 57/4 (Randdurchmesser 15 cm; am Randband hängendes Wellenband). - Tiryns, „Epichosis“ (SH IIIB Ende [-IIIC Früh 1]): VoigTLÄNDER 2003, 94 und Taf. 129/Si 122 (allerdings mit tropfenförmiger Lippe). 


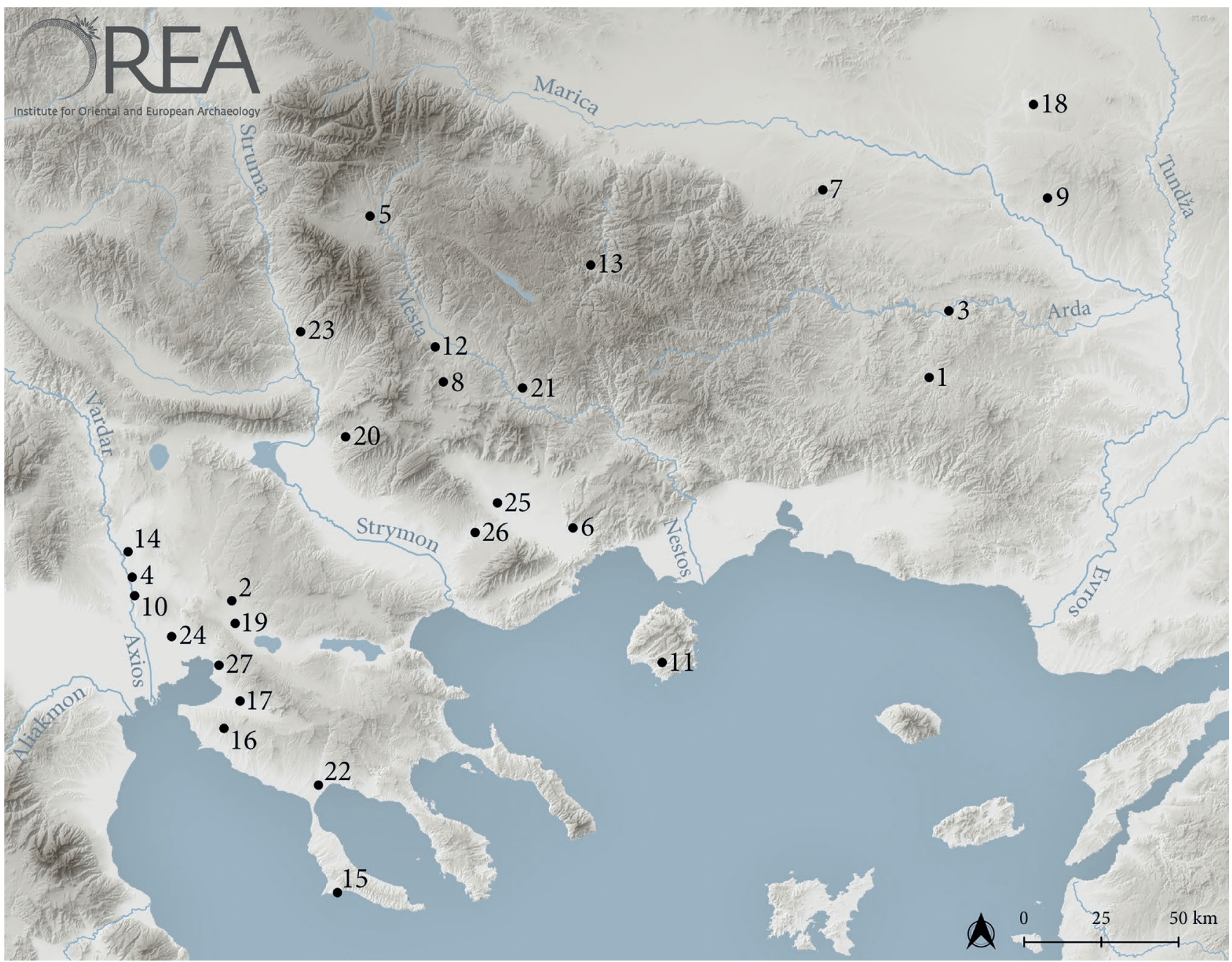

Abb. 8. Karte des nordägäischen Raums und des südlichen Ostbalkans mit den im Text genannten Fundorten. - 1. Ada Tepe. - 2. Ássiros A. 3. Aul Kaya. - 4. Axiochóri. - 5.Bresto. - 6. Dikili Taş. - 7. Dragojna. - 8. Exochí. - 9. Izvorovo. - 10. Kastanás. - 11. Kastrí (Thasos). - 12. Koprivlen. - 13. Lilovo. - 14. Limnótopos. - 15. Mendē, Wíghla. - 16. Messimerianí Toúmba. - 17. Néa Rädhestós. - 18. Ovčarci. - 19. Periwoláki. - 20. Phäá Pétra. - 21. Potamí. - 22. Prähistorisches Olynth. - 23. Sandanski. - 24. Sindos. - 25. Sitaghrí. - 26. Stathmós Anjístas. - 27. Toumba von Thessaloníki (Grafik: M. Börner/OREA).

vermutlich eine Ausnahme bildeten. ${ }^{65}$ Zudem sind die südgriechischen Wellenbandskyphoi mit $17,6 \mathrm{~cm}$ durchschnittlichem Randdurchmesser ${ }^{66}$ meist größer als das Gefäß aus

65 Die Grube 1 von Kontopíghadho, eine Deponierung der Phase SH IIIC Früh 1, enthielt an Wellenbandskyphoi ausschließlich innen monochrom dekorierte Exemplare (KAZA-PAPAgEORgIOU et al. 2011, 226-227, 235-237 und Abb. 7/21-24). Ein Skyphos mit schmalem Randband und breitem Unterband (Dekor $9.2+$ Unterband 2.1) steht dem Skyphos aus Koprivlen stilistisch am nächsten (KAzAPapageorgiou et al. 2011, 235-236 und Abb. 7/23). Sein Randdurchmesser beträgt allerdings $18 \mathrm{~cm}$, womit er der südgriechischen Norm für den Wellenbandskyphos entspricht und sich von dem bulgarischen Fund wiederum unterscheidet (siehe unten).

66 Berechnet auf der Grundlage der Skyphoi A und C mit einfachem Wellenband aus der Tirynther „Epichosis“: VOIGTLÄNDER 2003, 73-75, Kat. Nr. SW 1-27; 94, Kat. Nr. Si 122.
Koprivlen mit seinem maximalen Gefäßdurchmesser von 13,5 cm. Eine gute Parallele hinsichtlich Muster, Dekor und Größe stellt hingegen ein Wellenbandskpyhos aus dem mittelgriechischen Kalapódhi dar, das der in SH IIIC Entwickelt datierten Schicht 2 zugewiesen wurde. ${ }^{67}$ Ein sehr ähnliches Gefäß ist auch von der thessalischen Magoula von Ktoúri in der Ebene von Kardhítsa publiziert. ${ }^{68}$

Letztlich lässt sich nicht ausschließen, dass es sich bei dem fragmentarisch erhaltenen Gefäß aus Koprivlen auch um einen Skyphos mit verdicktem Rand handeln könnte,

67 Јасов-Felsch 1996, 19-20, 125, Kat. Nr. 37 und Taf. 24/37 (Randdurchmesser $14 \mathrm{~cm}$ ).

68 Unstratifiziert: BÉQUignon 1932, 162 und Abb. 45/158; 164 (innen monochrom, Randdurchmesser $16 \mathrm{~cm}$ ). 
wie er in Westmakedonien schon ab der entwickelten Palastzeit mit weit geschwungenem Wellenband und Dekor 9 nachgewiesen ist, ${ }^{69}$ wobei eine Reihe von zentralmakedonischen Exemplaren eine Produktion vor allem in SH IIIC Früh belegt. ${ }^{70}$ Auch aus dem frühnachpalastzeitlichen Dhimíni liegt ein innen monochromer Wellenbandskyphos mit verdicktem Rand vor. ${ }^{71}$

Da die mykenischen Gefäße von Koprivlen alle der jüngeren Siedlungsphase Koprivlen II angehören, innerhalb derer jedoch keine feinstratigrafische Abfolge der Bauten feststellbar war, kann man als Gesamtzeitraum der Verwendungszeit mykenischer Keramik in Koprivlen diesen jüngeren, so genannten ersten Bauhorizont angeben und diesen mit den Phasen SH IIIB Früh bis SH IIIC Früh (eventuell auch bereits mit SH IIIA Spät) synchronisieren. Diese Maximalspanne ergibt sich aus der Kombination der chronologisch aussagekräftigen Merkmale der mykenischen Keramik, wobei der Skyphos A mit vertikaler Purpurschnecke die sichere zeitliche Obergrenze vorgibt. Der mögliche noch frühere Ansatz ab SH IIIA Spät hinge nur an dem aufgrund seiner monochromen Innenseite schwer datierbaren Kylixfragment mit schräger Purpurschnecke. Die übrigen Fragmente sprechen eher für einen Ansatz in der zweiten Hälfte des genannten chronologischen Rahmens. Auch die Auswertung der handgemachten Keramik liefert Hinweise, die in diesem Sinne zu interpretieren sind..$^{72}$ Somit datiert das mykenische Material von Koprivlen in seiner Gesamtheit in eine deutlich spätere historische Periode als jenes aus der Siedlung von Dragojna.

\subsection{Verkehrswege Richtung Süden}

Bei der Frage nach den Verkehrswegen, die die Siedlung von Koprivlen in der Spätbronzezeit mit den küstennahen Regionen im Süden verbunden haben könnten, ist zunächst zu bemerken, dass die Nestosschlucht in den Rhodopen sowie in dem Abschnitt zwischen diesen und dem Berg Falakrós/ Bozdağ kaum passierbar ist. Gemäß den Schriftquellen der

69 Äaní, keramikführende Schicht oberhalb der Grubengräber: Karamitrou-Medessidi 2003, 172, 180 und Abb. 5. - KaramitrouMedessidi 2009, 72, 75 und Abb. 117. - Zur Datierung der Schicht siehe Jung 2003a, 212, Anm. 16.

70 Kastanás, Schicht |14b: Jung 2002, 74-75, 333 und Taf. 9/101. Toumba von Thessaloníki, Phase 4: Andreou 2003, 206 und Abb. 6/ KA 555/960, KA 728. - AndREOU 2009, 33 und Abb. 7/6. - Bei vielen Exemplaren ist aufgrund des Erhaltungszustands nicht auszuschließen, dass es sich um hochfüßige Skyphoi FT 304/305 handelte, die ein gleichartiges Randprofil wie die Skyphoi mit verdicktem Rand aufwiesen.

71 Dhimíni, Zerstörungsschicht der „Megara“ (SH IIIC Früh 1): Adrymi-Sismani 2012, 173 und Abb. 6/BE 46755.

72 Alexandrov 2002, 79-80: beste Entsprechungen in den Kastanás-Schichten 14b bis 14a (SH IIIC Früh).
Antike, aber auch des 18. bis 19. Jhs. gab es aber zwei Hauptstraßen, die die Region von Nevrokop mit dem Gebiet des heutigen Griechenland bis zur ägäischen Küste verbanden. Bei Koprivlen gabeln sich diese Straßen Richtung Süden. Die erste führt durch die Rhodopen westlich am Berg Falakrós/Bozdağ vorbei über das Becken von Drama, westlich am Pangaion vorbei und zur Strymonmündung. Die moderne Straße von Gotse Delčev/Nevrokop nach Drama folgt im Wesentlichen dem Verlauf der antiken Straße, wobei ein gepflasterter Abschnitt (aus römischer Zeit?) auf dem Gyuredjik-Pass auf dem Falakrós/Bozdağ noch im 19. Jh. erhalten war. Die wichtigsten modernen Orte auf dieser Route sind Nevrokop, Koprivlen und Ilinden in Bulgarien sowie Exochí (Abb. 8/8), Káto Newrokópi und Drama in Griechenland. ${ }^{73}$

Es gab aber noch eine andere in der Vergangenheit genutzte Route, die von Gotse Delčev/Nevrokop nach Séres südlich am Piringebirge vorbei und durch das Strymontal führt. Die modernen Orte an dieser Route sind Gotse Delčev/Nevrokop, Koprivlen und Nova Lovča in Bulgarien sowie Turlis/Vathítopos, Sidhirókastro/Demir Hisar im Strymontal. Im 19./20. Jh. war die Straße nach Drama in schweren Wintern durch Schnee unpassierbar, so dass die Menschen die Straße durch Séres als Alternative benutzten.

Was die unmittelbare verkehrstechnische Anbindung an den Süden angeht, so war das Strymondelta mit Sicherheit ein günstiger Ausgangs- bzw. Anlaufpunkt, denn erstens bot es mehrere natürliche Hafenbecken, ${ }^{74}$ und zweitens war der Fluss selbst schiffbar.

\section{Neutronenaktivierungsanalyse von fünf mykenischen Gefäßen aus Koprivlen und Auswertung der Analysedaten}

\subsection{Methodik}

Die fünf im Katalog sowie in Tabelle 1 aufgeführten Gefäßfragmente Kopriv 1-5 wurden im Bonner Labor mittels NAA gemessen. Unsere Messmethode ist eine modifizierte Version der in Berkeley verwendeten Vorgehensweise ${ }^{75}$ und wird seit etwa 30 Jahren routinemäßig angewendet. ${ }^{76}$ Es wird von der heutigen Forschung allgemein akzeptiert, dass die Konzentrationsmuster der Massenprozente von Neben- und Spurenelementen in Keramik die von den prähistorischen Töpfern verwendeten Tonmassen charakterisieren und sich somit auf die Werkstätten beziehen lassen, die nach allgemeiner - und ethnoarchäologisch gestützter - Auffassung nicht weit entfernt von den Tonlagerstätten

73 Delev, Popov 2002.

74 Koukouli-Chrysanthaki et al. 1997, 652-655 und Abb. 13.

75 Perlman, Asaro 1969.

76 Mommsen et al. 1991. 
Tab. 1. Elementkonzentrationen der drei chemischen Einzelstücke von Koprivlen in $\mu \mathrm{g} / \mathrm{g}$ (ppm), wenn nicht anders bezeichnet, und ihre experimentellen Unsicherheiten $\delta$ in \%.

\begin{tabular}{|c|c|c|c|c|c|c|}
\hline & \multicolumn{2}{|c|}{$\begin{array}{c}\text { Kopriv } 1 \\
1 \text { Probe }\end{array}$} & \multicolumn{2}{|c|}{$\begin{array}{c}\text { Kopriv } 3 \\
1 \text { Probe }\end{array}$} & \multicolumn{2}{|c|}{$\begin{array}{c}\text { Kopriv } 4 \\
1 \text { Probe }\end{array}$} \\
\hline & C & $\delta(\%)$ & C & $\delta(\%)$ & C & $\delta(\%)$ \\
\hline As & 3,39 & $(3,4)$ & 5,77 & $(2,5)$ & 13,8 & $(1,0)$ \\
\hline $\mathrm{Ba}$ & 509 & $(5,8)$ & 459 & $(7,4)$ & 294 & $(9,8)$ \\
\hline $\mathrm{Ca} \backslash \%$ & 0,58 & (28) & 6,60 & $(3,2)$ & 3,95 & $(3,8)$ \\
\hline $\mathrm{Ce}$ & 61,5 & $(0,6)$ & 69,3 & $(0,6)$ & 33,6 & $(1,1)$ \\
\hline Co & 11,1 & $(0,8)$ & 29,2 & $(0,5)$ & 72,5 & $(0,3)$ \\
\hline $\mathrm{Cr}$ & 415 & $(0,3)$ & 335 & $(0,3)$ & 952 & $(0,3)$ \\
\hline Cs & 22,8 & $(0,7)$ & 3,04 & $(3,3)$ & 3,07 & $(4,0)$ \\
\hline $\mathrm{Eu}$ & 0,98 & $(1,9)$ & 1,37 & $(1,6)$ & 0,66 & $(3,1)$ \\
\hline $\mathrm{Fe} \backslash \%$ & 1,91 & $(0,4)$ & 5,68 & $(0,3)$ & 8,63 & $(0,3)$ \\
\hline $\mathrm{Ga}$ & 28,3 & $(8,2)$ & 27,4 & (11) & 18,6 & (16) \\
\hline $\mathrm{Hf}$ & 6,94 & $(0,9)$ & 5,48 & $(1,1)$ & 2,65 & $(2,4)$ \\
\hline $\mathrm{K} \backslash \%$ & 2,68 & $(1,0)$ & 1,44 & $(2,1)$ & 1,17 & $(2,0)$ \\
\hline $\mathrm{La}$ & 30,6 & $(0,3)$ & 33,4 & $(0,2)$ & 15,5 & $(0,4)$ \\
\hline $\mathrm{Lu}$ & 0,44 & $(2,9)$ & 0,53 & $(2,7)$ & 0,44 & $(3,8)$ \\
\hline $\mathrm{Na} \backslash \%$ & 0,98 & $(0,4)$ & 1,81 & $(0,4)$ & 0,76 & $(0,5)$ \\
\hline $\mathrm{Nd}$ & 28,9 & $(6,7)$ & 31,2 & $(7,0)$ & 16,3 & (14) \\
\hline $\mathrm{Ni}$ & 103 & (25) & 314 & (10) & 947 & $(5,0)$ \\
\hline $\mathrm{Rb}$ & 166 & $(1,5)$ & 78,3 & $(3,0)$ & 51,9 & $(5,3)$ \\
\hline $\mathrm{Sb}$ & 0,39 & $(6,6)$ & 0,52 & $(5,8)$ & 1,24 & $(2,3)$ \\
\hline $\mathrm{Sc}$ & 20,2 & $(0,1)$ & 22,8 & $(0,1)$ & 35,8 & $(, 08)$ \\
\hline $\mathrm{Sm}$ & 5,61 & $(1,4)$ & 6,23 & $(2,2)$ & 2,89 & $(5,2)$ \\
\hline $\mathrm{Ta}$ & 1,42 & $(2,8)$ & 0,91 & $(4,4)$ & 0,38 & (12) \\
\hline $\mathrm{Tb}$ & 0,68 & $(7,8)$ & 1,00 & $(6,4)$ & 0,43 & (17) \\
\hline Th & 17,5 & $(0,4)$ & 12,1 & $(0,6)$ & 7,37 & $(1,0)$ \\
\hline $\mathrm{U}$ & 5,16 & $(3,8)$ & 1,94 & (12) & 1,22 & (16) \\
\hline W & 3,32 & $(5,4)$ & 2,58 & $(8,5)$ & 2,52 & $(8,4)$ \\
\hline $\mathrm{Yb}$ & 3,02 & $(1,7)$ & 3,58 & $(1,7)$ & 2,14 & $(2,3)$ \\
\hline $\mathrm{Zn}$ & 59,3 & $(2,7)$ & 113 & $(1,9)$ & 119 & $(2,1)$ \\
\hline $\mathrm{Zr}$ & 235 & $(9,0)$ & 173 & (14) & 115 & (26) \\
\hline
\end{tabular}

lagen. Sofern viele verschiedene Elemente mit hoher Präzision gemessen werden, besteht eine hohe Wahrscheinlichkeit, dass das resultierende Konzentrationsmuster einmalig ist. Daher wird dieses meist mit dem einmaligen Muster eines menschlichen Fingerabdrucks verglichen, so dass diese Methode der Herkunftsbestimmung als chemische Fingerabdruck-Methode bezeichnet wird. ${ }^{77}$

77 Perlman, Asaro 1969. - Harbottle 1976. - Wilson 1978. Mommsen 2011.
Man kann annehmen, dass Keramikgefäße, die die gleiche Elementzusammensetzung aufweisen, in derselben oder in mehreren benachbart liegenden Werkstätten getöpfert wurden. Um verschiedene Muster miteinander zu vergleichen, sind statistische Methoden wie Principal Component Analysis (PCA) oder unterschiedliche Arten von Clusteranalysen (CA) in Verwendung. ${ }^{78}$ In Bonn haben wir ein Statistikpaket entwickelt, das wie ein Filter wirkt. ${ }^{79}$ Es ist in der Lage, aus einer großen Datenbank alle Proben herauszufiltern, deren Elementmuster einem gegebenen Muster ähneln, wobei experimentelle Fehler sowie auch die Möglichkeit berücksichtigt werden, dass die Tonmasse durch unterschiedliche Mengen von Zuschlagstoffen wie beispielsweise Sand $\left(\mathrm{SiO}_{2}\right)$ oder Kalzit $\left(\mathrm{CaCO}_{3}\right)$ verdünnt wurde. ${ }^{80}$ Dazu wird im Bezug zum gegebenen Filtermuster ein bester relativer Anpassungsfaktor berechnet, der so genannte Verdünnungsfaktor. Diese beiden Elemente können in einer PCA oder CA nicht berücksichtigt werden. Die pulverisierten Proben von Keramikfragmenten werden mittels eines Spitzbohrers aus Korund (reines Aluminiumoxid) mit einem Durchmesser von $10 \mathrm{~mm}$ gewonnen. Nur etwa $80 \mathrm{mg}$ werden für die Analyse benötigt, wobei die Probennahme in der Regel an der Gefäßinnenwandung erfolgt und dort eine flache Mulde von ca. $1 \mathrm{~cm}$ hinterlässt, was zukünftig auf das Vorliegen unserer Analyseresultate verweist.

Ein Probenset wurde zusammen mit sechs Proben des Bonner Keramikstandards ${ }^{81}$ zum Forschungsreaktor des Reaktorinstituts der TU Delft zur Neutronenbestrahlung gesandt (Flux 12.5 Neutronen/( $\mathrm{cm}^{2}$ s), Dauer $10 \mathrm{~h}$ ). Nach dem Transport der Proben nach Bonn wurde die radioaktive Strahlung die folgenden vier Wochen über gemessen und analysiert, um die Elementkonzentrationen von bis zu 30 verschiedenen Elementen zu bestimmen, sofern diese über der Nachweisgrenze lagen.

\subsection{NAA-Ergebnisse und inre Interpretation}

Die Analyse der Konzentrationsmuster der Proben aus Koprivlen ergab die Herkunftsbestimmung zweier Gefäße, Kopriv 2 und 5, die eine uns bereits bekannte Zusammensetzung aufweisen. Die verbleibenden drei sind chemische Einzelfälle. Ihre Konzentrationsmuster sind in Tabelle 1 aufgeführt. Aus den chemischen Einzelfällen können keine näheren Schlussfolgerungen gezogen werden. Sie können entweder ein Tonrezept einer bislang unbekannten Töpferwerkstatt repräsentieren, oder aber sie wurden in der Bronzezeit oder in unserem Labor kontaminiert.

\footnotetext{
78 BAXTER 2003.

79 Mommsen, Kreuser, Weber 1988. - Beier, Mommsen 1994.

80 Mommsen, SJÖBerg 2007.

81 Zur Zusammensetzung siehe Mommsen, SJöberg 2007.
} 
Die Probe Kopriv 2 des Gefäßes Kat. Nr. 3 ähnelt in ihrer Zusammensetzung (abgesehen von einer kleinen Abweichung des Cs-Werts) einer großen Gruppe von 46 Proben, die AkaR genannt und der Region von Ätoloakarnanien zugewiesen wurde. ${ }^{82}$ Diese Zuweisung beruht lediglich auf der Fundverteilung der Gruppenmitglieder, die hauptsächlich aus diesem Gebiet stammen. ${ }^{83}$ Eine gute Referenzprobe ist für diese Gruppe leider nicht vorhanden, so dass die Herkunft von Kopriv 2 aus Ätoloakarnanien nicht als sicher nachgewiesen gelten kann. Die Daten dieser Probe werden dem Muster der Gruppe AkaR in Tabelle 2 gegenübergestellt.

Auch für die zweite Probe eines bekannten Musters, Kopriv 5 von Kat. Nr. 2, lässt sich nur eine allgemeine Herkunftsregion bestimmen. Wie die in Tabelle 2 aufgelisteten Daten zeigen, ähnelt die Zusammensetzung statistisch der Gruppe X057 aus unserer Datenbank. Wiederum ist die genaue Lage der Werkstatt, die Ton dieser Zusammensetzung verarbeitete, unbekannt, doch fast alle Gruppenmitglieder kommen aus Makedonien in Nordgriechenland, so dass man mit hoher Wahrscheinlichkeit davon ausgehen kann, dass das kleine geschlossene Gefäß Kat. Nr. 2 in Makedonien getöpfert wurde. ${ }^{84}$

Im Detail besteht die Gruppe X057 aus 15 Proben von acht verschiedenen Fundorten, die größtenteils in Zentralmakedonien (einschließlich der Chalkidiki) liegen: Ássiros A (Toumba von Ássiros, Abb. 8/2), ${ }^{85}$ Prähistorisches Olynth (Toumba von Ájios Mámas, Abb. 8/22), ${ }^{86}$ Messimerianí Toúmba, Abb. 8/16, ${ }^{87}$ Néa Rädhestós (Nea Rhaidestos, Abb. 8/17), ${ }^{88}$ Sitaghrí (Sitagroi, Abb. 8/25), Sindos (Doppelte Trapeza von Anchíalos, Abb. 8/24), ${ }^{89}$ Mendē (Abb. 8/15) ${ }^{90}$ und Koprivlen (Abb. 8/12). Allerdings handelt es sich mit

82 Jung, Mommsen, Paciarelli 2015

83 Das Material, das in den Magazinen von Patras aufbewahrt wird, stammt aus Loutrákis Katoúnas.

84 Gerundete und eckige Alabastra sind mit zahlreichen Exemplaren in Makedonien vertreten: Jung 2002, 160-164 und Abb. 59 (Verbreitungskarte). - Die nördlichsten Funde im zentral- bzw. ostbalkanischen Raum sind derzeit Dimov Grob bei Ulanci im Vardartal Nordmakedoniens (VIDEski 2007, 212 und Taf. 54/e) und Bresto im Becken von Razlog (Athanassov et al. 2017a, 135-136 und Abb. 3. - Athanassov et al. 2017b, 19-20). - Auch Amphoriskoi unterschiedlicher Typen gehören zu den geläufigen Funden in makedonischen Siedlungen und Nekropolen: Jung 2002, 164-169 und Abb. 62 (Verbreitungskarte).

85 Grammenos et al. 1997, 16-17, 79, Nr.16 („Ássiros A Toumba“).

86 Grammenos et al. 1997, 52, 83, Nr. 4 („Ájios Mámas“).

87 Grammenos et al. 1997, 38, 82, Nr. 112 („Trílofos B“). Grammenos, Kotsos 2002.

88 Grammenos et al. 1997, 29, 81, Nr. 75.

89 Grammenos et al. 1997, 14, 79, Nr. 5 („Anchíalos A“).

90 Grammenos et al. 1997, 59, 84, Nr. 27. - Moschonissioti 1998.

- Anagnostopoulou-Chatzipolychroni, Gimatzidis 2013.
Ausnahme der Probe von Koprivlen nicht um mykenische Keramik. Einige wenige Proben stammen von eisenzeitlichen Gefäßen, ${ }^{91}$ während die Probe aus Sitaghrí sicher frühbronzezeitlich ist. ${ }^{92}$ Die Probe aus Ássiros A wurde von einem spätbronzezeitlichen Gefäß handgemachter Feinware genommen. ${ }^{93}$

Für die chemischen Übereinstimmungen mit Proben von Gefäßen verschiedener Keramikklassen unterschiedlicher Zeitstellung und verschiedener makedonischer Fundorte kann es mehrere Erklärungen geben: Es könnte in Zentralmakedonien und auf der Chalkidiki Tonlagerstätten geben, die von verschiedenen, nur wenige Kilometer voneinander entfernt liegenden Siedlungen genutzt wurden. Der Befund ließe sich aber auch so erklären, dass Tone verschiedener makedonischer Mikroregionen sich chemisch nicht differenzieren lassen. In beiden Fällen wären Funde derselben chemischen Gruppe von weiter entfernt liegenden Orten (z. B. Sitaghrí oder Koprivlen) als Importe in ihrer jeweiligen Periode und am jeweiligen Ort anzusehen.

Immerhin liegen drei Fundorte mit insgesamt neun Proben der Gruppe X057 (60 \% der Gesamtprobenzahl) auf der westlichen Chalkidiki, so dass die Tonlagerstätte, die zur Produktion der Gefäße der Gruppe X057 verwendet wurde, in jener geografischen Region zu verorten sein könnte. Andererseits wissen wir kaum etwas über die Zirkulation spätbronzezeitlicher Keramik im Raum zwischen der zentralmakedonischen Ebene und den angrenzenden Regionen der Chalkidiki.

Man kann aber zumindest einzelne Mikroregionen als Herkunftszonen der Gruppe X057 mit einer gewissen Wahrscheinlichkeit ausschließen: Die NAA-Daten aus Kastanás ${ }^{94}$ deuteten auf eine regionale Produktion mykenischer Keramik am Axios bzw. der damaligen Bucht von Kastanás, dem nördlichen Ausläufer des Thermaischen Golfs hin - etwa im Bereich der Toumben von Limnótopos (Abb. 8/14), Kastanás und Axiochóri (Abb. 8/4). Erstens umfassen zwei ausschließlich in Kastanás belegte chemische Gruppen neben mykenischen Gefäßen auch handgemachte Gefäße aus Kastanás. ${ }^{95}$ Zweitens zeigt eine der größten NAA-Gruppen aus Kastanás, die vor allem für das Ende der Periode SH IIIC und die folgenden früheisenzeitlichen Schichten belegt ist, ${ }^{96}$ eine signifikante geografische

91 Zur Keramik aus Sindos siehe Gimatzidis 2010.

92 Eine Schale mit einziehendem Rand. - Vgl. Sitagroi Vb: SHERratT 1986, 439, 472 und Abb. 13.26/1-5.

93 Jones 1986, 109-110 und Tab. 3.2: „Brown Burnished common throughout the LBA“.

94 Mommsen et al. 1989.

95 Jung 2002, 52-53 und Abb. 4; 56: Gruppen M 4 und M 5.

96 Gruppe G I: G 1: Mommsen et al. 1989. - Jung 2002, 52-53 und Abb. 4; 56-64. - Heute wird diese Gruppe unter dem Sigel GKM geführt. 
Tab. 2. Probe Kopriv 2 verglichen mit der Gruppe AkaR (Ätoloakarnanien?) und Probe Kopriv 5 verglichen mit der Gruppe X057 (Nordgriechenland/Makedonien). Gegeben sind die Konzentrationswerte C für die Proben und die mittleren Konzentrationen M für die Gruppen in $\mu \mathrm{g} / \mathrm{g}(\mathrm{ppm})$, wenn nicht anders bezeichnet. $\delta$ sind experimentelle Unsicherheiten in \% der Werte C, und $\sigma$ ist die Standardabweichung (Wurzel aus der mittleren quadratischen Abweichung) der Mittelwerte $\mathrm{M}$ in \%. Die individuellen Werte der einzelnen Proben als Mitglieder der Gruppen sind mit dem besten relativen Anpassungsfaktor (Faktor) in Bezug auf die Gruppen-Mittelwerte korrigiert. Die Werte der Proben Kopriv 2 und 5 sind ebenfalls mit dem gegebenen Anpassungsfaktor in Bezug auf ihre Gruppe multipliziert.

\begin{tabular}{|c|c|c|c|c|c|c|c|c|}
\hline & & $\begin{array}{l}\text { iv } 2 \\
\text { be } \\
0.79\end{array}$ & & $\begin{array}{l}\text { R } \\
\text { ben } \\
1.00\end{array}$ & & & & $\begin{array}{l}7 \\
\text { ben } \\
1.00\end{array}$ \\
\hline & C & $\delta(\%)$ & $\mathbf{M}$ & $\sigma(\%)$ & C & $\delta(\%)$ & $\mathbf{M}$ & $\sigma(\%)$ \\
\hline As & 5,46 & $(2,0)$ & 7,09 & (59) & 4,78 & $(2,9)$ & 15,0 & (53) \\
\hline $\mathrm{Ba}$ & 406 & $(6,4)$ & 535 & (36) & 924 & $(3,7)$ & 588 & (33) \\
\hline $\mathrm{Ca} \backslash \%$ & 2,66 & $(5,6)$ & 6,96 & (57) & 6,17 & $(3,2)$ & 2,11 & (72) \\
\hline $\mathrm{Ce}$ & 58,3 & $(0,5)$ & 59,0 & $(4,5)$ & 82,3 & $(0,5)$ & 80,4 & $(4,9)$ \\
\hline Co & 31,7 & $(0,4)$ & 31,1 & $(8,7)$ & 18,2 & $(0,6)$ & 17,8 & (13) \\
\hline $\mathrm{Cr}$ & 321 & $(0,3)$ & 318 & (14) & 115 & $(0,6)$ & 121 & (11) \\
\hline Cs & 7,43 & $(1,3)$ & 5,60 & (12) & 3,72 & $(2,4)$ & 4,84 & (12) \\
\hline $\mathrm{Eu}$ & 1,12 & $(1,6)$ & 1,16 & $(3,7)$ & 1,52 & $(1,4)$ & 1,35 & $(8,8)$ \\
\hline $\mathrm{Fe} \backslash \%$ & 5,22 & $(0,3)$ & 5,09 & $(3,8)$ & 4,87 & $(0,3)$ & 4,55 & $(9,3)$ \\
\hline $\mathrm{Ga}$ & 22,7 & $(9,9)$ & 19,8 & (31) & 19,9 & (15) & 22,8 & (21) \\
\hline $\mathrm{Hf}$ & 3,79 & $(1,3)$ & 4,04 & $(6,8)$ & 5,42 & $(1,0)$ & 6,52 & $(6,6)$ \\
\hline $\mathrm{K} \backslash \%$ & 2,00 & $(1,2)$ & 2,08 & $(6,3)$ & 2,86 & $(1,2)$ & 2,69 & $(8,0)$ \\
\hline $\mathrm{La}$ & 27,0 & $(0,2)$ & 28,1 & $(4,5)$ & 38,7 & $(0,2)$ & 37,8 & $(3,9)$ \\
\hline $\mathrm{Lu}$ & 0,47 & $(2,5)$ & 0,43 & $(6,0)$ & 0,52 & $(2,5)$ & 0,55 & $(7,1)$ \\
\hline $\mathrm{Na} \backslash \%$ & 1,14 & $(0,4)$ & 0,87 & (22) & 1,69 & $(0,4)$ & 1,22 & (25) \\
\hline $\mathrm{Nd}$ & 22,5 & $(7,8)$ & 25,7 & $(6,2)$ & 34,0 & $(5,9)$ & 34,0 & $(3,3)$ \\
\hline $\mathrm{Ni}$ & 399 & $(7,0)$ & 307 & (18) & 128 & (21) & 79,9 & (23) \\
\hline $\mathrm{Rb}$ & 111 & $(2,0)$ & 117 & $(7,6)$ & 131 & $(1,8)$ & 129 & $(6,9)$ \\
\hline $\mathrm{Sb}$ & 0,48 & $(5,0)$ & 0,52 & (18) & 0,31 & $(9,1)$ & 1,09 & (46) \\
\hline Sc & 20,8 & $(0,10)$ & 20,1 & $(4,8)$ & 16,3 & $(0,1)$ & 18,1 & $(8,2)$ \\
\hline $\mathrm{Sm}$ & 4,87 & $(2,6)$ & 4,95 & $(4,2)$ & 6,92 & $(1,2)$ & 6,63 & $(5,7)$ \\
\hline $\mathrm{Ta}$ & 0,72 & $(4,7)$ & 0,78 & $(6,7)$ & 1,08 & $(3,5)$ & 1,18 & $(5,7)$ \\
\hline $\mathrm{Tb}$ & 0,79 & $(6,7)$ & 0,73 & $(6,3)$ & 0,93 & $(5,9)$ & 1,02 & (11) \\
\hline Th & 10,4 & $(0,6)$ & 10,0 & $(4,8)$ & 15,6 & $(0,5)$ & 15,3 & $(7,3)$ \\
\hline $\mathrm{U}$ & 1,82 & $(9,4)$ & 2,02 & $(8,7)$ & 3,27 & $(6,5)$ & 2,66 & (31) \\
\hline W & 2,17 & $(7,6)$ & 2,00 & (15) & 2,26 & $(9,2)$ & 2,56 & (13) \\
\hline $\mathrm{Yb}$ & 2,75 & $(1,7)$ & 2,76 & $(4,0)$ & 3,58 & $(1,6)$ & 3,87 & (12) \\
\hline $\mathrm{Zn}$ & 97,9 & $(1,8)$ & 114 & (14) & 96,1 & $(1,9)$ & 90,2 & $(7,4)$ \\
\hline $\mathrm{Zr}$ & 124 & (16) & 171 & (18) & 220 & $(9,5)$ & 252 & (10) \\
\hline
\end{tabular}


Streuung von bemalter scheibengedrehter Keramik: Von 21 beprobten Gefäßen dieser Gruppe GKM wurden 14 in Kastanás gefunden, sechs auf der Messimerianí Toumba und eine auf der Toumba von Thessaloníki. Außerdem wurde eine der Proben aus Kastanás von einem Grauwarengefäß genommen. ${ }^{97}$ Diese Keramikklasse war in der Axiosregion verbreitet, fehlt jedoch auf der Chalkidiki südöstlich der im äußersten Nordwesten der Halbinsel gelegenen Toumba von Góna gänzlich. ${ }^{98}$

Wichtig für die Beurteilung der Verbreitung spätmykenischer bis protogeometrischer Produkte ist nun die Tatsache, dass mindestens zwei der Gefäße der Gruppe X057, die von der Messimerianí Toumba auf der westlichen Chalkidiki stammen, bemalte Drehscheibenprodukte sind. Andererseits hat die Forschergruppe des Athener Demokritos-Instituts betont, die Gruppe GKM entspräche in ihrer chemischen Zusammensetzung nicht den aus mykenischer Keramik von den Toumben von Ássiros und Thessaloníki gebildeten Gruppen. ${ }^{99}$ All dies spricht dafür, dass mit der NAA-Gruppe GKM tatsächlich Erzeugnisse der Töpferwerkstätten in der Axiosregion erfasst werden und dass deren Produkte in begrenztem Umfang auch in benachbarte Regionen Zentralmakedoniens gelangten.

Um zu Koprivlen zurückzukehren, könnte man nun im Gegenzug aus der Tatsache, dass Gruppe X057 unter den 87 aus Kastanás analysierten Gefäßen völlig fehlt, schließen, dass Gefäße mit den chemischen Charakteristika der Gruppe X057 höchstwahrscheinlich nicht in der Axiosregion gefertigt wurden. Auch mykenische Gefäße dieser nicht genauer zu lokalisierenden Werkstättenregion Zentralmakedoniens zirkulierten jedoch im nordägäisch-innerbalkanischen Raum, wie das Gefäß Kat. Nr. 2 aus Koprivlen beweist.

Schließlich bestätigt auch ein Vergleich der Probe Kopriv 5 mit Messungen mykenischer und protogeometrischer Drehscheibenkeramik aus den Grabungen im Prähistorischen Olynth die Zuweisung dieses nach Koprivlen importierten kleinen geschlossenen Gefäßes zum Produktionsraum Zentralmakedoniens (siehe Appendix A).

Der zugegebenermaßen noch äußerst lückenhafte archäometrische Forschungsstand zur mykenischen Keramikproduktion und Distribution in Makedonien deutet nach dem Gesagten darauf hin, dass im Laufe des Aufkommens und der Entwicklung der lokalen Herstellung mykenischer Keramik im weiteren zentralmakedonischen Raum jede Mikroregion ihre eigenen Töpferwerkstätten für dieses Drehscheibengeschirr unterhielt, dass allerdings eine

97 Jung 2002, 451 und Taf. 68/550 (Probe Kasg 1).

98 Jung 2007b, Abb. 2.

99 Buxeda i Garrigós et al. 2003, 269. begrenzte Zirkulation dieser lokalen Produkte durchaus stattfand.

Die wahrscheinliche Herkunft des Wellenbandskyphos' Kat. Nr. 3 (Probe Kopriv 2) aus dem nordwestgriechischen Ätoloakarnanien ist nur schwer aus dem archäologischen Befundbild jener Region heraus zu beurteilen. Nur sehr wenig spätmykenische Keramik wurde bislang in Ätoloakarnanien gefunden und publiziert. ${ }^{100}$ Die meisten Phasen mykenischer Keramikproduktion sind in Thérmos belegt. Dazu gehören auch Produkte verschiedener Phasen der Periode SH IIIC. ${ }^{101}$ Was die Austauschkontakte betrifft, so war die Bevölkerung im 13. bis frühen 12. Jh. v. u. Z. offenbar einerseits nach Westen orientiert, was fünf Gefäße spätpalastzeitlicher bis frühnachpalastzeitlicher Zeitstellung im kalabrischen Punta di Zambrone nahelegen, die der chemischem Gruppe AkaR angehören. ${ }^{102}$ Andererseits bestanden offensichtlich auch Austauschbeziehungen nach Norden, bei denen zentralgriechische Landrouten verwendet wurden, denn die einzigen mittels NAA mit einer gewissen Wahrscheinlichkeit Ätoloakarnanien zugeordneten mykenischen Gefäße, die in Griechenland außerhalb ihrer wahrscheinlichen Produktionsregion gefunden wurden, stammen bislang aus Thessalien: Es handelt sich um Proben aus Bunar Başı und aus der Region von Vólos. Bunar Başı ist ein Siedlungshügel von $250 \times 350 \mathrm{~m}$, der mit seiner Lage am nördlichen Ausgang der vom Ossagebirge umschlossenen Ebene von Sikourion „eine Schlüsselstellung am westlichen Zugang zum Tempe-Tal“"103 einnahm. Er lag also in beherrschender Stellung an der auch heute noch wichtigsten Landroute von Nordthessalien nach Westmakedonien. Über diese Route könnten auch akarnanische Produkte nach Makedonien und weiter entlang der oben beschriebenen Routen Richtung Rhodopen und nach Koprivlen gelangt sein. Zum mykenischen Fundmaterial von der Hügeloberfläche von Bunar Başı zählen auch Scherben palast- wie nachpalastzeitlicher Gefäße, ${ }^{104}$ doch der Forschungsstand erlaubt es nicht, weiter reichende Schlussfolgerungen aus diesen Funden zu ziehen.

100 Mountjoy 1999, 798, 802-805 und Abb. 320/27-34; 321.

101 Wardle, Wardle 2003, 150, 154 und Abb. 3. - PapapostoLOU 2008, 134, 179-180 und Abb. 58, 60. - Ioannis Moschos wies allerdings den Kriegerkrater aus Thérmos einer Werkstatt in Voúdeni (Achaia) zu, so dass mit Sicherheit nicht sämtliche Keramik aus Thérmos aus lokaler Produktion stammt: Moschos 2009, 360-361. 102 Jung, Mommsen, Pacciarelli 2015, 458-459 und Tab. 1. - Zu diesen Gefäßen gehören ein Skyphos A, ein monochromer Skyphos, ein wahrscheinlich als Skyphos C zu bestimmendes kleines offenes Gefäß, ein Krater und ein großes geschlossenes Gefäß: JuNG et al. 2015, 70 und Abb. 13/1, 4, 9; 73 und Abb. 14/20.

103 Kilian 1976, 65 und Taf. IX-X.

104 Kilian 1976, 66-71 und Taf. XIII-XVIII. 


\section{Die sozialökonomischen Grundlagen des überregionalen Austauschs}

Bei der Gesamtinterpretation des bisher bekannten Befundbilds mykenischer Artefakte auf dem Ostbalkan kann man mit aller gebotenen Vorsicht zwei historisch-ökonomische Perioden ostbalkanisch-mykenischer Kontakte voneinander unterscheiden. Die frühere zeichnete sich durch den Import mykenischer Keramik wie auch mykenischer Waffen aus den Gebieten des sich etablierenden und expandierenden mykenischen Palaststaats aus. Dies war die Zeit der ägäischen Phasen SH IIB und SH IIIA1, d. h. das 15. und frühe 14. Jh. v. u. Z. Sowohl die Ergebnisse der NAA, die den Keramikimport aus Dhimíni am Golf von Vólos in die zentralen Rhodopen belegen, als auch die weite Streuung mykenischer Schwerter und Lanzen im ostbalkanischen Raum sprechen sehr dafür, dass wir es hier mit den Hinterlassenschaften direkter Austauschbeziehungen zwischen den vorstaatlichen Gemeinschaften im Norden und zumindest einer Palastregion des Südens zu tun haben. Weiterhin gibt es inzwischen eine Reihe von Indizien dafür, dass das Gold der Rhodopen bei diesen Kontakten eine zentrale Rolle gespielt haben dürfte: ${ }^{105}$ Zunächst liegt Dragojna in den an Gold reichen Lagerstättenregionen der Rhodopen. ${ }^{106}$ Weiterhin gelangten auch mykenische Schwerter der Zeitstellung SH IIB-IIIA1 in diese Gebirgszone, wie die Funde zweier marmorner Schwertknäufe der zeittypischen Form belegen, die auf dem Ada Tepe (Abb. 8/1) und dem Aul Kaja (Dolno Čerkovište, Abb. 8/3) in den Ostrhodopen gefunden wurden. ${ }^{107}$ Mehr noch: Mit dem Ada Tepe konnte erstmals ein bronzezeitlicher Bergbau mit zugehöriger Siedlung dieser Region erfasst und in großer Gründlichkeit dokumentiert werden, der auch die direkte kontextuelle Verbindung zwischen spätbronzezeitlicher Goldproduktion und mykenischen Importen der frühen Palastzeit herstellt. ${ }^{108}$ Darüber hinaus erbrachten neuere Grabungsergebnisse im Ostbalkanraum auch klare Indizien für die Herausbildung einer stärkeren sozialen Ungleichheit innerhalb der lokalen Gemeinschaften, die sich schon ab der Mittelbronzezeit und verstärkt in einer frühen Stufe der Spätbronzezeit im Grabbrauch sowie in Deponierungen ${ }^{109}$ niederschlug und

105 Bozhinova, Jung, Mommsen 2013, 77-84 und Abb. 4. - Jung 2017, 70-71 und Karten 1-2.

106 Der nächstgelegene alte Bergbau ist Čala in etwa $9 \mathrm{~km}$ Entfernung von Dragojna. - Siehe Dimitrov, Stojčev 2017, 21-22 und Karten 1-2; 25.

107 Jung 2017, 70 und Karte 2. - Nechrizov, Cvetrova 2017, 54-55 und Abb. 3/1-2.

108 Siehe dazu die Beiträge von Popov et al. 2017 und Horejs 2017 im vorliegenden Band. - Außerdem Popov, Jockenhövel, Groer 2011. - Popov 2017. - Popov, Jockenhövel 2017.

109 Zum Hortfund von Svištov siehe Alexandrov, Christova, MARINOV 2017. bei deren Zurschaustellung bezeichnenderweise wiederum oft Objekte ägäischen Typs eine zentrale Rolle spielten: Dies verdeutlichen die minoische oder mykenische Goldperlenkette sowie weitere Goldblechobjekte aus dem 17,20 $\times 19,60 \mathrm{~m}$ großen und 1,80 m hohen Tumulus 1 von Izvorovo im Sakargebirge (Abb. 8/9). ${ }^{110}$ Auch die Nekropole von Lilovo in den Westrhodopen (Abb. 8/13) kann hier genannt werden, denn im Grab 4 des Grabhügels 1 lag eine Brandbestattung mit einem Schwert des frühmykenischen Typs A zusammen mit Keramikbeigaben, während zugehörige Gold und Bronzeobjekte in verschmolzenem Zustand auf dem $2 \mathrm{~m}$ entfernt errichteten Scheiterhaufen verblieben waren. ${ }^{111} \mathrm{Am}$ anderen Ende der sozialen Skala in den Rhodopen mögen die Einwohner des Nordostquartiers der Siedlung auf dem Ada Tepe gestanden haben, wie bereits das von B. Horejs im vorliegenden Band analysierte bescheidene Hausinventar eines Hauses andeutet. ${ }^{112}$

Die jüngere der beiden genannten Perioden ostbalkanisch-ägäischer Kontakte, die mindestens die Periode SH IIIB und die Phase SH IIIC Früh - also das 13. und frühe 12. Jh. v. u. Z. umfasst, war durch ein radikal verändertes Befundbild charakterisiert: Nun kam die mykenische Importkeramik - den Funden von Koprivlen nach zu urteilen - aus den unterschiedlichsten Produktionsregionen, während ein Import oder auch nur eine Imitation spätpalast- oder nachpalastzeitlicher Waffen nicht mehr stattfand. Man ging stattdessen zur Herstellung moderner Hiebschwerter der zentraleuropäischen Hiebschwertform Naue II über. ${ }^{113}$ Der Hortfund von Kozman Deresi Mevkii, beim Dorf İğdebağları ca. $3 \mathrm{~km}$ von der nördlichen Küste des Marmarameers entfernt gelegen, markiert auf dem Balkan den nördlichsten Fundpunkt des Dolch- bzw. Kurzschwerttyps E II. Die Waffe kann dorthin entweder ebenfalls bereits zur Zeit der Phase SH IIIA1 gelangt sein, oder aber sie stellt den Ausnahmefall eines geringfügig jüngeren mykenischen Waffenimports der entwickelten Palastzeit

110 Borislavov 2010. - Borislavov 2017a. - Horejs, Jung 2017, 98 und Abb. 1; 100-101 und Abb. 2. - HAAG et al. 2017, 171, Kat. Nr. 40-43. - Das der Brandbestattung von Izvorovo beigegebene bronzene Rasiermesser (Borislavov 2010, 13-14 und Abb. 14; 26, Kat. Nr. 3. - HAAg et al. 2017, 171, Kat. Nr. 43) steht einem zweischneidigen ägäischen Rasiermessertyp sehr nahe, der von SM II/SH IIB bis mindestens SH IIIA2 datiert: Weber 1996, 81-86 und Taf. 9/111; 10; 11/123-126. - Horejs, Jung im Druck.

111 Borislavov 2008, 154, 156 und Abb. 13. - Borislavov 2017b. 112 Vorbehaltlich der Auswertung der übrigen Häuser, wie auch Horejs schreibt, siehe auch Popov 2017, 147-148, zum allgemein bescheidenen Charakter der materiellen Kultur dieser Bergbausiedlung. Der zitierte marmorne mykenische Schwertknauf aus dem Siedlungsareal auf dem Gipfel hebt sich demgegenüber ab. 113 Dazu bereits Hänsel 1970. 
dar. ${ }^{114}$ Auch bei der letztgenannten Interpretationsmöglichkeit würden sich aber der generelle Befund und damit das historische Bild nicht ändern.

Bezeichnend könnte in diesem Zusammenhang auch sein, dass die mit Gold ausgestatteten Gräber der bulgarischen Bronzezeit anscheinend alle in einen frühen $\mathrm{Ab}$ schnitt der Spätbronzezeit bzw. zum Teil schon in die Mittelbronzezeit zu datieren sind. ${ }^{115}$ Spätere Nekropolen wie etwa jene von Sandanski im Strumatal (Abb. 8/23) enthalten nur bedeutend bescheidenere Beigabenensembles, was eventuell darauf hindeuten könnte, dass auch die stärker hierarchischen Gesellschaftsstrukturen im ostbalkanischen Raum nach dem Ende der regelmäßigeren Austauschbeziehungen mit der Ägäis zusammengebrochen waren. $^{117}$

Mykenische Keramik stellt im Übrigen auch heute noch im gesamten ostmakedonischen Raum eine Seltenheit dar. Ob tatsächlich an der Küste - etwa in der Nähe des Strymondeltas - Siedlungen bestanden, in denen mykenische Keramik, sei sie importiert, sei sie aus lokaler Produktion, häufiger verwendet wurde, ${ }^{118}$ muss derzeit Hypothese bleiben. ${ }^{119}$ Stathmós Anjístas ist derzeit die einzige Siedlung im festländischen Ostmakedonien, die gesichert mehr als ein Fragment mykenischer Keramik erbrachte. Aus Dikili Taş (Abb. 8/6) hingegen liegt trotz der inzwischen vermehrt

114 Harmankaya 1995, 223, 239 und Abb. 2/b (Länge laut Abbildungsmaßstab 39,4 cm). - Zur Typenbestimmung vgl. SANDARs 1963, 133. - Kilian-Dirlmeier 1993, 76-88 und Abb. 21-23; 177-178. Doch auch der Dolchtyp E II dürfte im 13. Jh. in der Ägäis nur noch in Ausnahmefällen in Verwendung gewesen sein; sein chronologischer Schwerpunkt liegt laut Sandars und Kilian-Dirlmeier in SH IIIA1IIIA2 (siehe oben). - Siehe dazu auch PAPAdopoulos 1998, 21-24, $55)$.

115 Neben den bereits genannten Tumuli von Lilovo und Izvorovo ist auch die Nachbestattung Grab Nr. 7 im Hügel von Ovčarci (Abb. 8/18) in der Region von Stara Zagora zu nennen. Es enthielt neben bronzenen Kleidungsaccessoires auch elf goldene Spiralröllchen und einen goldenen Lockenring sowie ein bemaltes Drehscheibengefäß (AlexANDrov 2017). Letzteres kommt sicher aus dem ägäischen Raum (Pavúk 2017, 104 und Abb. 1; 108 und Abb. 3) und hat seine bislang beste Form- und Musterparallele in dem von Søren Dietz in MH IIIB datierten Schachtgrab B des Gräberrunds B von Mykene (Inv. Nr. EAM 8584): Mrlonas 1972-1973, 40, Kat. Nr. B-14 Taf. 27/ $\alpha-\beta ;$ 241/B-14. - Dietz 1991, 108, 231, 233, Nr. LD-1; 250 und Abb. 78.

116 Alexandrov, Petkov, Ivanov 2007.

117 Neufunde könnten an diesem letztgenannten Aspekt selbstverständlich noch Korrekturen erforderlich machen.

118 Vgl. Koukouli-Chrysanthaki 1980, 79.

119 Der heutige Forschungsstand erlaubt leider keine Verifizierung der These, dass in der Siedlung auf dem Hügel Paliókastro beim Dorf Káriani nahe dem antiken Galēpsos tatsächlich mykenische Keramik gefunden wurde: Koukouli-Chrysanthaki 1977, 528 und Taf. 462/ß. - Koukouli-Chrysanthaki 1980, 79. freigelegten Baubefunde der Spätbronzezeit nur ein einziges Skyphosfragment vor. ${ }^{120}$ Stathmós Anjístas liegt dem wohl wichtigsten Meereszugang Ostmakedoniens, den die Strymonebene und die natürlichen Häfen an der Strymonmündung gebildet haben müssen, immerhin am nächsten (Abb. 8/26). Bezeichnend ist ferner die Tatsache, dass das dortige Gefäßrepertoire mykenischer Keramik in seiner Typenkombination und Zeitstellung jenem aus Koprivlen vergleichsweise gut entspricht: Zwei Randfragmente hochfüßiger Skyphoi FT 304/305 oder Skyphoi mit verdicktem Rand, ein Randfragment eines Skyphos FT 284/285A, ein Randfragment einer Kylix FT 257, eine Randscherbe einer Schale FT 295 mit verdicktem Rand, ein Kylixfuß sowie das Schulterfragment eines großen geschlossenen Gefäßes liegen aus verschiedenen Schichten vor. ${ }^{121}$ Weiter nördlich auf der oben beschriebenen Route nach Koprivlen über Sidhirókastro, Turlis/Vathítopos und Nova Lovča liegt die Nekropole von Phäá Pétra (Abb. 8/20) nordöstlich von Sidhirókastro. In dieser wurden neben 26 handgemachten Keramikbeigaben auch zwei mykenische Bügelkannen gefunden, ${ }^{122}$ von denen das publizierte Exemplar des Typs FT 167 aus dem Grabbezirk 5 ins frühe bis mittlere SH IIIB datiert werden kann. ${ }^{123}$ Zwei kleine Goldtutuli aus Grabbezirk 1 könnten einen vagen Hinweis auf Bezüge zu den rhodopischen Goldvorkommen darstellen. ${ }^{124}$ Wenn man derselben Route weiter nach Norden folgt, kommt man zu dem am nächsten zu Koprivlen gelegenen Fundort mit mykenischer Keramik, dem Tumulus von Exochí (Abb. 8/8) mit Brandbestattungen in Aschenurnen lokaler handgemachter Keramik. Hier fanden sich auch mykenische Alabastra ohne erhaltene Bemalung, die nur sehr grob mit den mykenischen Funden von Koprivlen synchronisiert werden können. ${ }^{125}$

$\mathrm{Zu}$ fragen ist nun, welche ökonomische Basis dem Import regionalmykenischer wie auch sehr begrenzt südmykenischer Keramik in Ostmakedonien und den unmittelbar nördlich angrenzenden ostbalkanischen Regionen im 13. und frühen 12. Jh. zugrunde lag. Koprivlen ist eine eher bescheidene Siedlung mit nur begrenzten Vorratskapazitäten (siehe die Pithoi auf Abb. 4). Terrassenmauern sind

120 Darcque et al. 2011, 534-535 und Abb. 10. - Horejs, Jung im Druck.

121 Koukouli-Chrysanthaki 1980. - Jung 2002, 239-240, 564566 und Taf. 73/4-8.

122 VAlla 2007, 368-369 und Abb. 18. - Valla et al. 2013, 239.

123 Valla 2004, 158-161 und Zeichnung 3; 163 und Abb. 5. - Valla 2007, 368-369 und Abb. 18. - Zur Datierung siehe auch Jung 2007a, 222, Anm. 43 (mit Literatur).

124 Valla 2007, 368-370 und Abb. 19.

125 Grammenos 1981, 30, 38, 40 und Abb. 7/2; 41, 43, 45 und

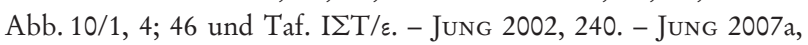
$222-223$. 
nachgewiesen, doch keine Befestigung oder hervorgehobene bzw. öffentliche Bauten. Die gleichzeitigen Nekropolen der Pirin- und Westrhodopenregion (Sandanski, Phäá Pétra und vielleicht auch Exochí) deuten auch auf eine nur wenig hierarchische Gesellschaft kleiner Gemeinschaften hin. ${ }^{126}$

Trotz intensivierter archäologischer Forschungsaktivitäten seit den 1970er Jahren sind wir leider auch über die politisch-ökonomischen Strukturen der Einwohner/innen des spätbronzezeitlichen Zentralmakedonien, einer der Herkunftsregionen der Keramik von Koprivlen, nur recht lückenhaft unterrichtet. Die Keramikanalyseergebnisse deuten, wie berichtet, gewisse regionale Austauschprozesse zwischen verschiedenen Produktionszentren an. Entscheidend bei der Beantwortung der Frage nach der ökonomischen Integration der unterschiedlichen makedonischen Tellsiedlungen bzw. dem Problem ihrer ökonomischen Autarkie oder ihrer Integration in mikroregionale ökonomische Systeme mit potentiell hierarchischer Struktur ist es, die Art und Weise der Lagerung des landwirtschaftlichen Mehrprodukts (Surplus) zu bestimmen - sowohl innerhalb der Siedlungen als auch im regionalen Vergleich.

Auslöser für eine entsprechende Debatte war in den 1980er Jahren der Fund großer, dicht gefüllter Magazinräume auf der Toumba von Ássiros (Ássiros A) im Becken von Langadhás (Abb. 8/2). Es handelt sich um die Phase 9 der Siedlung, deren publizierte Datierungsspanne vom Ende von SH IIIA 2 bis zur Phase SH IIIB Früh reicht. ${ }^{127}$ Von dieser Siedlungsphase wurden ein $9 \times 4$ m großer Vorratsraum sowie vier kleinere, deren Maße ca. $4 \times 4$ m betragen, freigelegt. Der Befundinterpretation nach bildeten sie nicht die Erdgeschossräume von zweistöckigen Wohnhäusern, sondern eingeschossige Magazine, die zwischen parallel verlaufenden engen Gassen angeordnet waren. Die vier übrigen ausgegrabenen Räume dieser Phase dienten nicht der Vorratshaltung. ${ }^{128}$ Gelagert wurden in den Magazinen verschiedene Getreidearten und Hülsenfrüchte, wobei allein

126 In Phäá Pétra enthielten die sechs bekannten Grabbezirke die Reste von 12 Bestatteten beiderlei Geschlechts einschließlich Kindern: Valla et al. 2013, 236 und Abb. 6. - Aus der Nekropole von Sandanski sind nur Gräber von Neugeborenen und Jugendlichen überliefert: Alexandrov, Petkov, Ivanov 2007, 377, 385-387.

127 Wardle 1993, 126-127 und Abb. 3/1. - Wardle, Wardle 2007, 459, 463-464 und Taf. 7/b. - Bislang wurde leider nur ein einziges mykenisches Gefäß dieser Phase publiziert, ein hochfüßiger Skyphos FT 304/305 oder Skyphos mit verdicktem Rand, der mit dem für makedonische Verhältnisse typischen Bänderdekor und dem ebenfalls typischen breiten und weit geschwungenen waagerechten Wellenband bemalt ist.

128 Wardle 1987, 326-329 und Abb. 7-8 sowie Taf. 52/c-d. Wardle 1989, 460-463 und Abb. 4 sowie Taf. 71/d. - WARdLE, WARDLE 2007, 456 und Taf. 4-5; 458-463. die Vorräte des größten Magazins zur Produktion von $12 \mathrm{t}$ gedroschenem Getreide gereicht hätten, was als hinreichend für die Ernährung von 50 Personen während eines Jahres eingeschätzt wird. Die eingelagerten Nahrungsmittel aller Vorratsräume der Phase 9 hätten somit die für die Bedürfnisse der Toumbabewohner nötigen Mengen bei weitem überschritten. ${ }^{129}$ Das zwischen den einzelnen Magazinräumen divergierende Artenspektrum der Nutzpflanzen wurde als Argument dafür aufgefasst, dass nicht jeder Raum das Eigentum einer einzelnen Familie darstellte, sondern dass vielmehr mehrere (oder alle) Speicherräume kollektiv genutzt wurden, wofür auch einige Merkmale der architektonischen Struktur sprächen. ${ }^{130}$ Dieses Speichersystem interpretierten die Bearbeiterinnen und Bearbeiter als Vorstufe zu einem redistributiven System, wie man es aus den Tempel- und Palastökonomien des Nahen Ostens, Kretas und des mykenischen Griechenland kennt. Ássiros A hätte eine Zentrumsfunktion für die umliegenden Siedlungen gehabt und sei von etwa 50-100 Personen bewohnt gewesen, die die Umfassungsmauer instand gehalten hätten. „Der Rest [der Bevölkerung] wohnte wohl in den umliegenden Siedlungen und erhielt für seine Mithilfe bei den Bauarbeiten Schutz, Lebensmittel und sonstige soziale Vorteile. “131 Das auf der Toumba eingelagerte Getreide hätte die Lagerhaltung der einzelnen Haushalte ergänzt, nicht aber ersetzt. Es sei nur der Surplus als Sicherung gegen Ertragsschwankungen zentral gelagert worden. ${ }^{132}$ Zuletzt konkretisierten die Ausgräber von Ássiros die Rekonstruktion dieses redistributiven Systems noch, indem sie andeuteten, dass die Magazine der Phase 9 ein verwaltungstechnisches System wiederspiegeln würden, in dem die Toumba von Ássiros die administrativ wichtigste Siedlung gewesen sei. Zu diesem System hätten außerdem die Toumben von Tou Lákkou (oder Toúmba Lákko = Ássiros E), Koutsoulítis (= Ássiros B), Periwoláki und Dhrimós gehört, die alle bequem zu Fuß zu erreichen gewesen seien. ${ }^{133}$

Vorberichte zu einem Prospektionsprojekt im Langadhásbecken lassen erkennen, dass zu den früh in der Spätbronzezeit besiedelten größeren Tellsiedlungen im Laufe

129 Jones et al. 1986, 92-93 und Abb. 5. - WARdLe, WArdle 2007, 461. - Die Gesamteinwohnerzahl der Phase 9 wurde auf 50-100 Personen geschätzt: JonEs et al. 1986, 95. - Die Berechnung der Lagerkapazitäten wurde jedoch kritisiert; sie lässt sich mangels kompletter Keramikvorlage und abschließender Befundpublikation nicht nachprüfen: Margomenou 2008, 201.

130 JoNEs et al. 1986, 93.

131 Jones et al. 1986, 95.

132 Jones et al. 1986, 95.

133 Wardle, WardLE 2007, 461. 
der Periode kleinere, eher peripher gelegene hinzukamen. ${ }^{134}$ Leider wurde aber keine der übrigen Toumben des Langadhásbeckens modern und großflächig ausgegraben. Zu Periwoláki gibt es Ergebnisse aus Sondagegrabungen während der 1920er Jahre, die eine längere Besiedlung während der Spätbronzezeit belegen, welche unter anderem auch mit Phase 9 von Ássiros A überlappte. ${ }^{135}$ Von den anderen Toumben - mit Ausnahme von Koutsoulítis, auf der nur die Eisenzeit belegt ist - gibt es zumindest Oberflächenfunde der Spätbronzezeit. ${ }^{136}$

Was Ássiros A betrifft, so wurde die Verteilung der Magazine über die Siedlung in der auf Phase 9 folgenden Siedlungsphase 8 anscheinend in der bereits etablierten Weise fortgesetzt, ${ }^{137}$ doch mit Phase 7, die von den Ausgräbern in SH IIIC datiert wird und zumindest partiell mit Schicht 14 b von Kastanás zeitgleich war, ${ }^{138}$ änderte sich die Organisation der Vorratshaltung auf der Toumba von Ássiros grundlegend: Ab dieser Phase befanden sich kleine Mengen von Pithoi und Lehmtonnen in vielen Räumen und allen Hauseinheiten. Kenneth und Diana Wardle charakterisierten diese Veränderung als einen Wechsel der Rolle von Ássiros A als einem regionalen Verwaltungszentrum hin zu einer Dorfgemeinschaft, die nun keine Rolle mehr in einem Netzwerk benachbarter Siedlungen spielte. ${ }^{139}$

Andere Wissenschaftler/innen zogen die Interpretation des Ássiros-Teams partiell in Zweifel. Sie stimmten dem Ássiros-Team zwar darin zu, dass der Umfang der Magazinierung der Risikominimierung innerhalb eines Siedlungsnetzwerks diente - möglicherweise auch mit einer hierarchischen Organisation. Sie betonten jedoch vor allem die geringe Größe dieses Systems und seinen instabilen Charakter, der es deutlich von den redistributiven Palastökonomien des mykenischen Südens absetze. Außerdem weise die Toumba von Periwoláki eine ähnliche Größe und Bauweise wie Ássiros A auf, so dass diese als ein weiteres Zentrum im Langadhásbecken anzusprechen sei. Diese Siedlungskammer habe also eine ganze Reihe von mikroregionalen Netzwerken umfasst. ${ }^{140}$ Außerdem lenkten sie die Aufmerksamkeit auf das Faktum, dass die Magazine der

134 Andreou 2001, 162-163 und Abb. 11.2.

135 Heurtley 1939, 26-31, 206-207 und Abb. 72-73 (unter dem alten Namen Saratsé). - HochstetTer 1984, 293-294, 299 und Abb. 54. - Zur Datierung der mykenischen Keramik aus Periwoláki siehe Jung 2002, 233-234, 560-562 und Taf. 70/6-10; 71/1-7.

136 Grammenos et al. 1997, 17-18, Nr. 17, 20; 20, Nr. 31; 32-33, Nr. 91; 79-80, Nr. 17, 20, 31 und 91 und Taf. 6/1.

137 WARDLE, WARDLE 2007, 463-465.

138 JUNG 2002, 233.

139 Wardle, Wardle 2007, 460 und Abb. 2; 464-465 und Taf. 8.

140 Andreou, Fotiadis, Kotsakis 1996, 579-580.
Phase 9 von Ássiros zu verschiedenen Gebäudekomplexen gehörten und dass sich ein ähnliches Bild der Magazinierung auch auf der Toumba von Thessaloníki feststellen lasse. Man könne diese Befunde dahingehend interpretieren, dass die Hauskomplexe von größeren Deszendenzgruppen bewohnt worden seien, deren Oberhäupter die eingelagerten Vorräte kontrolliert hätten. ${ }^{141}$ Darüber hinaus könne der Wechsel des Magazinierungssystems in Ássiros A vom 14./13. zum 12. Jh. v. u. Z. bei ausbleibendem Wechsel im generellen Bebauungsschema darauf hindeuten, dass die Macht der mächtigsten Deszendenzgruppen direkt infrage gestellt worden sei. ${ }^{142}$ In diesen Punkten ist den Kritikerinnen und Kritikern durchaus zuzustimmen.

Entscheidend für die Beurteilung der Rolle der Magazinierung von agrarischem Surplus für die politische Ökonomie einer Gesellschaft sind jedoch nicht nur seine absolute Menge sowie seine relative Menge im Verhältnis zu den Konsumenten, sondern auch die Möglichkeit der Konsumenten, Zugang zum gelagerten Mehrprodukt zu erhalten: War dieses einer kollektiven Kontrolle unterstellt oder dem von Personengruppen oder sogar Einzelpersonen, die bevorrechtigt oder exklusiv die Produktionsmittel kontrollierten?

Eine partielle Antwort auf diese Fragen konnte basierend auf einer Analyse der Zuordnung der Magazine zu Wohneinheiten gegeben werden (siehe oben). Bei der Bewertung des Siedlungsbefunds in Phase 9 von Ássiros A ist es jedoch ebenfalls wichtig, darauf hinzuweisen, dass jene Sicherungsvorrichtungen und Zugangskontrollen bzw. -beschränkungen wie Tür- und Kastenversiegelungen im Bereich der Magazinräume fehlen, die stets am Anfang der Entwicklung von Mechanismen zur formalisierten Kontrolle landwirtschaftlichen Überschusses und einer Verwaltung im eigentlichen Sinne standen. Verweisen kann man auf eine Vielzahl von Varianten solcher frühen administrativen Praktiken, von Mesopotamien und dem Hochland Nordkurdistans im 4. Jt. v. u. Z., ${ }^{143}$ über das prä- und frühdynastische Ägypten des späten 4. und des 3. Jts. v. u. Z. ${ }^{144}$ bis hin zum frühhelladischen Südgriechenland und dem frühminoischen Kreta des 3. Jts. v. u. Z. ${ }^{145}$ Tönerne Raum-, Möbel- und Gefäßverschlüsse mit Siegelabdrücken, beschriftete und/oder versiegelte Plomben oder auch Etiketten mit Symbolen/ Zeichen fehlen nicht nur in Ássiros A, sondern im gesamten

141 Andreou 2001, 167-168. - Margomenou 2008, 202-203 und Abb. 4.

142 Andreou 2001, 170-171.

143 FrangiPAnE 2016.

144 Dreyer 1998. - Hartung 1998. - Engel 2013.

145 RAHMSTORF 2016. 
Befundbild der zentralmakedonischen Spätbronzezeit. ${ }^{146}$ Resümierend ist zu sagen, dass man von einer Vorratshaltung, die über den Bedarf der Einwohnerschaft der Toumba hinausging, anhand der Magazine in der Siedlungsphase 9 von Ássiros A ziemlich sicher ausgehen kann, nicht jedoch von einer siedlungsinternen Zentralisierung oder gar einem administrativen System. Wir hätten es somit mit einer einfachen Version der tributären Produktionsweise ${ }^{147} \mathrm{zu}$ tun, deren genauer Typ aber erst nach Vorliegen der abschließenden Publikation zu bestimmen wäre.

Zunächst vor allem für die Früheisenzeit und das Ende der Bronzezeit postuliert, ${ }^{148}$ ist wohl auch für die Spätbronzezeit insgesamt an der Bucht von Kastanás, im heutigen Axiostal, mit einem Siedlungssystem zu rechnen, das mehrere Toumben umfasste und in dem die größte, Axiochóri, die „Zentrale“ bildete, während Kastanás und die übrigen Toumben im Norden und Süden „Satellitensiedlungen“ waren. ${ }^{149}$ Über etwa $17 \mathrm{~km}$, von Próchoma im Süden bis Limnótopos im Norden, hätte sich dieses hypothetische politisch-ökonomische System entlang des Axios bzw. der Bucht von Kastanás erstreckt. ${ }^{150}$ Im Einzelnen hätte Axiochóri in mittiger Position mit den beiden Toumben Limnótopos und Áspros im Norden und Kastanás sowie Próchoma im Süden dieses System gebildet. Obgleich keine präzise Synchronisierung der in den 1920er Jahren ausgegrabenen Toumben von Axiochóri und Limnótopos mit der modernen Sequenz von Kastanás durchführbar ist, lässt sich doch sagen, dass diese drei Siedlungshügel die längste Zeit der Spätbronzezeit über synchron besiedelt waren. ${ }^{151}$

Die Magazinierung des Surplus auf der potentiell von Axiochóri abhängigen Toumba von Kastanás war in der Spätbronzezeit eindeutig nach anderen Regeln organisiert als auf den großen Toumben von Ássiros A und Thessaloníki: Vorratshaltung fand in zahlreichen Räumen statt, doch dienten diese oft auch zu anderen häuslichen Aktivitäten, ${ }^{152}$

146 Daran ändert im Prinzip auch ein als Imitation einer LinearB-Tafel angesprochenes Objekt aus Phase 50 an der Hügelkante (synchronisiert mit der Phase 9 auf dem Hügel selbst) von Ássiros A nichts, das von den Ausgräbern im Sinne der lokalen Kenntnis der mykenischen Schrift interpretiert wurde. Es blieb bislang bedauerlicherweise unpubliziert: WARDLE, WARdLE 2007, 459, 463.

147 Bernieck 1994, 33 und Abb. 4; 50-71.

148 HÄNSEL 1989, 340-341.

149 HäNSEL 2003, 89-90 (unter Bezug auf Schulz 1989, 376 und Abb. 1).

150 Vgl. Schulz 1989, 376 und Abb. 1.

151 Hochstetter 1984, 278-286, 298-302 und Abb. 54. - Jung 2002, 230-232. - Axiochóri und Limnótopos erbrachten auch Funde mykenischer Keramik: Jung 2002, 559-560 und Taf. 70/1-5.

152 In dieser Hinsicht ähnelt die Mischnutzung der Vorratsräume in Kastanás der Funktion des Hauses 7 des Ada Tepe: siehe Horejs 2017 im vorliegenden Band. während in Ássiros A (Phasen 9-8) und Thessaloníki (Phase 4) spezialisierte Magazinräume unterhalten wurden, die potentiell nicht nur dem Konsum der Bewohner der jeweiligen Hauseinheit dienten. ${ }^{153}$ Interessant ist das Pithoshaus der mit Phase 9 von Ássiros A partiell gleichzeitigen Schicht 16 von Kastanás, denn in diesem war ein Pithos mit 16001 Fassungsvermögen fest installiert. In den anderen Häusern dieser zu 10 Flächenprozent freigelegten Siedlungsphase sind derartige Gefäße hingegen nicht in situ erhalten. Je nach Füllung könnte der Vorrat dieses Pithos' für eine Familie von zwei bis drei Erwachsenen und drei bis fünf Kindern ein Jahr lang ausgereicht haben. ${ }^{154}$ Allerdings wurde auf der Grundlage des übrigen Fundbilds auch die These geäußert, dass das Pithoshaus „mehr den Zwecken der ganzen Gemeinschaft (Vorratshaltung und Kochen im größeren Rahmen) als den Belangen einer einzigen Familie“ gedient habe. ${ }^{155}$ Geht man von der letztgenannten Hypothese aus und nimmt man ferner an, dass die ergrabene Fläche einen repräsentativen Ausschnitt der Siedlung darstellt, so wird klar, dass um 1300 v. u. Z. die in der Tellsiedlung befindlichen Vorratskapazitäten von Kastanás hinter denen des gleichzeitigen Ássiros A deutlich zurückstanden, auch wenn die übrigen Häuser ebenfalls über einzelne Pithoi verfügten. ${ }^{156}$ Einen unerwarteten Kontrast stellt vor diesem Hintergrund das im Vergleich zu Ássiros A reiche mykenische Keramikspektrum der Schicht 16 von Kastanás dar: Auf einer Fläche von $207 \mathrm{~m}^{2}$ wurden 23 mykenische Fragmente guter bis sehr guter Qualität gefunden, ${ }^{157}$ während in Phase 9 der Toumba von Ássiros auf $245 \mathrm{~m}^{2}$ nur 13 Fragmente größtenteils mittlerer Qualität zutage kamen. ${ }^{158}$ Zudem ist ein kleines geschlossenes Gefäß (wohl eine gedrückte Bügelkanne FT 178/180/181) aus Kastanás, Schicht 16, gemäß dem NAA-Ergebnis ein aus der nördlichen Argolis (chemische Gruppe MYBE) importiertes Stück. ${ }^{159}$ Dies belegt, dass auch die Bevölkerung

153 Vgl. Margomenou, Andreou, Kotsakis 2007. - MargomeNOU 2008, 204-206 und Abb. 5.

154 HochstetTer 1984, 152 und Taf. 21/1. - Hänsel 1989, 87-107 und Plan 9.

155 BECKER 1995, 103-105.

156 Pithoi waren vor der Zerstörung auch in anderen Häusern der Schicht 16 in Verwendung, selbst wenn sie nicht in situ erhalten blieben: HochstetTer 1984, 207, 210 und Taf. 19; 21/1-2; 23/7-8; 25; 26/2-4, 6-7; 28/9. - HäNSEL 1989, 104 und Abb. 31/5.

157 Zur ergrabenen Oberfläche siehe HäNSEL 1989, 87. - Zur mykenischen Keramik siehe Jung 2002, 219, 306-308 und Taf. 1/7-13; 2/14-17; 75. - Vermutlich kommt auch noch eine sicher importierte Kylix FT 258B hinzu: Jung 2002, 219, 311-312 und Taf. 3/25.

158 Wardle 1993, 126 und Abb. 3/1; 127. - Wardle, Wardle 2007, 463.

159 Jung 2002, 52-53, 56, 307-308, Kat. Nr. 14 (NAA-Nr. KAS 87) und Taf. 2/14. - Jung 2003a, 214, 221 und Abb. 4/1. 
kleinerer zentralmakedonischer Siedlungen guten Zugang zur seltenen verzierten Drehscheibenkeramik und sogar zu Südimporten hatte, ${ }^{160}$ wodurch auch der wahrscheinliche Südimport aus Ätoloakarnanien in Koprivlen verständlicher wird.

Aus dem Vergleich der verschiedenen Siedlungsbefunde Zentralmakedoniens könnte geschlossen werden, dass in Axiochóri eine Vorratshaltung zu erwarten wäre, wie man sie aus dem gleichzeitigen Ássiros A oder der Toumba von Thessaloníki kennt. Umgekehrt könnte man postulieren, dass Vorräte auf den kleineren Toumben in der näheren Umgebung von Ássiros A und Thessaloníki ähnlich gelagert wurden wie in Kastanás. Die Größe der mikroregionalen Siedlungssysteme mit tributärer Produktionsweise können aber, was die Bevölkerungsgröße angeht, höchstens die niedrigste Komplexitätsstufe eines Häuptlingstums erreicht haben. ${ }^{161}$

Die Methode, das Befundbild einer Region unter Rückgriff auf Daten aus anderen Regionen zu ergänzen und dieses kombinierte Befundbild im Sinne eines übergreifenden Modells für Zentralmakedonien als Ganzes zu interpretieren, ist jedoch keinesfalls unproblematisch. Zunächst hat selbst die Analyse von Ássiros A und Thessaloníki gezeigt, dass Gemeinsamkeiten in der Vorratshaltung zwischen nicht gleichzeitigen Phasen bestanden, nämlich zwischen Ássiros, Phasen 9 bis 8 (SH IIIA2 - IIIB), und Thessaloníki, Phase 4 (SH IIIC Früh - Entwickelt ${ }^{162}$ ). Dies verdeutlicht, dass die ökonomischen und politischen Entwicklungen der zentralmakedonischen Siedlungen durch Widersprüche und Diskontinuitäten charakterisiert waren und dass diese keineswegs synchron miteinander auftraten. In einigen Fällen hatten sie wohl überwiegend interne Gründe, in anderen überregionale. ${ }^{163}$ Die Funktionsweise einer der genannten Siedlungen im Kontext eines potentiellen regionalen ökonomisch-politischen Systems zu verstehen, hätte umso mehr zur Voraussetzung, dass zeitgleiche Schichten zweier verschiedener Siedlungen innerhalb derselben Mikroregion modern ausgegraben und abschließend publiziert wären. Doch Kastanás, Ássiros A, die Toumba von Thessaloníki und das Prähistorische Olynth liegen in vier verschiedenen Mikroregionen.

160 Die Fragmente zweier weiterer aus der nördlichen Argolis importierten geschlossenen Gefäße wurden in Schicht 15 sowie in zwei Kontexten der Schichten 14b und 14a gefunden: Jung 2002, 50-53 und Abb. 3-4, 307-308, Kat. Nr. 44 (NAA-Nr. 33); 336-337, Kat. Nr. 116 (NAA-Nr. 33 und 34); und Taf. 4/44; 10/116. - Jung 2003a, 214, 221 und Abb. 4/2.

161 Vgl. Earle 1991, 3. - Earle 2002, 54.

162 Andreou 2009. - Jung, Andreou, Weninger 2009.

$163 \mathrm{Zu}$ diesen Aspekten siehe Andreou 2001. - Hänsel 2002. HäNSEL 2003, 89-97.
Der Befund der unterschiedlichsten Bereiche der materiellen Kultur dieser Mikroregionen verdeutlicht zudem, dass die Bewohner der vier Regionen - bei allen überregionalen Gemeinsamkeiten ${ }^{164}$ - durchaus verschiedene kulturelle Praktiken entwickelt hatten. Aufgrund dessen, dass kulturelle Praktiken stets auch den ökonomisch-politischen Strukturen angepasst sind, weil sie auf diesen fußen, können auch die mikroregionalen kulturellen Unterschiede Makedoniens als indirekte Hinweise auf kleinteilige wirtschaftlich-politische Einheiten verstanden werden.

Ein markantes archäologisches Korrelat für die kulturelle Autonomie der Gemeinschaften in den verschiedenen Regionen Makedoniens bildet der Umgang mit den Toten. In Westmakedonien, am Olymp und im Aliakmongebiet, legte man Nekropolen an, die vorwiegend aus Kisten- und Grubengräbern bestanden und seit der Periode SH IIIA gut belegt sind, ${ }^{165}$ von denen einige aber auch in frühmykenische Zeit zurückreichen. In Ostmakedonien und in Kastrí auf der Insel Thasos gab es Grabperiboloi, die einzelne Bestattungen unterschiedlicher Riten umgrenzten, ${ }^{166}$ oder auch Tumuli mit Brandgräbern, Exochí und Potamí (Abb. 8/21) in den südlichen Rhodopen (siehe oben). ${ }^{167}$

In Zentralmakedonien, vom Axios über das Langadhásbecken bis zur Chalkidiki wurden hingegen bislang keinerlei organisierte Nekropolen gefunden. ${ }^{168}$ Man kann das sicher nicht ausschließlich auf den schwierigen Nachweis von Flachgräberfeldern mit Kisten- und Grubengräbern zurückführen - zumal zumindest die Toumba von Thessaloníki im gleichnamigen, dicht bebauten Viertel der zweitgrößten Stadt Griechenlands liegt. Diese Toumba bietet zugleich eine weitere Erklärung für das Fehlen von Gräberfeldern, denn die Grabungen auf dem Siedlungshügel förderten bislang insgesamt elf ungestörte und sechs gestörte Bestattungen innerhalb der Siedlung selbst zutage. Sie gehören zu sieben Erwachsenen und zehn Kindern und Jugendlichen und datieren sämtlich in die Siedlungsphasen 4 und $3,{ }^{169} \mathrm{~d}$. h. in die Zeit zwischen SH IIIC Früh und Fortgeschritten bzw. gleichzeitig mit den Kastanás-Schichten 14b, 14a, 13 sowie dem Beginn von Schicht $12 .{ }^{170}$

Auf anderen Siedlungshügeln hingegen gibt es keine entsprechenden Bestattungsbefunde. Auf der vergleichsweise großflächig freigelegten und abschließend publizierten

164 Siehe Beitrag Horejs 2017 im vorliegenden Band sowie Horejs 2007a und Horejs 2009.

165 Andreou 2010, 651.

166 Triantaphyllou 2001. - Andreou 2010, 651.

167 Grammenos 1981.

168 Andreou 2010, 651.

169 Andreou, Efklidou, Triantafyllou 2014, 362 und Tab. 1. 170 Andreou 2009. - Jung, Andreou, Weninger 2009. 
Toumba von Kastanás konnten überhaupt keine regelhaften Bestattungen in den spätbronzezeitlichen Siedlungsschichten festgestellt werden. Vier einzelne Knochen stammen aus den Schichten 14b (einer von einem Erwachsenen, einer von einem Baby), 13 (von einem Erwachsenen) und 14a-13 (von einem Erwachsenen). ${ }^{171}$ Sie können aufgrund des völligen Fehlens eindeutiger Grabbefunde im Siedlungskontext sowie ihrer Vereinzelung kaum als Überreste von Bestattungen interpretiert werden, die bei Bauaktivitäten jüngerer Schichten gestört und umgelagert worden wären.

Auf der Toumba des Prähistorischen Olynth (in der älteren Forschung bekannt unter dem Namen Ájios Mámas, Abb. 8/22) wurden nur in den mittelbronzezeitlichen Schichten Siedlungsbestattungen ergraben, wobei hier ausschließlich Kinder bestattet worden waren. ${ }^{172}$ Die spätbronzezeitlichen Schichten erbrachten keine Bestattungen mehr, und die nur etwa $100 \mathrm{~m}$ vom Tell entfernt liegende prähistorische Flachgräbernekropole wurde gemäß den 14 ausgegrabenen Bestattungen nur in der Frühbronzezeit belegt. ${ }^{173}$

Eine detaillierte Analyse der mattbemalten Keramik im nordgriechischen bis innerbalkanischen Raum zeigte gewissermaßen Stilprovinzen dieser spätbronzezeitlichen Keramikkategorie auf, wobei beispielsweise die Siedlungen am Axiós zu einer Stilprovinz gehörten, jene im Langadhásbecken, um Thessaloníki und in der Nordwestchalkidiki zu einer weiteren und die im südlichen Zentrum der Chalkidiki zu einer dritten. ${ }^{174}$ Selbst in der makedonischen Produktion mykenischer Keramik lassen sich Lokalstile ausmachen: So sind zwei der häufigsten Gefäßformen der spätmykenischen Keramik des Prähistorischen Olynth, die so genannte olynthische Schale und der Kantharosamphoriskos, praktisch ganz auf diesen Fundort beschränkt und nur mit ganz vereinzelten Ausnahmeexemplaren an anderen zentralmakedonischen Orten vertreten. ${ }^{175}$ Diese wenigen Beispiele mögen zur Illustration des Phänomens genügen, das Barbara Horejs als mikroregionale Kommunikationsnetzwerke bezeichnete und die unabhängig vom mykenischen Süden und den dort seit dem Beginn der mykenischen Palastzeit (SH IIB/IIIA1) herrschenden Klassen funktionierten. ${ }^{176}$

171 BECKER 1986, 237-238.

172 Hänsel, Aslanis 2010, 112-113 und Abb. 56; 126-129 und Abb. 64-67; 177 und Abb. 94 sowie Beilage 2/2, 3/1, 5/1. - Das einzige potentiell bronzezeitliche Erwachsenengrab konnte nicht mit Sicherheit der Schicht 10 zugeordnet werden und ist möglicherweise mittelalterlich: HäNSEL, AsLANis 2010, 184-185 und Beilage 5/2.

173 PAPPÁ 2010.

174 Horejs 2007a, 299 und Taf. 77/a. - Horejs 2007b, 278-279 und Abb. 176.

175 Jung 2003a, 216-218, 224-225 und Abb. 12-14. - Jung 2003b, 140-141 und Abb. 3.

176 HoREJS 2009.
Im Rahmen dieser Austauschnetzwerke dürften auch die mykenischen Gefäße der Phasen SH IIIB bis IIIC Früh nach Koprivlen gelangt sein. Die für jedes der fünf mittels NAA analysierten Gefäße anders ausfallenden Herkunftsbestimmungen illustrieren augenfällig, dass an diesem Austausch verschiedene Produktionsregionen beteiligt waren. Daraus kann man wohl auch schließen, dass jeweils nur vergleichsweise geringe Gütermengen zwischen den Regionen ausgetauscht wurden und dass jener Austausch nicht immer kontinuierlichen Charakter hatte. Dies wiederum passt zu ökonomischen Kleinsystemen, die keinen größeren landwirtschaftlichen Surplus über längere Zeiträume produzieren und daher keine Basis für einen regelhaften Produktenaustausch bilden konnten.

Es steht zu hoffen, dass weitere Neutronenaktivierungsanalysen mykenischer Keramik aus dem ostbalkanischen wie dem nordgriechischen Raum das hier vorgestellte Bild ergänzen, korrigieren oder verifizieren werden, so dass Wege und Intensität des innerbalkanisch-mykenischen Güteraustauschs besser interpretierbar werden. Außerdem wird die weitere kontextuelle Auswertung der Funde aus den Siedlungen der goldführenden Rhodopenregionen wie Dragojna und Ada Tepe unser Verständnis der ökonomischen Basis dieses Güteraustauschs und seines sozialpolitischen Kontexts in den Frühphasen der Spätbronzezeit erweitern.

\section{Katalog}

Die typologische Klassifikation erfolgt hier nach dem bekannten System Arne Furumarks (FT = Furumark-Typ). Sofern eine klare morphologische Differenzierung zweier Furumark-Typen anhand der von ihm gegebenen Beschreibungen und zitierten Beispiele nicht möglich war, wurden diese unter Verwendung eines kombinierten Sigels zusammengefasst, so z. B. im Falle der Skyphoi FT 284 und FT 285: FT 284/285. ${ }^{177}$ Für die Einteilung der Ränder werden die von Christian Podzuweit definierten Randvarianten verwendet. ${ }^{178}$ Lineare und monochrome Dekorationen wurden entsprechend dem von Podzuweit entworfenen System mit einem Zahlencode verschlüsselt, allerdings unter Einbeziehung der späteren Zusätze und Änderungen durch Reinhard Jung und Eleftheria Kardamaki. ${ }^{179}$

Warenbeschreibungen wurden bei Tageslicht und unter Hinzuziehung der Munsell Soil Color Charts (Ausgabe

177 Z. B. Jung 2002, 75-76.

178 Podzuweit 2007, 184-185 und Taf. 103-106. 179 Jung 2002, 575-580 und Taf. I-XVII. - KARDAMAKI 2009, 14-15, 454-455 und Tab. 2-4. - Podzuweit 2007, 311-316 und Beilage 78a78j. - Was die Körperbänderung angeht, so wird im Folgenden Podzuweits ursprüngliches System verwendet. 
2000) angefertigt. Sie folgen weitgehend den von SCHNEIDER et al. 1989 publizierten Richtlinien.

\section{Kat. Nr. 1}

Abb. 7/1

Quadrant 23, 2313 (Scherbenbeschriftung: 2362), aus Struktur 23-60; Nr. KOP99/4000/1/1.

Zwei Randscherben einer Schulterhenkelamphore FT 34/ 35, Randvariante 5. - Randdurchmesser 16 cm (33\%). Dekor 11.10; Querstreifen als Randmuster. - Kleineres der beiden Fragmente sekundär verbrannt mit abgelagertem verbranntem Material; Bemalung deckend, heute stumpf, stellenweise schwach glänzend. - Farbe der Bemalung: 10YR 2/1 (black) bis überwiegend schwarz; Scherbenfarbe: 7.5YR 6/4 (light brown). - Hart gebrannt; sehr wenige feine bis mittlere Poren; keine sicheren Magerungspartikel erkennbar.

Publikation: Alexandrov 2002, 75, Kat. Nr. 3-4; 337 und Abb. 30/5, 7 .

NAA-Probe Kopriv 3.

\section{Kat. Nr. 2}

Abb. $7 / 2$

Quadrant 23, 2350 (28), Struktur 23-60; Nr. KOP99/4000/ $1 / 2$.

Alabastron FT85, FT 86, FT 94/96/97, Schulterhenkelamphoriskos FT 48 oder Bauchhenkelamphoriskos FT 59, FT 61; Randvariante 1. - Randdurchmesser 9 cm (12\%). Dekor: 10.4. - Bemalung rot, aber zu schlecht erhalten, um zuverlässig bestimmt zu werden; Scherbenfarbe: 7.5YR 7/4 (pink). - Scherben erhaltungsbedingt weich; keine sicheren Magerungspartikel erkennbar.

Publikation: Alexandrov 2002, 75, Kat. Nr. 2; 337 und Abb. 30/4.

NAA-Probe Kopriv 5.

\section{Kat. Nr. 3}

Abb. $7 / 3$

Gebäude in Quadrant 35 (Struktur 35-10), Fußboden; Nr. KOP99/4001/1/1.

Zwei Wandscherben eines Skyphos’ FT 284/285. - Größter Durchmesser 13,5 cm. - Dekor: 9, außen Unterband 2.1; weit geschwungenes breites Wellenband (FM 53,25). - Oberfläche zu schlecht erhalten, um beurteilt werden zu können; Bemalung außen stark abgerieben, innen recht gut erhalten, dort deckend und stumpf. - Farbe der Bemalung: innen schwarz, außen 7.5YR 3/1 (very dark gray); Scherbenfarbe: 10YR 6/3 (pale brown). - Klingend hart gebrannt; wenige feine bis mittlere weiße Partikel.
Publikation: Alexandrov 2002, 75, Kat. Nr. 6; 337 und Abb. 30/2, 6 .

NAA-Probe Kopriv 2.

\section{Kat. Nr. 4}

Abb. 7/4

Quadrant 25, 2513, nordöstlich der südlichen Stützmauer Struktur 25-10; Nr. KOP99/4002/1/1.

Wandscherbe einer Kylix FT 257. - Durchmesser unbestimmbar. - Dekor 9; schräg gestellte Purpurschnecke (FM 23,5). - Oberfläche poliert, glänzend; Bemalung stark abgerieben, dunkelrot, nicht näher bestimmbar; Farbe der Oberfläche aufgrund von Verschmutzung nicht zu beurteilen; Scherbenfarbe: zwischen 7.5YR 7/4 (pink) und 7/6 (reddish yellow). - Scherben erhaltungsbedingt weich; Scherben dicht, wenige feine bis mittlere Poren; keine sichtbaren Magerungspartikel.

Publikation: Alexandrov 2002, 75, Kat. Nr. 5; 337 und Abb. 30/1.

NAA-Probe Kopriv 4.

\section{Kat. Nr. 5}

Abb. 7/5

Genauer Fundkontext unbekannt, vermutlich aus Struktur 19-50, 22-10, 23-10; keine Grabungsinventarnummer; Nr. KOP99/4003/1/1.

Mittelgroßes geschlossenes Gefäß, Schulter. - Größter Durchmesser 19 cm. - Ein Bauchband unbekannter Breite; Reste eines Musters, vermutlich eines Netzmusters (FM 57). - Oberfläche sehr stark abgerieben; Bemalung zum Teil nur im Negativ nachweisbar. - Bemalungsfarbe unbestimmbar; Farbe des Scherbens an den Rändern: 2.5Y 7/3 (pale yellow); Scherbenkern hellgrau. - Wenige mittlere bis grobe Partikel (weiße Partikel und Quarz).

Publikation: Unpubliziert.

NAA-Probe Kopriv 1.

\section{Kat. Nr. 6}

Abb. 7/6

Quadrant 26, Struktur 26-30, Fußboden; keine Fundnummer.

Skyphos FT 284/285A. - Randdurchmesser 14 cm. - Schmales Randband außen, Innendekor stark abgerieben; senkrechte Purpurschnecke mit gefüllter Öffnung (FM 23,3). - Innenoberfläche stark abgerieben. - Bemalungsfarbe: dunkelrot; Scherbenfarbe: ockerfarben/hellgelb. - Keine sichtbaren Magerungspartikel.

Publikation: Alexandrov 2002, 74-75, Kat. Nr. 1; 337 und Abb. 30/3. 
Appendix A.

Späthelladische und protogeometrische Drehscheibenkeramik aus dem Prähistorischen Olynth (Toumba von Ájios Mámas), gemessen am Demokritos-Forschungsreaktor in Athen

Anno Hein, Vassilis Kilikoglou

Im Jahr 2001 wurden 67 Keramikproben aus dem Prähistorischen Olynth (der Toumba von Ájios Mámas) am Demokritos-Forschungsreaktor in Athen mit NAA gemessen. Bei den Proben handelte es sich um feine Drehscheibenkeramik späthelladischer bis protogeometrischer Zeitstellung, die aus den Forschungsgrabungen der Freien Universität Berlin stammen. ${ }^{180}$ Die bisher unveröffentlichten Analyseergebnisse ${ }^{181}$ wurden auf die ceraDAT Datenbank ${ }^{182}$ hochgeladen, die zur Zeit etwa 10.000 NAA-Datensätze von Keramikproben, hauptsächlich aus dem östlichen Mittelmeerraum, beinhaltet, die in verschiedenen Labors gemessen wurden. Die Datenbank bietet die Möglichkeit, Referenzgruppen nach der Bonner Methode ${ }^{183}$ zu bilden und Datensätze mit diesen Referenzgruppen zu vergleichen. Beim Vergleich von NAA-Daten aus unterschiedlichen Labors können zusätzlich Kalibrierungsfaktoren verwendet werden, die systematische Differenzen, etwa bedingt durch die Verwendung unterschiedlicher Standardreferenzmaterialien, berücksichtigen. ${ }^{184}$

Die NAA-Daten der Keramikproben aus dem Prähistorischen Olynth (der Toumba von Ájios Mámas) deuten für den Großteil der gemessenen Keramik eine beachtliche chemische Ähnlichkeit an. So bilden 32 Proben eine eng definierte Referenzgruppe (AGM DEMO) (Tab. 3), der im Grunde genommen mindestens 12 weitere Proben zugeordnet werden können. Der Vergleich mit der Gruppe X057, die in Bonn gemessen wurde, zeigt eine bemerkenswerte Übereinstimmung unter Berücksichtigung der entsprechenden Kalibrierungsfaktoren. Allerdings deutet der Vergleich der Probe Kopriv 5 mit der Gruppe AGM DEMO einige klare chemische Unterschiede an, wie zum Beispiel

180 Eine repräsentative Auswahl der mykenischen Keramik findet sich in HäNsEL et al. 2010, 312-337. - Einige der wenigen protogeometrischen Scherben sind bei HäNSEL 2009, 87, 90 und Abb. 5, und bei HäNSEL et al. 2010, 332, 336 und Abb. 12/27, abgebildet.

181 Die Analysen wurden durch die finanzielle Unterstützung des Institute for Aegean Prehistory (INSTAP) in Philadelphia (USA) ermöglicht.

182 Siehe www.ims.demokritos.gr/ceradat (letzter Zugriff 25.10.2017).

- Hein, Kilikoglou 2012.

183 Beier, Mommsen 1994.

184 Hein et al. 2002.
Tab. 3. Chemische Muster der Gruppen AGM DEMO und AGM DEMO B, die NAA-Daten aus dem Prähistorischen Olynth (der Toumba von Ájios Mámas), gemessen am Demokritos-Forschungsreaktor, beinhalten. Gegeben sind die mittleren Konzentrationen M für die Gruppen in $\mu \mathrm{g} / \mathrm{g}$ (ppm), wenn nicht anders bezeichnet, ist $\sigma$ die absolute Standardabweichung (Wurzel aus der mittleren quadratischen Abweichung) der Mittelwerte und $\sigma(\%)$ die Standardabweichung in \%. Gruppe AGM DEMO umfasst 32 Proben, während Gruppe AGM DEMO B drei Proben umfasst. Die individuellen Werte der einzelnen Proben als Mitglieder der Gruppen sind mit dem besten relativen Anpassungsfaktor (Faktor) in Bezug auf die Gruppen-Mittelwerte korrigiert. Außerdem sind einige Elementkonzentrationen mit Kalibrierungsfaktoren an die Bonner NAA angepasst, die systematische Differenzen zwischen den NAA-Labors in Demokritos und Bonn berücksichtigen (Hein et al. 2002).

\begin{tabular}{|l|c|c|c|c|c|c|}
\hline \multirow{2}{*}{} & \multicolumn{3}{|c|}{ AGM DEMO } & \multicolumn{3}{c|}{ AGM DEMO B } \\
\cline { 2 - 7 } & $M$ & $\sigma$ & $\sigma(\%)$ & $M$ & $\sigma$ & $\sigma(\%)$ \\
\hline $\mathrm{As}$ & 20,8 & 9,1 & 44 & 10,3 & 4,7 & 46 \\
\hline $\mathrm{Ca} \backslash \%$ & 2,7 & 0,8 & 30 & 4,8 & 2,6 & 55 \\
\hline $\mathrm{Ce}$ & 82,4 & 2,9 & 3,5 & 74,4 & 2,7 & 3,6 \\
\hline $\mathrm{Co}$ & 21,2 & 1,1 & 5,3 & 17,9 & 0,3 & 1,7 \\
\hline $\mathrm{Cr}$ & 157 & 10 & 6,2 & 129 & 11 & 8,2 \\
\hline $\mathrm{Cs}$ & 6,6 & 0,5 & 7,8 & 4,5 & 0,3 & 7,1 \\
\hline $\mathrm{Eu}$ & 1,29 & 0,06 & 4,7 & 1,33 & 0,02 & 1,8 \\
\hline $\mathrm{Fe} \backslash \%$ & 5,06 & 0,25 & 4,9 & 4,49 & 0,01 & 0,3 \\
\hline $\mathrm{Hf}$ & 6,21 & 0,69 & 11,1 & 5,87 & 0,11 & 1,8 \\
\hline $\mathrm{K} \backslash \%$ & 2,82 & 0,27 & 9,6 & 3,01 & 0,29 & 9,7 \\
\hline $\mathrm{La}$ & 39,9 & 1,5 & 3,8 & 35,6 & 1,6 & 4,5 \\
\hline $\mathrm{Lu}$ & 0,55 & 0,01 & 2,6 & 0,47 & 0,00 & 0,1 \\
\hline $\mathrm{Na} \backslash \%$ & 1,0 & 0,2 & 22 & 1,7 & 0,3 & 18 \\
\hline $\mathrm{Rb}$ & 145 & 10 & 7,1 & 136 & 10 & 7,0 \\
\hline $\mathrm{Sb}$ & 2,27 & 0,14 & 6,4 & 0,42 & 0,05 & 11,2 \\
\hline $\mathrm{Sc}$ & 20,8 & 0,9 & 4,2 & 16,0 & 0,7 & 4,3 \\
\hline $\mathrm{Sm}$ & 6,40 & 0,22 & 3,4 & 5,99 & 0,14 & 2,4 \\
\hline $\mathrm{Ta}$ & 1,58 & 0,09 & 5,7 & 1,23 & 0,06 & 5,2 \\
\hline $\mathrm{Tb}$ & 0,99 & 0,07 & 6,9 & 0,87 & 0,04 & 4,2 \\
\hline $\mathrm{Th}$ & 16,8 & 0,7 & 4,4 & 13,8 & 0,1 & 0,4 \\
\hline $\mathrm{U}$ & 2,71 & 0,23 & 8,6 & 2,78 & 0,03 & 1,2 \\
\hline $\mathrm{Yb}$ & 4,02 & 0,20 & 5,0 & 3,39 & 0,05 & 1,6 \\
\hline & & & & & & \\
\hline
\end{tabular}


niedrigere Co- und Sc-Konzentrationen und eine höhere Eu-Konzentration. Auch wenn alles auf einen generellen geochemischen und damit auch regionalen Zusammenhang der Tonlagestätten hinweist, ist das Gefäß Kopriv 5 wohl mit Ton aus einer anderen Lagerstätte hergestellt worden als der Ton, der zur Herstellung der Keramik aus Gruppe AGM DEMO verwendet wurde. In den Ájios-Mámas-Daten konnte jedoch noch eine weitere Gruppe mit drei Proben definiert werden, die in der Tat eine größere chemische Ähnlichkeit zu Probe Kopriv 5 aufweist (AGM DEMO B) (Tab. 3). Das Muster dieser kleineren Gruppe bestätigt zumindest, dass, unter Berücksichtigung von natürlichen geochemischen Variationen der regionalen Tonlagerstätten, das Gefäß Korpiv 5 mit hoher Wahrscheinlichkeit mit Ton aus der Region Zentralmakedonien/Chalkidiki hergestellt worden ist.

Weitere Informationen zu regionalen Referenzgruppen werden von der momentan laufenden Neuauswertung der NAA-Daten späthelladischer Keramik von der Toumba von Thessaloníki und aus Kastanás erwartet. Die Proben wurden ebenfalls am Demokritos-Forschungsreaktor gemessen. Die Ergebnisse sind aber bisher nur zum Teil veröffentlicht. ${ }^{185}$

\section{Danksagung}

Wir danken der Mannschaft des Bestrahlungsdienstes der GKSS in Geesthacht für die kompetente Durchführung der Neutronenbestrahlungen.

\section{Literatur}

AdRYMi-Sismani 2012

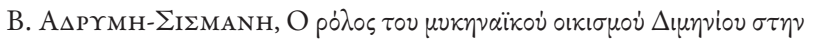

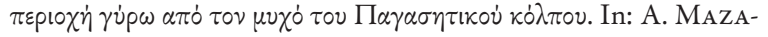

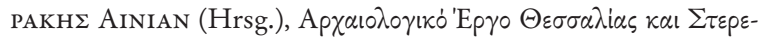

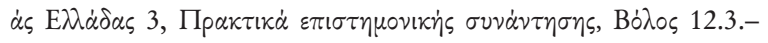
15.3.2009. Volos 2012, 159-176.

Alexandrov 2002

St. Alexandrov, The Late Bronze Age settlement at Koprivlen. In: A. Bozkova, P. Detev (Hrsg.), Koprivlen 1: Rescue Archaeological Investigations along the Gotse Delchev - Drama Road 1998-1999. Sofia 2002, 63-82, 323-340, 453-454.

Alexandrov 2017

St. Alexandrov, Der Grabhügel-Komplex (Grabstätte Nr. 7) von Ovčarci. In: S. HaAg, Ch. Popov, B. Horejs, St. Alexandrov, G. Plattner (Hrsg.), Das erste Gold: Ada Tepe: Das älteste Goldbergwerk Europas. Ausstellungskatalog der Sonderausstellung im KHM 2017, Wien 2017, 130-132.

Alexandrov, Christova, Marinov 2017

St. Alexandrov, T. Christova, M. Marinov, Der Hortfund von Svištov. In: S. HaAg, Ch. Popov, B. Horejs, St. Alexandrov, G. Plattner (Hrsg.), Das erste Gold: Ada Tepe: Das älteste Goldbergwerk Europas. Ausstellungskatalog der Sonderausstellung im KHM 2017, Wien 2017, 133-136.
Alexandrov, Petkov, Ivanov 2007

St. Alexandrov, V. Petkov, G. Ivanov, The Late Bronze Age necropolis in the town of Sandanski, southwest Bulgaria. In: H. Todorova, M. Stefanovich, G. Ivanov (Hrsg.), The Struma/ Strymon River Valley in Prehistory. Proceedings of the International Symposium „Strymon Praehistoricus“, Kjustendil-Blagoevgrad-Serres-Amphipolis, 27.09-01.10.2004. In The Steps of James Harvey Gaul 2, Sofia 2007, 373-387.

Anagnostopoulou-Chatzipolychroni, Gimatzidis 2013

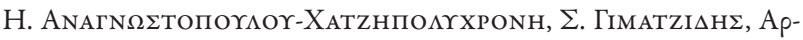

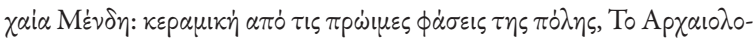

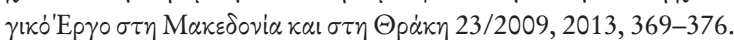

ANDREOU 2001

St. Andreou, Exploring the patterns of power in the Bronze Age settlements of northern Greece. In: K. BRANIGAN (Hrsg.), Urbanism in the Aegean Bronze Age. Sheffield Studies in Aegean Archaeology 4, Sheffield 2001, 160-173.

ANDREOU 2003

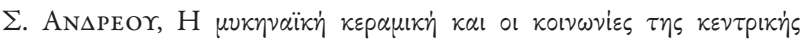

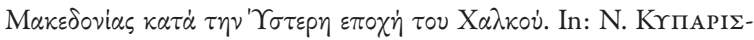

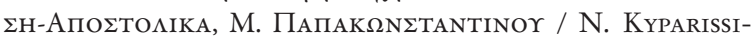
Apostolika, M. Papakonstantinou (Hrsg.), B’ $\Delta \iota \varepsilon \theta v \dot{\varepsilon} \varsigma \Delta t-$

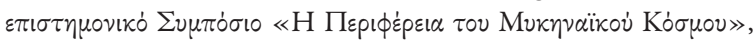
Lapia $1999 / 2^{\text {nd }}$ International Interdisciplinary Colloquium „The Periphery of the Mycenaean World“, Lamia 1999. Практ⿺$\kappa \dot{\alpha}$ / Proceedings, Athen 2003, 191-210.

ANDREOU 2009

St. Andreou, Stratified wheel made pottery deposits and absolute chronology of the LBA to the EIA transition at Thessaloniki Toumba. In: S. Deger-Jalkotzy, A. BÄchle (Hrsg.), LH IIIC Chronology and Synchronisms III: LH IIIC Late and the Transition to the Early Iron Age. Proceedings of the International Workshop at the Austrian Academy of Sciences at Vienna, February $23^{\text {rd }}$ and $24^{\text {th }}, 2007$. Veröffentlichungen der Mykenischen Kommission 30, Wien 2009, 15-40.

ANDREOU 2010

St. Andreou, Northern Aegean. In: E. H. Cline (Hrsg.), The Oxford Handbook of the Bronze Age Aegean (ca. 3000-1000 BCE). Oxford 2010, 643-659.

Andreou, Efklidou, Triantafyllou 2014

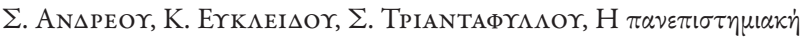
$\alpha v \alpha \sigma \kappa \alpha \phi \eta \dot{~ \sigma \tau \eta \nu ~ \tau о ن ่ \mu \pi \alpha ~ \Theta \varepsilon \sigma \sigma \alpha \lambda o v i k \eta s, ~ T o ~ A p x \alpha 10 \lambda o \gamma ı к o ́ ~ ' E p \gamma o ~ \sigma \tau \eta ~}$ M $\alpha \kappa \varepsilon \delta o v i \alpha ~ \kappa \alpha l ~ \sigma \tau \eta \Theta \rho \dot{\alpha} \kappa \eta$ 24/2010, 2014, 359-364.

Andreou, Fotiadis, Kotsakis 1996

St. Andreou, M. Fotiadis, K. Kotsakis, Review of Aegean prehistory V: the Neolithic and Bronze Age of northern Greece, American Journal of Archaeology 100, 1996, 537-597.

ANDRIKOU 2006

E. Andrikou, The Late Helladic III pottery. In: E. Andrikou, V. L. Aravantinos, L. Godart, A. Sacconi, J. Vroom, Thèbes. Fouilles de la Cadmée II.2. Les tablettes en linéaire B de la Odos Pelopidou: le contexte archéologique. La céramique de la Odos Pelopidou et la chronologie du linéaire B. Pisa - Rom 2006, 11 179.

ATHANASSOV et al. 2017a

Б. АТАНАСов, И. КУАОв, Ж. УЗУНОв, J. GORCZук, Н. Аdaм, M. Atahacoba, St. Eisenmann, T. Branezac, Н. АимиТРОвА, С.ИвАНОВ, Е.ИАИЕВА, В. КРАЙИЕВА, М. LерРек,

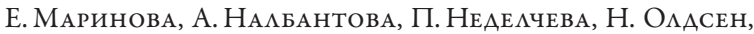
Th. Solarov, J. Pollanka, Ph. Watson, Й.Цветанов, $\mathrm{Ph}$. Sтоскнамmer, Разкопки на селеще от II-I хим. пр. Хр. в Бресто, с. Баня, община Размог, Археологически Открития и Разкопки през 2016, 2017, 134-136. 
Athanassov et al. 2017b

Б. АТАНАСОВ, И. КУАОв, Ж. УЗУНОВ, А. ГОРчИК, Ф. ЩОКХАМЕР, Бресто: укрепено селище от края на бронзовата епохавъв водосборния район на р. Места (с. Баня, община Размог). In: Бъмгарска Археология 2016. Каталог към изможба. Sofia, 19-20.

Batziou-EFstathiou 1999

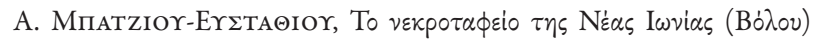
$\kappa \alpha \tau \dot{\alpha} \tau \eta \mu \varepsilon \tau \dot{\alpha} \beta \alpha \sigma \eta \alpha \pi \dot{~} \tau \eta \nu \Upsilon \mathrm{E}$ IIIГ $\sigma \tau \eta \nu \Pi \Gamma$ $\varepsilon \pi \circ \chi \dot{\eta}$. In: Ф. $\Delta \mathrm{AKOP} \Omega-$

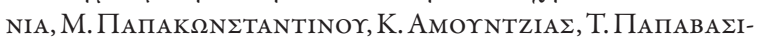

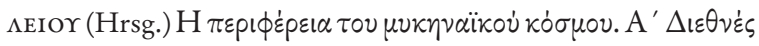

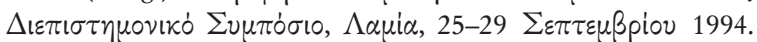

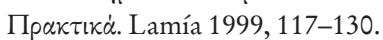

BAXTER 2003

M. BAXTER, Statistics in Archaeology. London, 2003.

BECKER 1986

C. Becker, Kastanas: Ausgrabungen in einem Siedlungshügel der Bronze- und Eisenzeit Makedoniens 1975-1979. Die Tierknochenfunde. Prähistorische Archäologie in Südosteuropa 5, Berlin 1986.

BECKER 1995

C. BECKER, Zur Rekonstruktion von Aktivitätsmustern in spätbronzezeitlichen Haushalten, untersucht am Fundmaterial aus Kastanas (Nordgriechenland), Prähistorische Zeitschrift 70, 1995, 96-114.

Beier, Mommsen 1994

T. Beier, H. Mommsen, Modified Mahalanobis filters for grouping pottery by chemical composition, Archaeometry 36, 1994, 287-306.

BÉQUIGNON 1932

Y. BÉQUignon, Études Thessaliennes, Bulletin de Correspondance Hellénique 56, 1932, 89-191.

BERNBECK 1994

R. Bernbeck, Die Auflösung der häuslichen Produktionsweise. Berliner Beiträge zum Vorderen Orient 14, Berlin 1994.

BORISLAVOV 2008

B. Borislavov, A Thracian tumular necropolis in Devin, Smolian region. In: I. D. Cholakov, K. Chukalev, Archaeology in Bulgaria, 2006 Season, American Journal of Archaeology 112, 2008, 143-170.

BORISLAVOV 2010

B. Borislavov, The Izvorovo gold: a Bronze Age tumulus from Harmanli district, southeastern Bulgaria (preliminary report), Archaeologia Bulgarica 14/1, 2010, 1-33.

BORISLAVOV 2017a

B. Borislavov, Grabhügel 1 von Izvorovo. In: S. HaAg, Ch. Popov, B. Horejs, St. Alexandrov, G. Plattiner (Hrsg.), Das erste Gold: Ada Tepe: Das älteste Goldbergwerk Europas. Ausstellungskatalog der Sonderausstellung im KHM 2017, Wien 2017, 128-129.

BORISLAVOV 2017b

B. Borislavov, Die Nekropole von Lilovo. In: S. HaAG, Ch. Popov, B. Horejs, St. Alexandrov, G. Plattiner (Hrsg.), Das erste Gold: Ada Tepe: Das älteste Goldbergwerk Europas. Ausstellungskatalog der Sonderausstellung im KHM 2017, Wien 2017, 143-144.

BozHINOVA 2014

Е. БожиновА, Крепостта на връх Арагойна от II-I химядолетие пр. Хр. Стратиграфия, хронология и интерпретация (резултати от археологическите проучвания $2004-2012$ г.). Годишник на Регионален археологически музей ПАовдив XII, 2014, 44-88.
Bozhinova, Jung, Mommsen 2013

E. Bozhinova, R. Jung, H. Mommsen, Dragojna - eine spätbronzezeitliche Höhensiedlung in den bulgarischen Rhodopen mit importierter mykenischer Keramik, Mitteilungen des Deutschen Archäologischen Instituts Athenische Abteilung 125/2010, 2013, 45-97.

Bozkova, Delev, Vulcheva 2002

A. Bozkova, P. Delev, D. Vulcheva (Hrsg.), Koprivlen 1: Rescue Archaeological Investigations along the Gotse Delchev - Drama Road 1998-1999. Sofia 2002.

Burke, Burns, Charami 2012:

B. Burke, B. Burns, A. Charami, EBAP 2012 Excavation Report, http://web.uvic.ca/ bburke/EBAP/documents/EBAP2012ExcavationReport.pdf (letzter Zugriff 21.05.2017).

BuXEDA i GARRIGós et al. 2003

J. Buxeda i Garrigós, R. E. Jones, V. Kilikoglou, S. T. Levi, Y. Maniatis, J. Mitchell, L. Vagnetti, K. A. Wardle, St. AnDREOU, Technology transfer at the periphery of the Mycenaean World: the cases of Mycenaean pottery found in Central Macedonia (Greece) and the Plain of Sybaris (Italy), Archaeometry 45, 2003, 263-284.

Darcque et al. 2011

P. Darcque, Ch. Koukouli-Chrysanthaki, D. Malamidou,

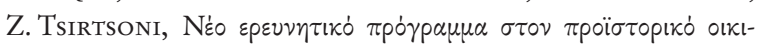

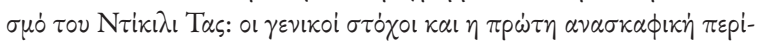

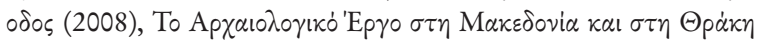
22/2008, 2011, 529-536.

Delev, Popov 2002

P. Delev, H. Popov, The ancient road network in the Middle Mesta region. In: A. Bozkova, P. Detev (Hrsg.), Koprivlen 1: Rescue Archaeological Investigations along the Gotse Delchev - Drama Road 1998-1999. Sofia 2002, 57-62.

Demakopoulou 2003

K. Demakopoulou, The pottery from the destruction layers in Midea: Late Helladic III B2 Late or Transitional Late Helladic III B2/ Late Helladic IIIC Early? In: S. Deger-Jalkotzy, M. Zavadil (Hrsg.), LH IIIC Chronology and Synchronisms. Proceedings of the International Workshop at the Austrian Academy of Sciences at Vienna, May $7^{\text {th }}$ and $8^{\text {th }}, 2001$. Veröffentlichungen der Mykenischen Kommission 20, Wien 2003, 77-92.

Demakopoulou, Divari-Valakou, Schallin 2004

K. Demakopoulou, N. Divari-Valakou, A.-L. Schallin, Excavations in Midea 2002, Opuscula Atheniensia 28/2003, 2004, 7-28.

DieTz 1991

S. Dietz, The Argolid at the Transition to the Mycenaean Age: Studies in the Chronology and Cultural Development in the Shaft Grave Period. Kopenhagen 1991.

Dimitrov, Stojčev 2017

K. Dimitrov, R. Stojčev, Der Ostbalkanraum als Metall- und Rohstoffquelle von der Vorgeschichte bis zur Antike. In: S. HaAG, Ch. Popov, B. Horejs, St. Alexandrov, G. Plattner (Hrsg.), Das erste Gold: Ada Tepe: Das älteste Goldbergwerk Europas. Ausstellungskatalog der Sonderausstellung im KHM 2017, Wien 2017, 21-27.

DREYER 1998

G. Dreyer, Umm el-Qaab I: Das prädynastische Königsgrab U-j und seine frühen Schriftzeugnisse. Archäologische Veröffentlichungen 86, Mainz 1998. 
EARLE 1991

T. EARLe, The evolution of chiefdoms. In: T. EARLE (Hrsg.), Chiefdoms: Power, Economy, and Ideology. Cambridge 1991, 1-15.

EARLE 2002

T. EArle, Bronze Age Economics: The Beginning of Political Economies. Cambridge, 2002.

ENGEL 2013

E.-M. EngEL, The organization of a nascent state: Egypt until the beginning of the $4^{\text {th }}$ dynasty. In: J. C. Moreno García (Hrsg.), Ancient Egyptian Administration. Handbook of Oriental Studies / Handbuch der Orientalistik, Section 1, Ancient Near East, Bd. 104, Leiden - Boston 2013, 19-40.

FrangiPANE 2016

M. Frangipane, The development of centralised societies in Greater Mesopotamia and the foundation of economic inequality. In: H. Meller, H. P. Hahn, R. Jung, R. Risch (Hrsg.), Arm und Reich - Zur Ressourcenverteilung in prähistorischen Gesellschaften. 8. Mitteldeutscher Archäologentag vom 22. bis 24. Oktober 2015 in Halle (Saale) / Rich and Poor - Competing for Resources in Prehistoric Societies. $8^{\text {th }}$ Archaeological Conference of Central Germany, October 22-24, 2015 in Halle (Saale). Tagungen des Landesmuseums für Vorgeschichte Halle 14, Halle 2016, 469-490.

French, TAYlour 2007

E. B. French, W. D. Taylour, The Service Areas of the Cult Centre. Well Built Mycenae, Fascicule 13, Oxford 2007.

FURUMARK 1941

A. Furumark, Mycenaean Pottery: Analysis and Classification. Stockholm 1941.

FURUMARK 1992

A. Furumark, Mycenaean Pottery III: Plates. Stockholm 1992.

GimATZIDIS 2010

S. GimatZidis, Die Stadt Sindos: Eine Siedlung von der späten Bronze- bis zur klassischen Zeit am Thermaischen Golf in Makedonien. Prähistorische Archäologie in Südosteuropa 26, Rahden/ Westf. 2010.

GimatZIDIs in Vorbereitung

S. Gimatzidis, Early Greek Colonisation in Macedonia and Italy, in Vorbereitung.

Grammenos 1981

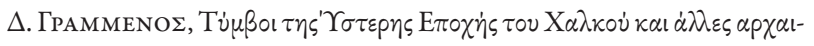

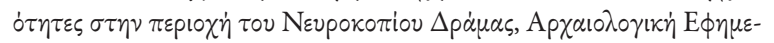
pis 1979, 1981, Apxaı

Grammenos, Котsos 2002

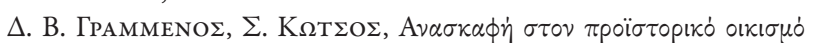

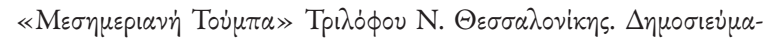

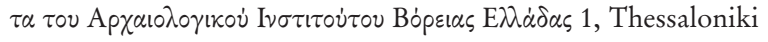
2002.

Grammenos et al. 1997

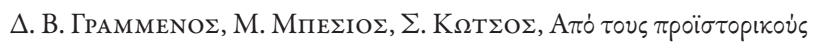

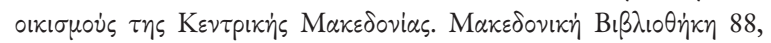
Thessaloniki 1997.

HAAG et al. 2017

S. Haag, Ch. Popov, B. Horejs, St. Alexandrov, G. Plattiner (Hrsg.), Das erste Gold: Ada Tepe: Das älteste Goldbergwerk Europas. Ausstellungskatalog der Sonderausstellung im KHM 2017, Wien 2017.

HÄNSEL 1970

B. Hänsel, Bronzene Griffzungenschwerter aus Bulgarien, Prähistorische Zeitschrift 45, 1970, 26-41.
HÄNSEL 1989

B. HäNSEL, Kastanas. Ausgrabungen in einem Siedlungshügel der Bronze- und Eisenzeit Makedoniens 1975-1979: Die Grabung und der Baubefund. Prähistorische Archäologie in Südosteuropa 7, Berlin 1989.

HäNSEL 2002

B. HëNSEL, Zusammenfassende Bemerkungen zum Siedlungsverlauf in Kastanas - Kontinuität und Bevölkerungswandel. In: R. JunG, Kastanas. Ausgrabungen in einem Siedlungshügel der Bronzeund Eisenzeit Makedoniens 1975-1979: Die Drehscheibenkeramik der Schichten 19-11. Prähistorische Archäologie in Südosteuropa 18, Kiel 2002, 11-27.

HÄNSEL 2003

B. HÄNSEL, Stationen der Bronzezeit zwischen Griechenland und Mitteleuropa, Bericht der Römisch-Germanischen Kommission 83/2002, 2003, 69-97.

HÄNSEL 2009

B. HäNSEL, Das Ende der Tellsiedlungen aus der Sicht eines Ausgräbers. In: П. А $\triangle A M-B e \Lambda E N H, K$. Tzanabaph, M. Intzez (Hrsg.),

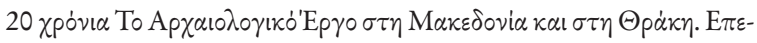

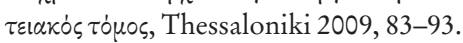

HäNSEl, Aslanis 2010

B. Hänsel, I. Aslanis, Das Prähistorische Olynth. Ausgrabungen in der Toumba Agios Mamas 1994-1996: Die Grabung und der Baubefund. Prähistorische Archäologie in Südosteuropa 23, Rahden/Westf. 2010.

HäNSEL et al. 2010

B. Hänsel, B. Horejs, R. Jung, B. Weninger, Die absolute Chronologie der Schichten des Prähistorischen Olynth. In: B. HäNSEL, I. Aslanis, Das Prähistorische Olynth. Ausgrabungen in der Toumba Agios Mamas 1994-1996: Die Grabung und der Baubefund. Prähistorische Archäologie in Südosteuropa 23, Rahden/ Westf. 2010, 301-381.

HaRbotTLE 1976

G. НАRвотTLE, Activation analysis in archaeology, Radiochemistry 3, 1976, 33-72.

HARMANKAYA 1995

N.S. Harmankaya, Kozman Deresi Mevkii (Şarköy, Tekirdağ) Maden Buluntuları. In: Halet Çambel için: Prehistorya yazıları / Readings in Prehistory: Studies Presented to Halet Çambel. Istanbul 1995, 217-254.

HARTUNG 1998

U. Hartung, Zur Entwicklung des Handels und zum Beginn wirtschaftlicher Administration im prädynastischen Ägypten, Studien zur altägyptischen Kultur 26, 1998, 35-50.

Hein, Kilikoglou 2012

A. Hein, V. Kilikoglou, ceraDAT - Prototype of a web based relational database for archaeological ceramics, Archaeometry 54, 2012, 230-243.

Hein et al. 2002

A. Hein, A. Tsolakidou, I. Iliopoulos, H. Mommsen, J. Buxeda i Garrigós, G. Montana, V. Kilikoglou, Standardisation of elemental analytical techniques applied to provenance studies of ancient ceramics, The Analyst 127, 2002, 542-553.

HeUrTley 1939

W. A. Heurtley, Prehistoric Macedonia: An Archaeological Reconnaissance of Greek Macedonia (West of the Struma) in the Neolithic, Bronze, and Early Iron Ages. Cambridge 1939. 


\section{HochsteTter 1984}

A. HochstetTer, Kastanas. Ausgrabungen in einem Siedlungshügel der Bronze- und Eisenzeit Makedoniens 1975-1979. Die handgemachte Keramik, Schichten 19 bis 1. Prähistorische Archäologie in Südosteuropa 3, Berlin 1984.

HOREJS 2007a

B. Horejs, Das Prähistorische Olynth. Ausgrabungen in der Toumba Agios Mamas 1994-1996: Die spätbronzezeitliche handgemachte Keramik der Schichten 13 bis 1. Prähistorische Archäologie in Südosteuropa 21, Rahden/Westf. 2007.

HoREJs 2007b

B. Horejs, Macedonia: mediator or buffer zone between cultural spheres? In: I. Galanaki, H. Tomas, Y. Galanakis, R. LaffiNeur (Hrsg.), Between the Aegean and Baltic Seas: Prehistory Across Borders. Proceedings of the International Conference Bronze and Early Iron Age Interconnections and Contemporary Developments between the Aegean and the Regions of the Balkan Peninsula, Central and Northern Europe. University of Zagreb, 11-14 April 2005. Aegaeum 27, Eupen 2007, 293-306.

Horejs 2009

B. Horejs, Alltagskulturen und Eliten zwischen Karpatenbecken und Ägäis: Verschiedene Kommunikationsmodelle ? In: A. Kreen-Leeb, H.-J. Beier, E. Classen, F. Falkenstein, St. Schwenzer (Hrsg.), Mobilität, Migration und Kommunikation in Europa während des Neolithikums und der Bronzezeit. Beiträge der Sitzungen der Arbeitsgemeinschaften Neolithikum und Bronzezeit während der Jahrestagung des West- und Süddeutschen Verbandes für Altertumsforschung e. V. in Xanten, 6.-8. Juni 2006. Varia Neolithica V, Beiträge zur Ur- und Frühgeschichte Mitteleuropas 53, Langenweissbach 2009, 197-207.

Horejs 2017

B. Horejs, Zum Alltagsleben der Ada Tepe Goldproduzenten im 15. Jh. v. Chr. Das Fundensemble aus Haus 7 in funktionaler und kontextueller Analyse, Archaeologia Austriaca 101, 2017, 205-268.

Horejs, Jung 2017

B. Horejs, R. Jung, Netzwerke und Kulturkontakte in die Ägäis. In: S. Haag, Ch. Popov, B. Horejs, St. Alexandrov, G. Plattiner (Hrsg.), Das erste Gold: Ada Tepe: Das älteste Goldbergwerk Europas. Ausstellungskatalog der Sonderausstellung im KHM 2017, Wien 2017, 98-103.

Horejs, Jung im Druck

B. Horejs, R. Jung, Ein Update zu den ägäisch-balkanischen Beziehungen in der Bronzezeit. In: H. Popov (Hrsg.), 30 Years Department for Thracian Archaeology. Известия на археологическия институт ИАИ, im Druck.

JACOB-Felsch 1996

M. ЈАСОв-FеLsch, Die spätmykenische bis frühprotogeometrische Keramik. In: R. C. S. FeLsch (Hrsg.), Kalapodi: Ergebnisse der Ausgrabungen im Heiligtum der Artemis und des Apollon von Hyampolis in der antiken Phokis I. Mainz 1996, 1-213.

JONES 1986

R. E. Jones, Greek and Cypriot Pottery - A Review of Scientific Studies, Athen 1986

JoNes et al. 1986

G. Jones, K. Wardle, P. Halstead, D. Wardle, Kornspeicherung in Assiros, Spektrum der Wissenschaft 5/1986, 88-95.

JuNG 2002

R. Jung, Kastanas. Ausgrabungen in einem Siedlungshügel der Bronze- und Eisenzeit Makedoniens 1975-1979: Die Drehscheibenkeramik der Schichten 19-11. Prähistorische Archäologie in Südosteuropa 18, Kiel 2002.
JUNG 2003a

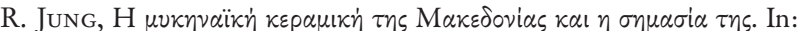

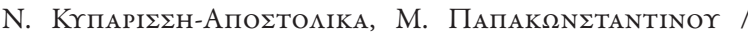
N. Kyparissi-Apostolika, M. Papakonstantinou (Hrsg.), B>

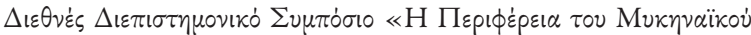

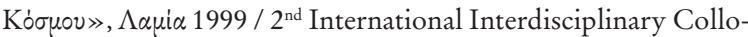
quium „The Periphery of the Mycenaean World“, Lamia 1999.

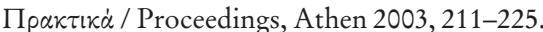

Jung 2003b

R. Jung, LH IIIC at the Toúmbes of Kastanás and Ólynthos - and the problems of Macedonian Mycenaean Pottery. In: S. DeGer-Jalkotzy, M. Zavadil (Hrsg.), LH IIIC Chronology and Synchronisms. Proceedings of the International Workshop at the Austrian Academy of Sciences at Vienna, May $7^{\text {th }}$ and $8^{\text {th }}, 2001$. Veröffentlichungen der Mykenischen Kommission 20, Wien 2003, 131-144.

JUNG 2007a

R. Jung, $\Delta \dot{\omega} \sigma^{\prime} \mu \circ v \phi \omega \tau \dot{\alpha}$. Woher kamen die Brandbestattungsriten der spätbronzezeitlichen Ägäis? In: I. Galanaki, H. Tomas, Y. Galanakis, R. Laffineur (Hrsg.), Between the Aegean and Baltic Seas: Prehistory Across Borders. Proceedings of the International Conference Bronze and Early Iron Age Interconnections and Contemporary Developments between the Aegean and the Regions of the Balkan Peninsula, Central and Northern Europe. University of Zagreb, 11-14 April 2005. Aegaeum 27, Eupen 2007, 215-230.

Jung 2007b

R. Jung, On the origin of the wheel-made Grey Ware found in Central Macedonia http://www.aegeobalkanprehistory.net/index. php?p=article\&id_art=4 (letzter Zugriff 22.05.2017).

JUNG 2017

R. Jung, Krieger und Waffen auf dem Zentral- und Ostbalkan. In: S. HaAg, Ch. Popov, B. Horejs, St. Alexandrov, G. Plattner (Hrsg.), Das erste Gold: Ada Tepe: Das älteste Goldbergwerk Europas. Ausstellungskatalog der Sonderausstellung im KHM 2017, Wien 2017, 68-73.

Jung, Andreou, Weninger 2009

R. Jung, St. Andreou, B. Weninger, Synchronisation of Kastanás and Thessaloníki Toumba at the end of the Bronze and the beginning of the Iron Age. In: S. Deger-Jalkotzy, A. Bächle (Hrsg.), LH IIIC Chronology and Synchronisms III: LH IIIC Late and the Transition to the Early Iron Age. Proceedings of the International Workshop at the Austrian Academy of Sciences at Vienna, February $23^{\text {rd }}$ and $24^{\text {th }}, 2007$. Veröffentlichungen der Mykenischen Kommission 30, Wien 2009, 183-202.

Jung, Mommsen, Paciarelli 2015

R. Jung, H. Mommsen, M. Paciarelli, From West to West: determining production regions of Mycenaean pottery of Punta di Zambrone (Calabria, Italy), Journal of Archaeological Science Reports 3, 2015, 455-463.

Jung et al. 2015

R. Jung, M. Pacciarelli, B. Zach, M. Klee, U. Thanheiser, Punta di Zambrone (Calabria) - a Bronze Age harbour site: first preliminary report on the Recent Bronze Age (2011-2012 campaigns), Archaeologia Austriaca 99, 2015, 53-110.

Karamitrou-MEdESSIDi 2003

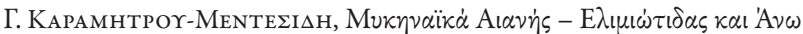

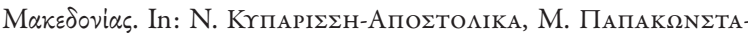
ntinor / N. Kyparissi-Apostolika, M. Papakonstantinou

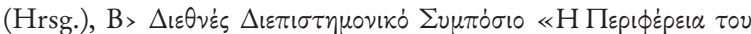

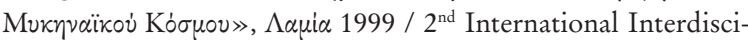
plinary Colloquium „The Periphery of the Mycenaean World“,

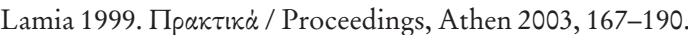


Karamitrou-Medessidi 2009

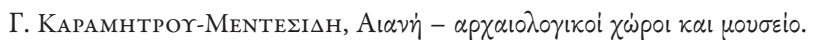

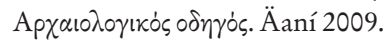

KARANTZALI 2012

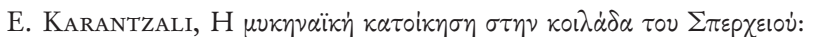

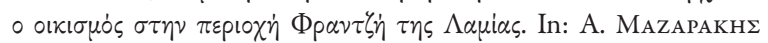
Ainian (Hrsg.), Apxaı

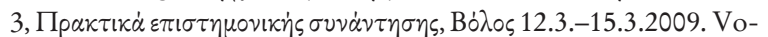
los 2012, 1213-1233.

KARDAMAKI 2009

E. KARDAMAKI, Ein neuer Keramikfund aus dem Bereich der Westtreppe von Tiryns: Bemalte mykenische Keramik aus dem auf der Westtreppenanlage deponierten Palastschutt. Inaugural-Dissertation in der Philosophischen Fakultät der Ruprecht-KarlsUniversität Heidelberg, im Januar 2009, Bd. I and II, Heidelberg 2013, http://archiv.ub.uni-heidelberg.de/volltextserver/14756/ (letzter Zugriff 21.05.2017).

KARDAMAKI 2015

E. Kardamaki, Conclusions from the new deposit at the Western Staircase terrace at Tiryns. In: A.-L. Schallin, I. TournaviTOU (Hrsg.), Mycenaeans Up to Date: The Archaeology of the North-Eastern Peloponnese - Current Concepts and New Directions. Stockholm 2015, 79-97.

Kaza-Papageorgiou et al. 2011

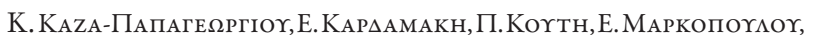

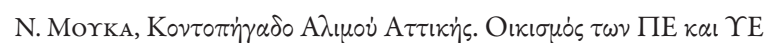

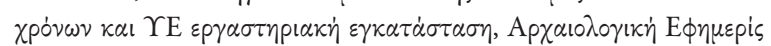
150, 2011, 197-274.

KILIAN 1976

K. Kilian, Der Siedlungshügel Bunar Baschi bei Sikourion. In: V. Milojčić, A. von den Driesch, K. Enderle, J. Milojčićvon Zumbusch, K. Kilian, Die deutschen Ausgrabungen auf Magulen um Larisa in Thessalien: Agia Sofia-Magula, KaragyösMagula, Bunar Baschi. Bonn 1976, 65-71.

Kilian-Dirlmeier 1993

I. Kilian-Dirlmeier, Die Schwerter in Griechenland (außerhalb der Peloponnes), Bulgarien und Albanien. Prähistorische Bronzefunde IV/12. Stuttgart 1993.

KOUKOULI-ChrysanthaKi 1977

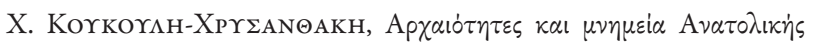

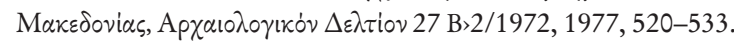

KOUKOULI-CHRYSANTHAKI 1980

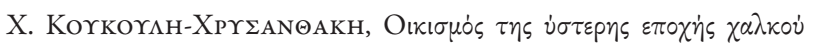

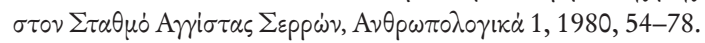

KoukOuli-Chrysanthaki et al. 1997

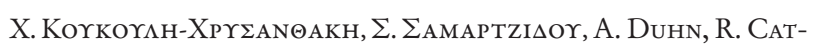

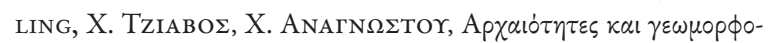

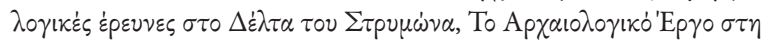

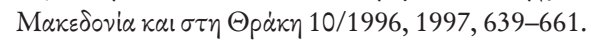

LiCHARDUS et al. 1996

J. Lichardus, A. Fol, L. Getov, F. Bertemes, R. Echt, R. KatinČarov, I. KRĂSTEv Iliev, Bericht über die bulgarischdeutschen Ausgrabungen in Drama (1989-1995), Bericht der Römisch-Germanischen Kommission 77, 1996, 5-119.

LichARDUs et al. 2002

J. Lichardus, R. Echt, I. K. Iliev, Ch. J. Christov, Die Spätbronzezeit an der unteren Tundža und die ostägäischen Verbindungen in Südostbulgarien, Eurasia Antiqua 8, 2002, 135-184.

Madzharov 2009

М. МААЖАРОв, Римски пътища в Бъцгария. Принос в развитието на римската пътна система в провинциите Мизия и Тракия. Weliko Tarnowo 2009.
Madzharov 2010

М. МААЖАРОВ, ИЗТочНИЯт ПреАродоПсКИ рИмСКИ Път. In: Б. БоРИСОв (Hrsg.) Великотърновският университет „Св. Св. Кирим и Методий” и бъмгарската археология 1. Weliko Tarnowo 2010, 333-348.

Margomenou 2008

D. Margomenou, Food storage in prehistoric northern Greece: interrogating complexity at the margins of the "Mycenaean World”, Journal of Mediterranean Archaeology 21, 2008, 191212.

Margomenou, Andreou, Kotsakis 2007

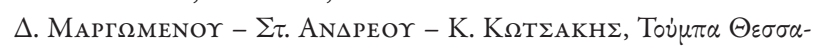

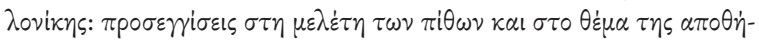

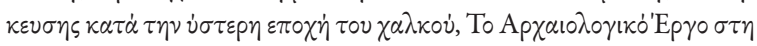

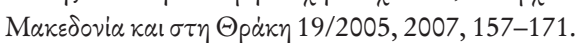

Mommsen 2011

H. Mommsen, Provenancing of pottery. In: Nuclear Techniques for Cultural Heritage Research. IAEA Radiation Technology Series 2, Wien 2011, 41-70.

Mommsen, SJÖberg 2007

H. Mommsen, B. L. SJÖBERG, The importance of the 'best relative fit factor' when evaluating elemental concentration data of pottery demonstrated with Mycenaean sherds from Sinda, Cyprus, Archaeometry 49, 2007, 357-369.

Mommsen, Kreuser, Weber 1988

H. Mommsen, A. Kreuser, J. Weber, A method for grouping pottery by chemical composition, Archaeometry 30, 1988, 47-57.

Mommsen et al. 1989

H. Mommsen, A. Kreuser, J. Weber, Ch. Podzuweit, Classification of Mycenaean pottery from Kastanas by neutron activation analysis. In: Archaeometry. Proceedings of the $25^{\text {th }}$ International Symposium, Athens 19-23 May 1986. Amsterdam - Oxford New York 1989, 515-523.

Mommsen et al. 1991

H. Mommsen, A. Kreuser, E. Lewandowski, J. Weber, Provenancing of pottery: a status report on neutron activation analysis and classification. In: M. Hughes, M. Cowell, D. Hook (Hrsg.), Neutron Activation and Plasma Emission Spectrometric Analysis in Archaeology. British Museum Occasional Paper 82, 1991, 57-65.

Mommsen et al. 1996

H. Mommsen, A. Hein, R. Echt, I. K. Krăstev Iliev, Neutronenaktivierungsanalyse (NAA) an verschiedenen in Südostbulgarien importierten Gefäßen, Bericht der Römisch-Germanischen Kommission 77, 1996, 130-136.

Moschonissioti 1998

S. Moschonissioti, Excavation at ancient Mende. In: M. BAts, B. D’Agostino (Hrsg.), Euboica: l'eubea e la presenza euboica in Calcidica e in Occidente. Atti del Convegno Internazionale di Napoli, 13-16 novembre 1996. Neapel 1998, 255-271.

Moschos 2009

I. Moschos, Evidence of social re-organization and reconstruction in Late Helladic IIIC Achaea and modes of contacts and exchange via the Ionian and Adriatic Sea. In: E. Borgna, P. CÀssola GuiDA (Eds.), Dall'Egeo all'Adriatico: Organizzazioni sociali, modi di scambio e interazione in età postpalaziale (XII-XI sec. a. C.) / From the Aegean to the Adriatic: Social Organisations, Modes of Exchange and Interaction in Postpalatial Times (12th - 11th c. BC). Atti del Seminario internazionale, Udine, 1-2 dicembre 2006. Studi e ricerche di protostoria mediterranea 8, Rom 2009, 345-414. 
MountJoy 1999

P. A. Mountjoy, Regional Mycenaean Decorated Pottery. Rahden/ Westf. 1999.

Mylonas 1972-1973

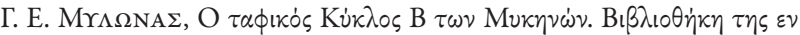

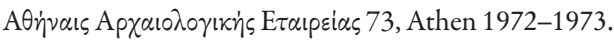

Nechrizov, Cvetkova 2017

G. Nechrizov, J. Cvetkova, Die Bronzezeit in den östlichen Rhodopen. In: S. HaAg, Ch. Popov, B. Horejs, St. Alexandrov, G. Plattiner (Hrsg.), Das erste Gold: Ada Tepe: Das älteste Goldbergwerk Europas. Ausstellungskatalog der Sonderausstellung im KHM 2017, Wien 2017, 48-55.

Papadimitriou, Petsas 1951

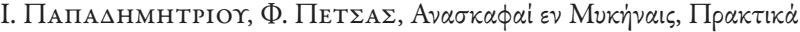

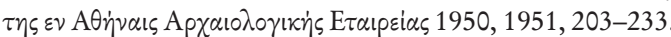

Papadopoulos 1998

I. Papadopoulos, The Late Bronze Age Daggers of the Aegean I: The Greek Mainland. Prähistorische Bronzefunde VI/11, Stuttgart 1998

Papapostolou 2008

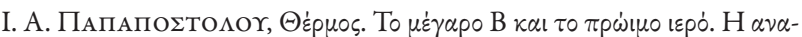

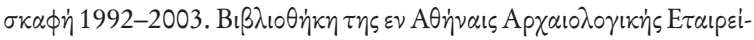
as 261, Athen 2008.

PAPpá 2010

M. Pappá, Die Nekropole der frühen Bronzezeit bei der Toumba Agios Mamas. In: B. Hänsel, I. Aslanis, Das Prähistorische Olynth. Ausgrabungen in der Toumba Agios Mamas 1994-1996: Die Grabung und der Baubefund. Prähistorische Archäologie in Südosteuropa 23, Rahden/Westf. 2010, 382-440.

PAvúK 2017

P. PAvúK, Thrakien, Troia und Anatolien: Troia und seine Kontakte in den Balkan. In: S. HaAg, Ch. Popov, B. Horejs, St. AlexanDrov, G. Plattner (Hrsg.), Das erste Gold: Ada Tepe: Das älteste Goldbergwerk Europas. Ausstellungskatalog der Sonderausstellung im KHM 2017, Wien 2017, 104-109.

Perlman, Asaro 1969

I. Perlman, F. Asaro, Pottery analysis by neutron activation, Archaeometry $11,1969,21-52$

Persson 1931

A. W. Persson, The Royal Tombs at Dendra Near Midea. Lund 1931. Podzuweit 1981

Ch. Podzuweit, Ausgrabungen in Tiryns 1978. 1979: Bericht zur spätmykenischen Keramik, Archäologischer Anzeiger 1981, $194-220$.

Podzuweit 2007

Ch. Podzuweit, Studien zur spätmykenischen Keramik. Tiryns XIV, Wiesbaden 2007

Popov 2017

H. Popov, Der Ada Tepe - spätbronzezeitliches Goldbergwerk und Siedlung. In: S. HaAg, Ch. Popov, B. Horejs, St. Alexandrov, G. Plattner (Hrsg.), Das erste Gold: Ada Tepe: Das älteste Goldbergwerk Europas. Ausstellungskatalog der Sonderausstellung im KHM 2017, Wien 2017, 145-149.

Popov, Jockenhövel 2017

H. Popov, A. Jockenhövel, Das spätbronzezeitliche Goldbergwerk auf dem Ada Tepe. In: S. HaAg, Ch. Popov, B. Horejs, St. Alexandrov, G. Plattiner (Hrsg.), Das erste Gold: Ada Tepe: Das älteste Goldbergwerk Europas. Ausstellungskatalog der Sonderausstellung im KHM 2017, Wien 2017, 56-61.
Popov, Jockenhövel, Groer 201

H. Popov, A. Jockenhövel, C. Groer, Ada Tepe (Ost-Rhodopen, Bulgarien): Spätbronzezeitlicher - ältereisenzeitlicher Goldbergbau, Kampagne 2008. In: Ü. YalçıN (Hrsg.), Anatolian Metal V, Der Anschnitt Beiheft 24. Veröffentlichungen aus dem Deutschen Bergbau-Museum 180, Bochum 2011, 111-126.

Popov et al. 2017

H. Popov, M. Koleva, A. Andonova, J. Dimitrova, I. Vălčev, Das Goldbergwerk auf dem Ada Tepe: Zu Topografie, Stratigrafie, Chronologie und Interpretation des Nordareals, Archaeologia Austriaca 101, 2017, 161-204.

RAHMSTORF 2016

L. Rahmstorf, Emerging economic complexity in the Aegean and Western Anatolia during earlier third millennium. In: B. MoLLOY (Hrsg.), Of Odysseys and Oddities. Sheffield Studies in Aegean Archaeology 10, Oxford 2016, 225-276.

SANDARS 1963

N. K. Sandars, Later Aegean Bronze Swords, American Journal of Archaeology 67, 1963, 117-153.

SCHNEIDER et al. 1989

G. Schneider, A. Burmester, C. Goedicke, H. W. Hennicke, B. Kleinmann, H. Knoll, M. Magnetti, R. Rottländer, Naturwissenschaftliche Kriterien und Verfahren zur Beschreibung von Keramik, Acta Praehistorica et Archaeologica 21, 1989, 7-39. SCHÖNFELD 1988

G. SCHÖNFELD, Ausgrabungen in Tiryns 1982/83: Bericht zur bemalten mykenischen Keramik, Archäologischer Anzeiger 1988, 153-211.

SCHULZ 1989

H. D. Schulz, Die geologische Entwicklung der Bucht von Kastanas im Holozän. In: B. HäNSEL, Kastanas. Ausgrabungen in einem Siedlungshügel der Bronze- und Eisenzeit Makedoniens 1975-1979: Die Grabung und der Baubefund. Prähistorische Archäologie in Südosteuropa 7, Berlin 1989, 375-393.

SHELTON 2007

K. S. Shelton, Foot soldiers and cannon fodder: the underrepresented majority of the Mycenaean civilization. In: S. P. MORRIS, R. Laffineur (Hrsg.), Epos: Reconsidering Greek Epic and Aegean Bronze Age Archaeology. Proceedings of the $11^{\text {th }}$ International Aegean Conference / $11^{\mathrm{e}}$ Recontre égéenne international, Los Angeles, UCLA - The J. Paul Getty Villa, 20-23 April 2006. Aegaeum 28, 2007, 169-175.

SHERRATT 1986

A. SherratT, The pottery of phases IV and V: the Early Bronze Age. In: C. Renfrew, M. Gimbutas, E. S. Elster (Hrsg.), Excavations at Sitagroi: A Prehistoric Village in Northeast Greece 1. Los Angeles, 429-476.

TRIANTAPHYLLOU 2001

S. Triantaphyllou, A Bioarchaeological Approach to Prehistoric Cemetery Populations from Central and Western Greek Macedonia. British Archaeological Reports S 976, Oxford 2001.

VALLa 2004

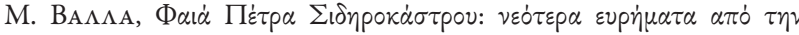

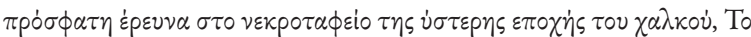

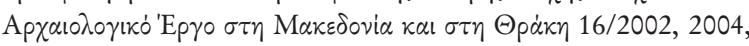
157-164. 
ValLa 2007

M. Valla, A Late Bronze Age cemetery in Faia Petra, east of the middle Strymon valley. In: H. Todorova, M. Stefanovich, G. Ivanov (Hrsg.), The Struma/Strymon River Valley in Prehistory. Proceedings of the International Symposium „Strymon Praehistoricus“, Kjustendil-Blagoevgrad-Serres-Amphipolis, 27.09-01.10.2004. In The Steps of James Harvey Gaul 2, Sofia 2007, 359-372.

Valla et al. 2013

M. Valla, S. Triantaphyllou, P. Halstead, V. Isaakidou, Handling of death at the end of the Late Bronze Age: the case of Faia Petra, $13^{\text {th }}$ c. BC, Eastern Macedonia, Greece. In: M. Lochner, F. Ruppenstein (Hrsg.), Brandbestattungen von der mittleren Donau bis zur Ägäis zwischen 1300 und 750 v. Chr. Akten des internationalen Symposiums an der Österreichischen Akademie der Wissenschaften in Wien, 11.-12. Februar 2010 / Cremation Burials in the Region between the Middle Danube and the Aegean, 1300-750 BC. Proceedings of the International Symposium held at the Austrian Academy of Sciences at Vienna, February $11^{\text {th }}-12^{\text {th }}, 2010$. Mitteilungen der Prähistorischen Kommission 77, Veröffentlichungen der Mykenischen Kommission 32, Wien 2013, 231-248.

VIDESKI 2007

Z. VIDESKI, Mycenaean influences in the FYRO Macedonia identified in the Late Bronze Age cemeteries. In: I. Galanaki, H. Tomas, Y. Galanakis, R. Laffineur (Hrsg.), Between the Aegean and Baltic Seas: Prehistory Across Borders. Proceedings of the International Conference Bronze and Early Iron Age Interconnections and Contemporary Developments between the Aegean and the Regions of the Balkan Peninsula, Central and Northern Europe. University of Zagreb, 11-14 April 2005. Aegaeum 27, Eupen 2007, 211-214.

VOIGTLÄNDER 2003

W. Voigtländer, Die Palastkeramik. Tiryns X, Mainz 2003.

WACE 1932

A. J. B. WACE, Chamber Tombs at Mycenae. Archaeologia 82, Oxford 1932.

WARDLE 1987

K. A. WARdLe, Excavations at Assiros Toumba 1986: a preliminary report, The Annual of the British School at Athens 82, 1987, 313-329.

WARDLE 1989

K. A. Wardle, Excavations at Assiros Toumba 1988: a preliminary report, The Annual of the British School at Athens 84, 1989, 447-463.

WARDLE 1993

K. A. Wardle, Mycenaean trade and influence in northern Greece. In: C. Zerner, P. Zerner, J. Winder (Hrsg.), Wace and Blegen: Pottery as Evidence for Trade in the Aegean Bronze Age 19391989. Proceedings of the International Conference Held at the American School of Classical Studies at Athens, Athens, December 2-3, 1989. Amsterdam 1993, 117-141.

WARDLE, WARDLE 2003

K. A. WARdLe, D. WARdLE, Prehistoric Thermon: pottery of the Late

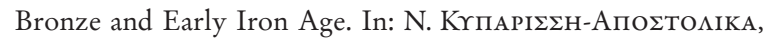
M. ПаחAK $\Omega$ nztantinor / N. Kyparissi-Apostolika, M. Pa-

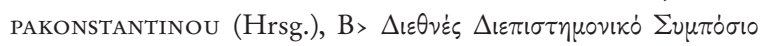

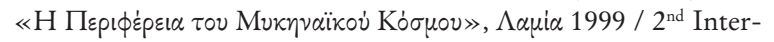
national Interdisciplinary Colloquium "The Periphery of the

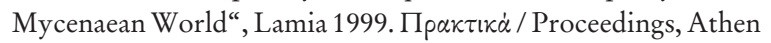
2003, 147-156.
Wardle, Wardle 2007

K. A. Wardle, D. Wardle, Assiros Toumba: a brief history of the settlement. In: H. Todorova, M. Stefanovich, G. Ivanov (Hrsg.), The Struma/Strymon River Valley in Prehistory. Proceedings of the International Symposium „Strymon Praehistoricus“, Kjustendil-Blagoevgrad-Serres-Amphipolis, 27.09-01.10.2004. In The Steps of James Harvey Gaul 2, Sofia 2007, 451-479.

WEBER 1996

C. Weber, Die Rasiermesser in Südosteuropa (Albanien, BosnienHerzegowina, Bulgarien, Griechenland, Kroatien, Mazedonien, Montenegro, Rumänien, Serbien, Slowenien und Ungarn). Prähistorische Bronzefunde VIII/5, Stuttgart 1996.

WiLsON 1978

A. L. Wilson, Elemental analysis of pottery in study of its provenance: a review, Journal of Archaeological Science 5, 1978, 219-236.

Reinhard Jung

Institut für Orientalische und Europäische Archäologie Österreichische Akademie der Wissenschaften Hollandstr. 11-13 1020 Wien Österreich reinhard.jung@oeaw.ac.at orcid.org/0000-0001-7618-3761

Stefan Alexandrov Abteilung Thrakische Archäologie Nationales Archäologisches Institut mit Museum Bulgarische Akademie der Wissenschaften

Saborna Str. 2 1000 Sofia Bulgarien

Стефан Александров

Национален археологически институт смузей - БАН ул. „Свборна” 2 1000 София Бглгария stefanalexandrov@abv.bg orcid.org/0000-0003-2868-3125

$$
\begin{array}{r}
\text { Elena Bozhinova } \\
\text { Archäologisches Regionalmuseum Plovdiv } \\
\text { Saedinenie Platz } 1 \\
\text { Plovdiv } 4000 \\
\text { Bulgarien } \\
\text { Елена Божинова } \\
\text { Регионален археологиескимуеи в Пловдив, пл. } \\
\text { „бединение”№ } 1 \\
\text { Пловдив 4000 } \\
\text { България } \\
\text { (D) orcid.org/0000-0002-3279-4410 }
\end{array}
$$




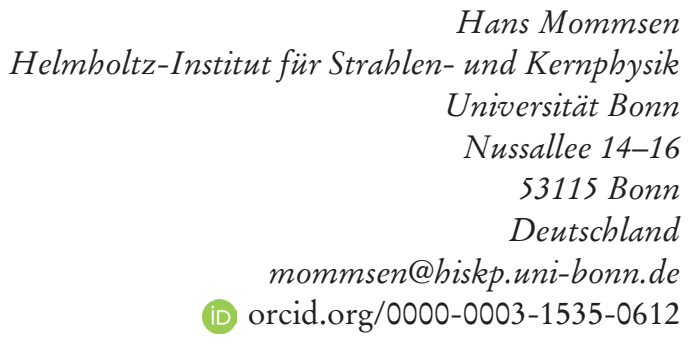

Institut für Nanowissenschaften und Nanotechnologie

$$
\text { Anno Hein }
$$

$$
\begin{gathered}
\text { N.C.S.R. "Demokritos“ } \\
15310 \text { Aghia Paraskevi }
\end{gathered}
$$$$
\text { Attika }
$$

Griechenland

$$
\text { Anno Hein }
$$

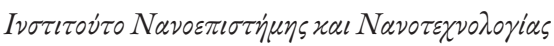

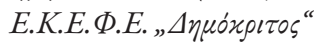

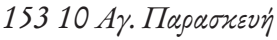

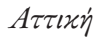

$E \lambda \lambda \alpha \dot{\delta} \alpha$

a.bein@inn.demokritos.gr orcid.org/0000-0002-1129-4820

Vassilis Kilikoglou Institut für Nanowissenschaften und Nanotechnologie

N.C.S.R. "Demokritos“

15310 Aghia Paraskevi Attika

Griechenland

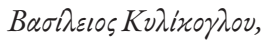

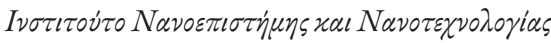

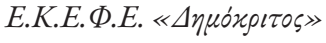

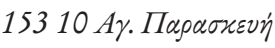

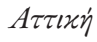

$E \lambda \lambda \alpha \dot{\delta} \alpha$

v.kilikoglou@inn.demokritos.gr

(iD) orcid.org/0000-0003-0619-2931 